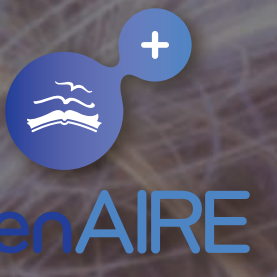

\title{
IMPLEMENTING OPEN ACCESS MANDATES IN EUROPE
}

OpenAIRE Study on the Development of Open Access Repository Communities in Europe

\author{
Birgit Schmidt \\ and Iryna Kuchma
}



Birgit Schmidt and Iryna Kuchma Implementing Open Access Mandates in Europe

This work is licensed under a Creative Commons Attribution 4.0 International License.

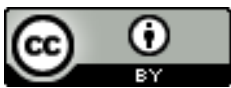


erschienen im Universitätsverlag Göttingen 2012 
Birgit Schmidt and

Iryna Kuchma

Implementing Open Access

Mandates in Europe

OpenAIRE Study on the

Development of Open Access

Repository Communities in Europe

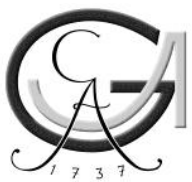

Universitätsverlag Göttingen

2012 


\section{Bibliographische Information der Deutschen Nationalbibliothek}

Die Deutsche Nationalbibliothek verzeichnet diese Publikation in der Deutschen Nationalbibliographie; detaillierte bibliographische Daten sind im Internet über $<$ http://dnb.ddb.de> abrufbar.

This work contains a description of the OpenAIRE project's findings, work and products. Certain parts might be under partner Intellectual Property Right (ipr) rules. If you believe that this document harms in any way the intellectual property rights held by you as a person or as a representative of an entity, please notify us immediately.

The authors of this work have taken all available measures to ensure that its contents to be accurate, consistent and lawful. However, neither the OpenAIRE project consortium as a whole nor the individual partners that implicitly or explicitly participated in the creation and publication of this work hold any sort of responsibility that might occur as a result of using its content.

This publication has been produced with the assistance of the European Union.

Contributors: OpenAIRE's National Open Access Desks (NOADs, see Annex 2), Mikael Karstensen Elbæk, Inge Van Nieuwerburgh, Gwen Franck, Eloy Rodrigues, Marnix van Berchum, Lilian van der Vaart, Najla Rettberg, Ricarda Blumentritt Reviewer(s): Abby Christel Clobridge, Astrid van Wesenbeeck Language Editing: Gioia Marini (Words Matter)

OpenAIRE is a project funded by the European Union. Grant Agreement 246686

This work is protected by German Intellectual Property Right Law.

It is also available as an Open Access version through the publisher's homepage and the Online Catalogue of the State and University Library of Goettingen (http://www.sub.uni-goettingen.de).

Layout: Adriaan de Jonge, Amsterdam

Cover design: Margo Bargheer, Göttingen

(C) 2012 Universitätsverlag Göttingen

http://univerlag.uni-goettingen.de

ISBN: 978-3-86395-095-8 


\section{Contents}

Table of Figures 8

List of Abbreviations 8

$1 \quad$ About the Authors 9

Summary 11

2 Introduction 13

3 Open Access Policies 17

3.1 Research funders' policies 19

3.1.1 European Commission 19

3.1.2 European Research Council 21

3.1.3 Other research funders' policies 23

3.2 Institutional open access policies and mandates 27

3.3 Other organisations and initiatives 30

3.3.1 European University Association 30

3.3.2 League of European Research Universities 32

3.3.3 EUROHORCs and European Science Foundation 35

3.4 Publishers' policies 37

3.4.1 Related projects 40

4 Implementation 49

4.1 EC, ERC and research areas 52

4.2 National Contact Points 54

4.3 Research managers and administrators 56

4.4 European countries 57

4.4.1 National research environments 59

4.4.2 National awareness of open access, mandates and repositories 60

4.4.3 Conclusions on funder and institutional oA mandates in Europe 89 
4.4.4 Summary of strategies 90

4.4.5 Evaluation and update of strategies 93

4.5 Repository infrastructures in Europe 95

4.5.1 Openaire Guidelines 96

4.5.2 Disciplinary repositories and networks 97

4.5.3 Openaire Orphan Repository 100

4.5.4 Networks of repositories 101

4.6 Advocacy and support networks 101

4.6.1 National networks 101

4.6.2 COAR 102

4.6.3 EIFL 103

4.6.4 SPARC Europe 104

4.6.5 Knowledge Exchange's open access working group 104

4.7 Publishers and journals 105

4.7.1 Publisher-assisted deposit 106

4.7.2 OpenAIRE compliance of publishers and journals 110

4.8 Other Stakeholders 112

4.8.1 UNESCO 112

4.8.2 Disciplinary scholarly societies 115

4.8.3 Younger researchers 116

4.8.4 Food and Agriculture Organization 118

4.8.5 General public 119

$5 \quad$ Conclusions and Roadmap 123

6 References 125

6.1 Articles and reports 125

6.2 Databases 130

6.3 Policies and Declarations 130

6.4 Presentations 133

$7 \quad$ Annex 1: European Policies on Open Access 135

7.1 ERC Scientific Council Guidelines for Open Access

(17 December 2007) 135

7.2 EC Special Clause 39137

7.3 Open Access Guidelines for researchers funded by the ERC (June 2012) 138 
7.4 EC Open Access policy for Horizon $2020 \quad 140$

$8 \quad$ Annex 2: National Open Access Desks (NOA Ds) 143

9 Annex 3: Tables 145

9.1 Table 1: Funder and institutional oA mandates in Europe 145

9.2 Table 2: Repositories in European countries 150

9.3 Table 3: National networks of repositories 151

9.4 Table 4: Information portals and support networks 153

$10 \quad$ Glossary 157

Notes 161 


\section{Table of Figures}

Figure 3-1 Open Access Mandates in Europe (as of 2012-08-25) 18

Figure 3-2 Growth of OA Mandates (based on ROARMAP, as of 2012-08-25) 18

Figure 4-1 Stakeholders 49

Figure 4-2 Ongoing sc 39 projects 51

Figure 4-3 Finalized sC 39 projects 51

\section{List of Abbreviations}

$\begin{array}{ll}\text { EC } & \text { European Commission } \\ \text { ERC } & \text { European Research Council } \\ \text { ESF } & \text { European Science Foundation } \\ \text { ETD } & \text { Electronic theses and dissertations } \\ \text { EU } & \text { European Union } \\ \text { EUA } & \text { European University Association } \\ \text { EUROHORCS } & \text { European Heads of Research Councils } \\ \text { FP7 } & \text { Seventh Framework Programme of the European } \\ & \text { Commission } \\ \text { IPR } & \text { Intellectual Property Rights } \\ \text { LERU } & \text { League of European Research Universities } \\ \text { NOADS } & \text { National Open Access Desks } \\ \text { OA } & \text { Open Access } \\ \text { SC39 } & \text { Special Clause 39, compare Annex 1 } \\ \text { SSH } & \text { Social Sciences and Humanities } \\ \text { STM } & \text { Science, Technology and Medicine }\end{array}$




\section{About the Authors}

DR BIRGIT SCHMIDT is Scientific Manager of the European Openaire project and coordinates international and national projects and initiatives in the Electronic Publishing unit at Goettingen State and University Library (PEER, OAPEN, open-access.net, OA Statistics, among others). From December 2009 to March 2012 she served as Executive Director of the Confederation of Open Access Repositories (COAR). She is an active member of COAR's working group Repository Content and the multistakeholder Open Access Agreements and Licenses Task Force. With a background in Mathematics and a postgraduate degree in Library and Information Science, she has worked on long term archiving of digital objects, open access publication models and service development.

IRYNA KUCHMA coordinates Eastern European activities of the OpenAIRE project and is the EIFL Open Access programme manager. Her responsibilities include advocacy of open access to research results and support in developing open access policies, training and support in setting up open repositories, organizing workshops and other knowledge sharing and capacity building events. She also chairs COAR's working group Repository and Repository Networks Support \& Training; is a member of IFLA's Open Access Taskforce, PLoS International Advisory Group, NDLTD (Networked Digital Library of Theses and Dissertations) Board of Directors, DSpace Community Advisory Team and E-LIS Advisory Board. In 2009-2010 she was a Steering Committee (and Task Group) member, InterAcademy Panel on International Issues (IAP) Programme on Digital Knowledge Resources and Infrastructure in Developing Countries. She has also served on the Access to Learning Award (ATLA) Committee of the Bill and Melinda Gates Foundation's Global Library Initiative. 



\section{Summary}

The OpenaI Re project supports the implementation of Europe's open access policies as outlined in the European Research Council's Guidelines for Open Access and the European Commission's Seventh Framework Programme (F P 7) Open Access Pilot.

This work highlights existing open access policies in Europe and provides an overview of publishers' self-archiving policies. It also highlights the strategies needed to implement these policies. It provides a unique overview of national awareness of open access in 32 European countries involving all Eu member states and in addition, Norway, Iceland, Croatia, Switzerland and Turkey. Moreover, it describes funder and institutional open access mandates in Europe and national strategies to introduce and implement them. An overview is provided of the repository infrastructure currently in place in European countries, including institutional and disciplinary repositories, national repository networks and national open access information portals and support networks.

There are robust regional and national networks of open access advocates representing libraries and some research discipline communities. More than half of the European countries covered in this work have already established national repository infrastructures. In some of these countries, the FP7 Open Access Pilot was the catalyst for discussions about funders' open access policies and the development of national research infrastructures (e.g. in Bulgaria, Estonia and Slovenia).

In its efforts to reach out to research institutions, researchers, project coordinators and publishers in the individual European countries, OpenAIRE is facilitated by a network of National Open Access Desks (NOADs). The NOADs also provide support to institutions in developing their open access policies: in implementing the European Commission's Open Access Pilot and the ERC's Guidelines on Open Access, in building synergies within institutional open access policies, and in making repositories and open access journals compliant with OpenAIRE's requirements for metadata harvesting (as laid out in the OpenAIre Guidelines). 
Among the outreach and dissemination strategies tried thus far, some have already been identified as particularly successful. These include the early outreach to researchers (i.e. when a F P7-funded project is launched), the active involvement of FP7 National Contact Points (NCPs), personal interaction with repository managers and the sharing of success stories to encourage new developments. The main issues that still need to be resolved in the coming years include the effective promotion of open access among research communities and support in copyright management for researchers and research institutions as well as intermediaries such as libraries and repositories.

This work also outlines the continuation project, OpenAI REplus which aims to grow the scope of OpenAIRE in terms of open access publications, and in addition connect these publications to other contextual information, such as research data and funding information. Opportunities for OpenA IRE to cooperate with other stakeholders in order to achieve European and global synergies are also highlighted. Such stakeholders include research communities and/or publishers, the international Confederation of Open Access Repositories (COAR), the Scholarly Publishing \& Academic Resources Coalition (sPARC) Europe, Electronic Information for Libraries (EIFL), UNEsCo, the Food and Agriculture Organization (FAO), international oA publishers, disciplinary scholarly societies and young researchers' organisations. 


\section{Introduction}

OpenaIRE, ${ }^{1}$ which stands for Open Access Infrastructure for Research in Europe, is a three-year project (2009-2012) that aims to develop a network of open repositories providing free online access to knowledge produced by researchers receiving grants from the European Commission (EC) or the European Research Council (ERC). The main goal of OpenAIRE, which is funded by the European Union's Seventh Framework Programme (FP7), is to support the Open Access Pilot launched by the EC in August 2008. In this pilot, researchers who receive FP7 grants in the fields of health, energy, the environment, information \& communication technologies, research infrastructures, social sciences \& humanities, and science in society are required to deposit their full-text research publications in an institutional or disciplinary open access repository that is made available worldwide. This represents around $20 \%$ of all projects funded by FP7.

OpenAIRE's three main objectives are to:

- build support structures for researchers in depositing F P 7- and ERCfunded research publications through the establishment of a European Helpdesk and by reaching out to all European member states via 27 National Open Access Desks (NOADs);

- establish and operate an electronic infrastructure for handling peer-reviewed articles as well as other important forms of publications (preprints or conference publications). This is achieved through the OpenAIRE portal that is the gateway to all user-level services offered, including access (search and browse) to scientific publications and other value-added functionalities (post authoring tools, monitoring tools through analysis of document, and usage statistics);

- work with several subject communities to explore the requirements, practices, incentives, workflows, data models and technologies for depositing, accessing and otherwise managing research data sets in their various forms. 
The main challenges in the course of the implementation process are:

- making the EC/ERC's policies known to researchers and project coordinators of all research areas involved and making them aware of their contractual obligation to honour these policies,

- supporting researchers and institutions with the depositing process through a network of open access experts: the National Open Access Desks (NOADs);

- enhancing the repository network by introducing rules for grant reporting in repositories that would support the linking of publications and projects (the OpenaIre Guidelines);

- involving and engaging all stakeholders in the implementation process and further facilitating the workflows for researchers, research administrators, repository managers and scholarly publishers.

To ensure that support is provided to researchers and institutions, the OpenAIRE project has developed a Europe-wide helpdesk system based on a network of national and regional open access desks in 32 countries (launched in March 2010 with 27 countries, extended by five more countries by August 2012). On 2 December 2010, the Openaire e-Infrastructure for repository networks was launched, which includes a repository facility for researchers who do not have access to an institutional or discipline-specific repository.

In order to explore the status quo of open access policies and repositorybased infrastructures, a country perspective was chosen for this work. The current and envisioned role of other transnational stakeholders are also described in this work, including the first steps that OpenAIRE has taken to involve them in promoting the implementation of the EU's open access policies.

The project is due to finalise in late 2012. OpenAIRE will have come far to motivate repositories to engage with the OpenAIRE infrastructure. However, take up of 'compliant' repositories has been slow. Reasons for this have been identified as repository manager time restrictions, and lack of 'value' in compliancy when the number of FP7 publications in repositories is low. OpenAIRE has done much to promote repository compliancy, however the weak SC39 mandate has also been a barrier to raising open access publication numbers: Persuading F P7 project participants to deposit 
final project publications is a challenge which the OpenAIRE community is dealing with by sending strong incentives for open access and clear workflows for deposit. ${ }^{2}$

OpenA IRE has also successfully worked with open access publishers to connect their publication lists to the information space ${ }^{3}$. Copernicus publications are now searchable via the OpenaIRE portal and, as an added benefit, the publisher is also aware of the FP7-funded publications they have published.

\section{Launch of the OpenaIR Eplus project}

In December 2011 an extension project, Openaireplus, was launched. Retaining its cross-disciplinary scope the project aims to enrich the scholarly process by providing links from the publication to contextual information such as related datasets, project details and author information. It is looking to expand to other funding streams (beyond F P7) and bring in a wider set of publications. All the DRIV ER repositories will be assimilated.

It will carry out a series of studies, such as data licensing issues and prototypes for 'enhanced publications'. OpenAIRE's Europe-wide community remains the same and the outreach and open access advocacy of the NOADS will be extended to cover promotion of good research data management across Europe and beyond. Some of the tasks of NOA Ds will be to identify data initiatives in their regions. These could be data repositories, either institutional or subject-specific, with a view to linking research outputs with the OpenAIR E information space. Another activity will be examining other funding streams in Europe and working with OpenaIRE to identify publications funded outside FP7. Above all, discovery, visibility and reuse of research data will be promoted.

Support for open science and the infrastructures that facilitate the reuse and visibility of research output have been made clear at EU policy and funding level. The EC's next funding programme, Horizon 2020 (20142020) will ensure its commitment to open access, re-use of research output, and interoperability between e-infrastructures will be supported ${ }^{4}$.

OpenaIRE will be thus well placed as a future open access publication infrastructure that provides a bridge to rapidly growing data infrastructures. 


\section{Methodology}

Data for this work was gathered through desk research-including detailed country reports on open access developments collected by Open$\mathrm{AIRE}^{5}$ and related websites and literature-and through documents and presentations provided for OpenA IRE meetings such as the general assembly and the launch event held on 1 and 2 December 2010 in Ghent. For specific questions, answers from the NOADs were directly sought. An update of the data was conducted in June-August 2012. 


\section{Open Access Policies}

Open access (OA) policies range from voluntary (i.e. researchers are requested to make their work open access) to mandatory policies (which require researchers to make their work open access). Depending on the kind of policy and the institution or organisation implementing it, specific challenges and needs crop up.

In principle, oA policies are based on the definition of open access as stated in the Berlin Declaration, ${ }^{6}$ which outlines two conditions that must be satisfied in order for a contribution to qualify as open access:

1. The author(s) and copyright holder(s) grant to all users a free, irrevocable, worldwide, perpetual (for the lifetime of the applicable copyright) right of access to, and a licence to copy, use, distribute, perform and display the work publicly and to make and distribute derivative works in any digital medium for any reasonable purpose, subject to proper attribution of authorship, as well as the right to make small numbers of printed copies for their personal use.

2. A complete version of the work and all supplemental materials, including a copy of the permission as stated above, in a suitable standard electronic format is deposited immediately upon initial publication in at least one online repository that is supported by an academic institution, scholarly society, government agency, or other well-established organisation that seeks to enable open access, unrestricted distribution, interoperability, and long-term archiving. (ibid.)

In practice, several policies allow weaker forms of open access. This is due to the fact that publishers often demand exclusive rights to a publication, which means that authors no longer hold the rights to grant such a wideranging licence. To enable open access and the wide dissemination of their work, authors are advised not to sign away copyright but to grant the journal or publisher a licence to publish. Such a licence must cover the rights 
granted to the journal/publisher while still allowing the author to deposit the article in an oA repository, which would make the work freely available to the public via the internet within a specified period after publication (known as the embargo period, which is often 6-12 months depending on the publisher).

The Registry of Open Access Repository Material Archiving Policies (ROARMAP $)^{7}$ provides an overview of several kinds of policies. As of 25 August 2012, ROARMAP listed 152 institutional, 34 departmental, 53 funder, 93 thesis and three multi-institutional oA archiving mandate-a total of 335 OA mandates. ${ }^{8}$ Almost $60 \%$ of these oA mandates are based in Europe, with 110 institutional, six departmental, two multi-institutional, 35 funder, 38 thesis mandates. 9

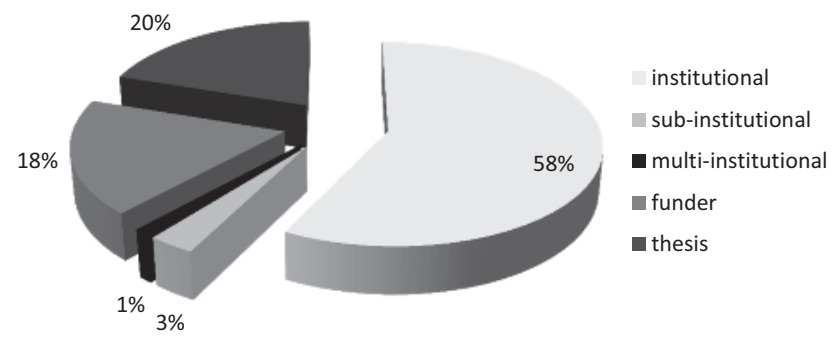

FIGURE 3-1 Open Access Mandates in Europe (as of 2012-08-25)

The number of oA mandates has grown significantly in recent years:

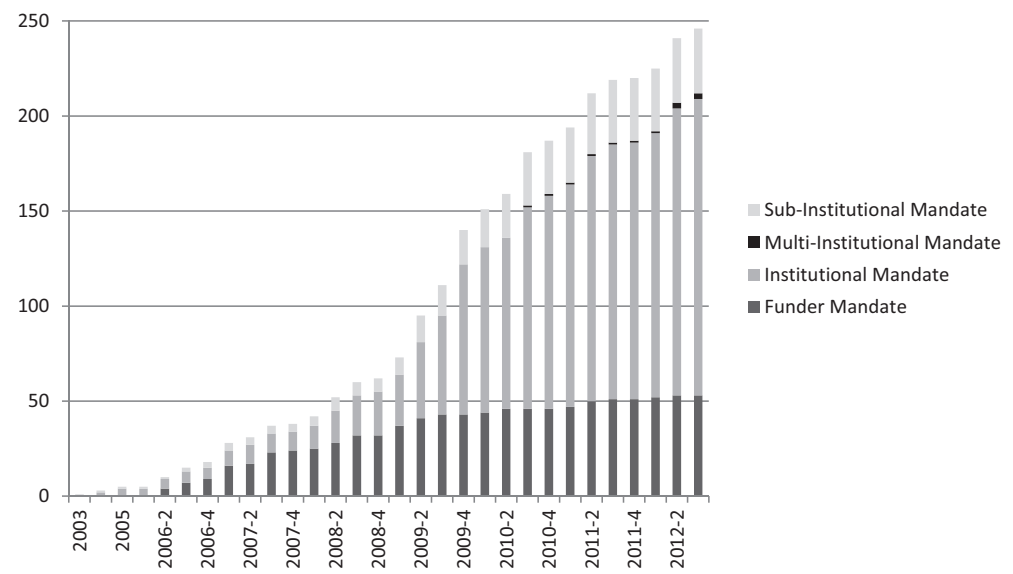

FIGURE 3-2 Growth of OA Mandates (based on ROARMAP, as of 2012-08-25) 
Although there are examples ${ }^{10}$ that demonstrate the efficiency and effectiveness of institutional, departmental and funder OA mandates, most OA mandates are still in the early stages of being implemented and evaluated. Moreover, the compliance rate of a mandate is not always easy to measure, since this requires knowledge about the actual body of work produced.

Below, we provide a short description of oA policies that are relevant for OpenAIRE and describe specific aspects that need special attention in their implementation.

\subsection{Research funders' policies}

Over the last decade, several research funders have established oA policies. An overview of research funders' OA policies can be found in the SHERPA/JULIE T database. ${ }^{11}$ Its counterpart, the SHER PA/RomeO database, ${ }^{12}$ as well as the ME LIB EA database ${ }^{13}$ show which publisher's policies on archiving comply with funding agencies' OA policies.

\subsubsection{European Commission}

Since August 2008, the European Commission has supported an initiative to improve the online accessibility of $\mathrm{EU}$-funded research results. ${ }^{14}$ This initiative, called the Open Access Pilot in the Seventh Framework Programme (FP7), encourages and supports FP7-funded researchers to make their research results openly accessible: either through open access publishing (the so-called 'gold route') or through open access self-archiving (the so-called 'green route').

To encourage the gold route, FP7 projects' publishing costs-including fees for publishing in OA journals-are fully eligible for reimbursements within the project period. ${ }^{15} \mathrm{~A}$ number of institutions are also developing funds for OA publishing, supported by overheads within research grants, out of the library budget and other sources, to pay the fees for OA publication. ${ }^{16}$

Nevertheless, the main emphasis in the Eu's Open Access Pilot is on the green route, which applies to any manuscript that:

- is peer-reviewed and accepted for publication;

- results from funded research in one of seven selected subject areas: 
energy, the environment (including climate change), health, information \& communication technologies (cognitive systems, interaction, robotics), research infrastructures (e-infrastructures), science in society, and social sciences \& the humanities;

- has a grant agreement signed after August 2008 (see Special Clause 39). ${ }^{17}$

The Commission expects researchers to:

- deposit their publications or final manuscripts upon publication into an appropriate institutional or disciplinary repository;

- make every effort to ensure open access to these articles within six or twelve months after publication (six months after publication for the first five subject areas listed above, twelve months for the remaining two subject areas).

The FP7 Open Access Pilot is supported and to some extent monitored by the OpenaIRE project. The impact of the pilot and its benefits to $\mathrm{EU}$-funded research will be analysed by the Commission together with the European Parliament, member states and all relevant stakeholders. The results of the pilot will be used as input for the Commission's deliberations on the next steps needed to enhance access to scientific research at both the European and national levels. ${ }^{18}$ This will in turn determine the policy for the next Framework Programme, FP 8, starting in 2014.

In Spring/Summer 2011, the Ec held a consultation on scientific information in the digital age: stakeholders were invited to contribute to workshops and hearings, and citizens and organisations were invited to respond to an online questionnaire. ${ }^{19}$ Moreover, in May 2011, the EC invited all project coordinators to contribute to a survey in order to collect feedback on their experiences of both the implementation of the open access pilot and the reimbursement of open access publishing costs. ${ }^{20} \mathrm{~A}$ total of 194 answers were received from 811 projects. The majority of those with opinion find it easy or very easy to self-archive peer-reviewed articles. However, for $60 \%$ of those with opinion, understanding copyright and licenses to publish is difficult or very difficult. The majority of respondents was not aware of the possibility to request full reimbursement of publication costs during the lifespan of $\mathrm{FP} 7$ projects. Almost $70 \%$ of respondents 
with an opinion think it is better to use self-archiving than open access publishing to satisfy the open access requirement in F P 7 .

On 17 July 2012, a Communication and Recommendation shaping the forthcoming policy have been released by the European Commission. ${ }^{21}$ As a first step, the Commission will make open access to scientific publications a general principle of Horizon 2020, the EU's Research \& Innovation funding programme for 2014-2020. Various stakeholders including OpenA IRE have welcomed the new policy. In Horizon 2020, both self-archiving ('Green' open access) and open access publishing ('Gold' open access) are considered as complementary approaches to achieve the aim of full open access to publications resulting from Horizon 2020 and to provide a framework and encourage open access to research data. ${ }^{22}$

\subsubsection{European Research Council}

The European Research Council (ERC) ${ }^{23}$ was established by the European Commission and funded by the EC's Seventh Research Framework Programme. The ERC awards individual researchers with grants under the F P7 Specific Programme 'Ideas'.

On 17 December 2007, the ERC Scientific Council released its Guidelines for Open Access based on its Statement on Open Access dating from December 2006 24; the Open Access Guidelines for researchers funded by the ERC have been updated in June 2012. ${ }^{25}$

In the 2007 guidelines, the ERC acknowledges that, in the age of the internet, free and efficient access to the vast quantities of information generated by scientific research is key to scientific progress. Moreover, the ERC stresses that peer review is of fundamental importance in ensuring the certification and dissemination of high-quality research, and policies towards access to peer-reviewed literature must guarantee the ability of the system to continue to deliver these certification services. Access to unprocessed data is not only needed for the verification of results, but more importantly for secure preservation, fresh analysis and the utilisation of data. Another fact noted by the ERC is that there are already some hundreds (over 400 at that time) research repositories and curated databases in the European Union that make publications and research data accessible (such as PubMed Central for life sciences and medicine, the arXiv for physics and mathematics, the DDBJ/EMBL/GenBank nucleotide sequence database and the RSCB-PDB/MSD-EBI/PDBj protein structure database). With a 
few exceptions, the social sciences and humanities ( $\mathrm{ssH}$ ) field does not yet have the benefit of such repositories for their publications. Moreover, access to primary sources is often hindered by private or even public or state ownership which permits access on a highly selective basis or not at all (e.g. social survey data and statistical data that exist in the public domain but usually at the national level).

In the updated Open Access Guidelines for researchers, the ERC requires electronic copies of any research papers and monographs that are supported in whole, or in part, by ERC funding to be made publicly available as soon as possible, and no later than six months after the official publication date of the original article. Moreover, the E RC strongly encourages ERC funded researchers to make their publications available in open access using discipline-specific repositories (the recommended repository for Life Sciences, is UK PubMed Central (to be known as Europe PMC from 1 November 2012); for Physical Sciences and Engineering ArXiv is recommended. If there is no appropriate discipline specific repository, researchers should make their publications available in institutional repositories or on their own webpage. ${ }^{26}$

The ERC Scientific Council is reviewing existing practices and open access infrastructures in Social Sciences and Humanities and will make recommendations in the future.

The ERC considers it essential that primary data, as well as data-related products such as computer codes, is deposited in the relevant databases as soon as possible, preferably immediately after publication and in any case not later than six months after the date of publication; encourages Host Institutions to cover open access fees of any research papers and monographs that are supported in whole, or in part, by ERC funding which arise in the period up to 24 months after the end of a grant; and reminds ERC funded researchers that open access fees are eligible costs that can be charged against ERC grants.

A recent survey carried out by the ERC found that between 50 and $70 \%$ of sample sets of ERC-funded articles are open access ${ }^{27}$. The number varies across discipline, with life sciences representing the highest number of open access articles. This seems to reflect the difference in current practices and policy direction to deposit as outlined above: in some research fields there are well-established repositories which have been instrumental in the development of open access and which work together with fun- 
ders, publishers and research organisations. Moreover, the ERC stresses that seeking alignment and a common approach throughout an institutional organisation on how to approach open access and support researchers is crucial. This will bolster the current 'soft' approaches to implementing policies and mandates.

In an interesting development, the ERC has also joined Europe $\mathrm{PMC}^{28}$. This increases the number of European funders within UKPMC, and as a result the service has now changed to Europe PMC, ensuring the widest visibility possible of European research output.

\section{Conclusions}

The European policies on open access described above are the raison dêtre of OpenAIRE, and the results of the OpenAIRE project will inform the EC's policymaking in this area. At the project's first-year launch and review held on 2 and 3 December 2010 respectively, OpenaIRE's achievements were welcomed by EC representatives, the project's reviewers and the public involved. The project's reviewers released a declaration ${ }^{29}$ recommending further steps to facilitate the project's efforts and to enhance related initiatives on open data, open source software and open educational resources.

OpenAIRE regularly reports on its experiences and insights and strives for recommendations to the EC at the policy and implementation levels to further the uptake of Europe's policies on open access. ${ }^{30}$

\subsubsection{Other research funders' policies}

One of the most prominent examples of a funder mandate is the open access policy of the Wellcome Trust, a UK-based foundation concentrating on biomedical research and the medical humanities. ${ }^{31}$ Its OA policy has been in place since October 2006 and was the first of its kind worldwide. Other funders that have established open access policies include the National Institutes of Health ${ }^{32}$ (mandate since April 2008), the Howard Hughes Medical Institute ${ }^{33}$ (since January 2008), the Australian Research Council (policy since December 2006, mandate since January 2008) and the National Research Council Canada ${ }^{34}$ (since January 2009). ${ }^{35}$

In this section we would like to examine the Wellcome Trust's oA policy in detail, as it is a pioneer in this field and can offer valuable lessons to other funders venturing into the world of open access. The Wellcome Trust is 
committed to ensuring that the published outputs of its funded research are made freely available, so that this knowledge can be built on and used in a manner that maximises health and public benefit. In its mandate, the Wellcome Trust:

- expects authors of research papers to maximise the opportunities to make their results available for free;

- requires that all research papers funded in whole or in part by the Wellcome Trust be made available via the u k PubMed Central repository as soon as possible, and in any event within six months of the date of publication;

- will provide grantholders with additional funding to cover open access charges, where appropriate, in order to meet the Trust's requirements;

- encourages-and where it pays an open access fee, requires-authors and publishers to license research papers in such a way that they may be freely copied and re-used (for example for text and data-mining purposes), provided that such uses are fully attributed;

- affirms the principle that it is the intrinsic merit of the work, and not the title of the journal in which an author's work is published, that should be considered in making funding decisions.

At the Berlin 8 Open Access Conference in October 2010, a representative of the Wellcome Trust reported about the progress that has been made over the past five years in terms of compliance with its mandate, providing the infrastructure to support open access, and working with publishers to develop Wellcome-compliant publishing policies. ${ }^{36}$ Additional steps to help realise the full potential of the $\mathrm{OA}$ mandate were presented.

To support the Trust's oA mandate, a central repository uk PubMed Central (UKPMC) was established together with 18 UK and European research funders. As of February 2011, over 12,000 full-text articles available in UKPMC have a connection to funding by the Wellcome Trust.

The Wellcome Trust provides funding to cover open access costs when: 1) publishers deposit the final version of the article in UKPMC on behalf of the author, 2) the article is made available at the time of publication (i.e. without an embargo period), and 3 ) the article is licensed in ways that allow re-use. To this end, the Trust has worked with publishers to develop 
Wellcome-compliant oA options. As a result, $98 \%$ of articles published in journals in 2009 had Wellcome-compliant policies, i.e. could in principle be made available in U Р P MC. In general, of the papers in UKP MC that have been deposited based on the Trust's oA mandate, roughly $85 \%$ are deposited by publishers and $15 \%$ are authors' self-archiving.

The rate of compliance with the Wellcome Trust's oA mandate was nearly $50 \%$ by the end of 2009 , although the rate was higher for some institutes where senior researchers support the idea of open access and was significantly lower for articles in some specific journals such as Nature (less than 25\%), Science, and Cell (both less than 10\%).

Despite the Wellcome Trust's open access policy having been in place for over five years, at present, only 55 per cent of research papers acknowledging Wellcome Trust funding comply with it. Sir Mark Walport, Director of the Wellcome Trust (Trust), said on June 28, 2012 that "it is simply unacceptable and so with immediate effect they will be tightening up enforcement of their policy". The following steps will be taken:

- "When Trust-funded researchers prepare final grant reports, it will require the principal investigator's institution to provide assurance that all papers associated with the grant comply with the Trust's policy. If they are unable to do this, the final payment on the grant will be withheld.

- Non-compliant publications will be discounted as part of a researcher's track record in any renewal of an existing grant or new grant application."

- Trust-funded researchers will be required to ensure that all publications associated with their Wellcome-funded research are compliant with the Trust's policy before any funding renewals or new grant awards will be activated."

All three steps will apply to research articles published from 1 October 2009 onwards. Moreover, "from early 2013, the Trust will also require that when it pays an open access fee, a paper is made freely available for all types of re-use (including commercial uses) subject to appropriate acknowledgement. The Trust believes that the full research and economic benefit of published content will only be realised when there are no restrictions on access to, and reuse of, this information. Its goal is to unleash that 
content while still allowing publishers to recoup their costs in an effective market. The Trust will partner with the Research Councils in taking forward discussions with publishers to implement this change over the coming months." ${ }^{37}$

To assist researchers, Wellcome Trust has created a list of 200 journals frequently used by Wellcome Trust-funded authors, along with advice - at the journal title level - on how best to comply with the Trust's open access requirements in a way that also meets the journal's publishing policy..$^{38}$

Research Councils uk released its new open access policy (Policy on Access to Research Outputs) on 16 July 2012. It will apply to articles published in peer-reviewed academic journals or conference proceedings being submitted for publication from 1 April 2013 and states that "peer reviewed research papers which result from research that is wholly or partially funded by the Research Councils: must be published in journals which are compliant with Research Council policy on Open Access, and; must include details of the funding that supported the research, and a statement on how the underlying research materials such as data, samples or models can be accessed." 39 The policy mandates use of the Creative Commons Attribution license, article processing charges are levied. The compliant journals must allow deposit of accepted manuscripts that include all changes resulting from peer review (but not necessarily incorporating the publisher's formatting) in institutional or subject repositories repositories, without restrictions on non-commercial re-use and within a defined period (no more than six months between on-line publication and a research paper becoming open access, except in the case of research papers arising from research funded by the AHRC and the ESRC where the maximum embargo period is twelve months)..$^{40}$

Several issues have been identified that can be instrumental in improving compliance with an oA mandate. Funders should be explicit about how researchers and institutions can access funding for $\mathrm{OA}$, monitor compliance, demonstrate the benefits of $\mathrm{OA}$ to researchers and follow a persuasive rather than punitive approach if the compliance rate is not satisfactory. Institutions and researchers, for their part, should improve access to oA funds, request these costs when applying for research funds, inform researchers about the $\mathrm{OA}$ funds in meetings, offer support from senior staff and encourage authors to self-archive. Publishers should simplify the process of selecting an oA option (when submitting the manuscript), inform authors about 
the possibility of selecting the ox option, and make the relationship between the $\mathrm{OA}$ option and the subscription costs explicit so that funders and institutions can be confident that they are not paying twice.

Moreover, officially reminding researchers by mail about their obligation to deposit their articles in UKРMC reportedly had a significant positive impact on the compliance rate.

\section{Conclusions}

The approach of the Wellcome Trust, presented above, is highly effective, as it relies on a central repository infrastructure providing a wide range of functionalities (grant reporting, searching supported by text mining, citation services, etc.). The majority of the deposits are publisher-assisted deposits. This reflects the Trust's close cooperation with publishers, which is fostered by the additional funding made available to authors selecting the oA option.

In comparison, the OA policies of the EC and the ERC put more emphasis on the self-archiving of articles by authors, encouraging researchers to use their institution's digital repository. If authors decide to use publication funds for OA options and ask publishers to deposit on their behalf, this makes it more time-consuming for the publisher, as there is a wide range of institutional and disciplinary repositories available. Nevertheless, there are ways to automate the process based on the SWORD protocol. ${ }^{41}$ This procedure has already been established by some oA publishers such as BioMed Central.

The experiences of the Wellcome Trust offer good examples and learning opportunities for OpenAIRE. In the course of the project, OpenaIRE will continue to evaluate the Trust's experiences and those of other funders, where possible in the context of collaborative projects with publishers such as the PEER project (see below).

\subsection{Institutional open access policies and mandates}

As with research funders' policies, institutional ox policies can be either voluntary or mandatory. There is some evidence that mandatory policies produce a higher level of self-archiving by researchers.

The Queensland University of Technology (QU T) was the first universi- 
ty to establish an institution-wide mandate. It went into effect in January 2004 and is reviewed every three years. ${ }^{42}$ Tom Cochrane, Deputy ViceChancellor, reports a steady rise of deposits and positive effects in terms of usage and citation impact. 43

Within Europe there are several institutional mandates, for example the oA mandate of the University of Minho in Portugal, which was first announced in December 2004. This mandate requires that:

1) all teachers and researchers at the University of Minho, being authors or co-authors of any type of published work, should deposit those resources in the institutional repository of the University of Minho, RepositoriUM, ${ }^{44}$ thereby granting permission for dissemination in open access;

2) all the organic units of the University of Minho should prescribe or adopt self-archiving policies for their own research output; and

3) all authors of theses and dissertations approved by the University of Minho should authorise their deposit and dissemination through the institutional repository.

In order to ensure that the policy was understood and applied by all stakeholders, the dean introduced a financial incentive in 2005 that was distributed to the departments according to the number of documents deposited in the institutional repository. As a result, in 2005, over 2,800 documents were deposited: $41 \%$ and $40 \%$ were journal articles and conference papers respectively, and 19\% were other types of documents (book chapters, books, working papers, etc.). ${ }^{45}$ By the end of 2005, there were 3,105 documents in the repository. In 2006, the dean provided another 30,000 euros to encourage self-archiving, which resulted in a total of 4,900 documents by the end of that year. With a steady growth in the following years, the repository now hosts over 10,500 full-text documents (as of February 2011).

The University of Liège in Belgium adopted an institutional immediatedeposit/optional-access mandate (ID/OA) in May 2007. In December 2009, Ghent University also adopted a similar institutional ID/OA mandate. ${ }^{46}$ The main elements of the Liège $\mathrm{OA}$ mandate are as follows: 
- All publications must be deposited.

- By default, access to a deposit will be closed access, except where oA has been authorised.

- In case of doubt, access remains closed in order to avoid any conflicts with publishers.

- The institutional repository will install an e-mail request button that allows authors to send an individual copy.

- As soon as conditions allow, the author asks for OA.

After an experimental phase based on volunteerism, the administrative board of the university has decided to make the following measures mandatory for all University of Liège members:

- The bibliographic references of all their publications since 2002 must be deposited.

- The full text of all articles published in periodicals since 2002 must be deposited.

- For future publications, deposit will be mandatory as soon as the article is accepted by the editor.

- From 1 October 2009, only those references introduced in the repository will be taken into consideration as the official list of publications accompanying any curriculum vitae for all 'in-house' evaluation procedures (designations, promotions, grant applications, etc.).

The last point in particular was reported to be highly effective, as it resulted in high deposit rates in advance of institutional research evaluations.

On 10 May 2012 the University of Luxembourg signed a collaboration agreement with the University of Liège to inspire researchers to selfarchive in open access in order to attain the success that the University of Liège has achieved with ORBi, its digital repository: in just under 6 years, researchers at University of Liège have entered 50,000 references with full text, which represents close to $61 \%$ of the deposits. As stated in 2011 by Bernard Rentier, Rector of University of Liège: "Today ORBi is the most active institutional repository of its type in the world". 47 This collaboration agreement will, through the transfer of knowledge and experience, strengthen the ties between the Universities and will provide the University of Luxembourg with its own digital repository, OR Bi lu. 
The University of Ghent combines its academic bibliography and institutional repository. The mandate covers articles, books and proceedings. As of 1 July 2010, only records submitted with full text are being accepted in the academic bibliography. ${ }^{4}$

\section{Conclusions}

One of the main challenges OpenAIRE faces however is to aggregate at a global level this local information, taking into account socio-cultural and regional differences of the communities involved (Lossau, 2012). However, the networked nature of OpenAIRE organisations, with open access experts in European countries (the National Open Access Desks), enables the project to support policy development at the institutional, regional and national levels. ${ }^{49}$ Via the NOADs and national organisations advocating for open access, institutions can be assisted in developing their own open access policies and mandates by providing examples and materials used in other countries and by adapting these to specific national and institutional circumstances.

\subsection{Other organisations and initiatives}

In this section we summarise initiatives that have had some impact on the development of open access policies at universities and their rectors' conferences and at research funders and organisations.

\subsubsection{European University Association}

In January 2007, the European University Association (EUA) established an expert Working Group on Open Access for a one-year period following requests from its members for the EUA to act as an independent European stakeholder for universities in the growing policy debate on open access scientific publishing..$^{50}$ The working group reflected perspectives on $\mathrm{OA}$ from the viewpoint of academic researchers, librarians and university management. It was tasked with gathering additional expert opinion on specific issues like oA business models, legal and copyright issues, the technical development of national repositories and their European networks and oA policies developed by funding agencies at the national level and by the European Commission. 
The recommendations of the EUA Working Group on Open Access were adopted by the EUA Council on 26 March 2008 during the EUA's spring conference held at the University of Barcelona in Spain..$^{11}$ Below, we summarise the recommendations which were addressed to the various university stakeholders.

- University leadership is encouraged to:

- develop institutional policies and strategies to foster the availability of quality-controlled research results for the broadest possible range of users, maximising their visibility, accessibility and scientific impact; - create an institutional repository or participate in a shared one that is established and managed according to best practices (following recommendations and guidelines from DRIVER and similar projects), complying with the OAI-PMH protocol and allowing interoperability and networking for wider usage;

- require that their researchers deposit their publications in the institutional repository immediately upon acceptance for publication (i.e. no embargo period for deposition), with an embargo permissible only for open access provision;

- include copyright in the institution's management of intellectual property rights (IPR), to inform researchers about IPR and copyright management in order to ensure the wide sharing and re-use of digital research content and to build up a clear institutional policy;

- explore how resources could be found and made available to researchers for author fees to support the emerging author-pays model of open access.

- National rectors conferences are encouraged to:

- work with national research-funding agencies and governments in their countries to implement the requirement of self-archiving of research publications in institutional repositories and other appropriate open access repositories according to the best-practice models of the ERC and existing national research-funding agencies that operate open access mandates;

- attach high priority to raising the awareness of university leadership regarding the importance of open access policies in terms of enhanced visibility, access and impact of their research results.

- The European University Association should continue to: 
- contribute actively to the policy dialogue on open access at the European level with a view to a self-archiving mandate for all research results arising from $\mathrm{EU}$ research funding, supporting and building upon the ERC position and other international initiatives such as that of the National Institutes of Health $(\mathrm{NIH})$ in the Us;

- be visible and to rally expertise from Europe's universities to provide input to European and international events advancing open access to scientific publications, research data and their preservation.

\section{Conclusions}

The EUA aims to monitor the implementation of its recommendations on the development of university institutional repositories. The recommendations have been presented at various events. At the EUA autumn conference in 2009, a break-out session was held entitled Open access - sharing knowledge.

Some national organisations of universities and rectors conferences jointly expressed their explicit support of the EUA's recommendations on open access, including the Conference of Rectors of the Portuguese Universities (CRUP). The Lithuanian Rectors Conference has discussed the EUA's recommendations with the aim of developing an open access mandate..$^{52}$

OpenAIRE aims to explore how the EUA can actively support efforts to raise awareness of European policies on $\mathrm{OA}$ among university leadership and national rectors conferences. The EC and ERC requirements on open access might serve as a strong motivator for the adoption and implementation of the EUA's recommendations. OpenAIR E provides the necessary information network, materials, infrastructure and helpdesk to assist the universities in these efforts.

\subsubsection{League of European Research Universities}

The League of European Research Universities (LERU) ${ }^{53}$, founded in 2002, is an association of 22 research-intensive universities sharing the values of high-quality teaching in an environment of internationally competitive research.

The LERU Roadmap to Open Access ${ }^{54}$ addresses European universities and aims to enhance "the dissemination, transfer and use of research results, including through open access to publications and data from pub- 
licly funded research". This was one of the action points identified by the EC in order to achieve a well-functioning European Research Area (ERA). The roadmap focuses on practical steps that universities can take to implement their part of the Commission's vision for the European Research Area and is designed to support European universities that wish to put in place structures, policies and practices to support open access.

The LERU Roadmap covers recommendations to support both selfarchiving in repositories (the so-called green route) and publishing in open access journals (the so-called gold route). For the green route, this includes an initial phase in which the institution develops an open access repository, creates a communication strategy, identifies the benefits for researchers and the institution, identifies the scope of the collection, embeds the oA efforts into pan-university strategies and collaborates with other institutions. Further on, institutions are advised to develop an institutional mandate requiring self-archiving (e.g. at University College London), which should be facilitated by user-friendly systems and preferably integrated into the institution's current research information systems. In addition, a proactive stance on copyright issues is recommended to safeguard authors' rights of archiving in repositories. To further the process, LERU advocates that European universities investigate the feasibility of storing primary data in repositories and linking data to research publications. Moreover, LERU sees a need to link efforts and avoid duplications with regard to search portals and to collaborate on the provision of secure digital curation infrastructures.

For the gold route, the roadmap urges all European universities to promote the benefits to their researchers-and to European research in general—of publishing in oA journals, and to seek to allocate funds to pay charges for submission and publication. In order to maximise the investments made by LERU institutions, LERU will investigate the feasibility of negotiating group agreements with 'gold' oA publishers for memberships and/or bigger discounts on publication charges. LERU envisions lobbying research funders and other stakeholders for the investments needed to foster the shift to open access. For those active in institution-based monograph publishing, LERU recommends linking up with the OAPEN ${ }^{55}$ network, an initiative of academic publishers and libraries to enhance open access for book publishing in the humanities and social sciences. LERU plans to work together with other European universities and university as- 
sociations in this area and to provide models of best practice from LERU institutions and partnerships.

\section{Conclusions}

The LERU Roadmap is in line with the EUA's recommendations on open access and summarises the ongoing practices at LERU member institutions. Other associations and groups of universities at both the European and national levels (UniCA, Coimbra Group, Compostela Group, Santander Group, Utrecht Network, Russell Group etc. $)^{56}$ might follow this example or take up the recommendations institutionally.

There are already some activities in this area. The Coimbra Group for example, aiming to develop a strategy for the humanities, held a workshop in September 2008 called Research Evaluation, Metrics and Open Access in the Humanities at Trinity College in Dublin. The UniCa group also conducted a seminar on scholarly communications on 7-9 November 2010 called Find It, Get It, Use It, Store It at the Universidade Nova de Lisboa. ${ }^{57}$ Sessions covered the digitization of content, the role of libraries (in particular with regards to open data and repositories), the implementation of open access mandates, and digital publishing and information literacy.

Another issue of importance for researchers and their institutions is how research is evaluated, in particular if based on publications and impact metrics. Currently, researchers of several fields tend to publish in traditional journals; in particular if ox journals are quite new and have not yet achieved comparable impact factor ratings or other rankings. ${ }^{58}$ These rankings of journals are of great importance to researchers seeking funding or applying for research positions. 59

For some universities, open access has already been integrated into strategic concepts. For example, Aarhus University's internationalisation strategy states that the university will foster the internationalisation of research by publishing research results internationally:

"Aarhus University will make large parts of its research available via internationally recognised journals. The international peer-review that is required for articles to be accepted is a seal of quality that makes the university's research visible and underpins efforts to establish new working relations with foreign research groups. In addition, 
Aarhus University will contribute to international attempts at providing free access to research publications via Open Access." ${ }^{\circ 0}$

As with the EUA, OpenAIRE will seek to collaborate with associations of universities in their efforts to advocate and support European policies on open access.

\subsubsection{EUROHORCS and European Science Foundation}

Until October 2011, the European Heads of Research Councils (EUROHORCs $)^{61}$ has been the principle European association of the heads of research funding and research performing organisations. It acted as an active player in the field of European research policy, promoting and enhancing inter-council cooperation. EUROHORCS run several working groups, including one that addresses open access. The main goal of this group was "to facilitate a process after which all peer-reviewed publications in scientific journals resulting from publicly funded research are available free of charge to the public no longer than six months after publication, either via self-archiving in institutional or subject repositories or via direct open access publishing in open access journals or as author-/funding agencysponsored open access articles." ${ }^{62}$

The European Science Foundation ${ }^{63}$ (ESF) provides a common platform for its member organisations in order to advance European research and to explore new directions for research at the European level. Through its activities, the ESF serves the needs of the European research community in a global context. It carries out an array of activities, ranging from organising scientific exploratory workshops to providing science policy advice. ${ }^{64}$

On 18 April 2008, the General Assembly of EUROHORCs agreed to recommend a minimal standard regarding open access to its member organisations. ${ }^{65}$ These recommendations were based on a report published by the European Research Advisory Board (EURAB) ${ }^{66}$ in December 2006. ${ }^{67}$ In July 2009, EUROH ORCs and the European Science Foundation (ESF) ${ }^{68}$ published their Vision on a Globally Competitive ERA and their Road Map for Action. ${ }^{69}$ Point 8 of this vision calls for: "open access to the output of publicly funded research and permanent access to primary quality-assured research data". The two organisations aim to achieve this by:

- developing a joint policy and a statement on open access and putting it into action; 
- supporting the necessary infrastructures for open access;

- promoting awareness of the importance of open access among researchers and administrators;

- initiating a dialogue with other national and European associations, publishers, and possibly other non-European research organisations to redefine the responsibilities and cost distribution of the publishing system;

- ensuring that permanent preservation and open access will be the rule for data repositories.

Based on these principles, EUROHORCs and the ESF decided to develop a joint policy and statement on open access. These would include:

- Joining the Berlin Declaration on Open Access to Knowledge in the sciences and humanities;

- Incorporating mandatory oA requirements into the conditions for all grants, including banning the transfer of the copyright to third parties without retaining the right to disseminate via OA outlets;

- On an intermediate time scale, a policy on grant management should include provisions for obtaining copyright for $\mathrm{OA}$. In the long run, the publication system has to undergo a transition from a reader-pays system to an author-pays or institution-pays system;

- Gradually introducing a process of verifying whether researchers and institutions comply with funder's recommendations;

- Formulating standards and good practice guidelines.

EUROHORCS and the ESF aim to support the necessary infrastructure for open access by:

- Allowing institutions to incorporate in their financial plans the legitimate costs of the infrastructure (i.e., the creation and maintenance of repositories);

- Allowing the legitimate costs of oA to be part of the dissemination costs of research findings;

- Considering the establishment of a European Repository (an initiative of the Max Planck Society) for institutions and/or disciplines without a repository. 
EUROHORCS and ESF member organisations have declared their readiness to promote the importance of open access among their researchers and administrators. Together with other national or European associations and possibly other non-EU research funding organisations, they will work with publishers to redefine the responsibilities and cost distribution of the publishing system.

It should be noted that EUROHOCs was dissolved in 2011, its successor being Science Europe ${ }^{70}$. This body is still fully committed to supporting open access within the European Research Area, where direct engagement with key partners will ensure scientific collaboration and developing a common open access policy. ${ }^{71}$

\section{Conclusions}

EUROHORCS and the ESF envision a fundamental change to the publishing system and recommend a range of support actions at the policy, financial and infrastructural levels. Since the publication of their vision, there have been no further activities or outcomes in this area.

OpenAIRE will explore opportunities for collaborating with Science Europe in its efforts to transform the publishing system and promote the implementation of open access mandates.

\subsection{Publishers' policies}

The SHERPA/ROMEO ${ }^{72}$ database collects information about the selfarchiving policies of publishers and journals. This resource can be used by authors or librarians as a starting point to check whether a certain journal allows articles to be deposited into repositories and if its conditions allow authors to comply with a funder's open access policy or mandate. ${ }^{73}$

As of August 2012, the database covered over 1,100 publishers and over 20,750 journals (this includes a few duplicates). Several national initiatives cooperate with SHER PA/ROMEO to provide interfaces in local languages as well as to extend its coverage. By now, German, Spanish, Portuguese and Hungarian versions are available $e^{74}$ and other countries including France and Norway are working on extensions as well. ${ }^{75}$ 
Several publishers and journals have already adapted their publishing agreements to meet the demands of authors who have to comply with funders' OA mandates. Typically, they differentiate between:

- the submitted work - that is, the version of the manuscript as submitted to the publisher for review and possible publication:

- the accepted work - that is, the version of the manuscript that has been accepted for publication and that includes all changes resulting from peer review but prior to the publishers' copy editing and production; and

- the published work - that is, the version of the work accepted for publication and that includes any changes resulting from peer review and publishers' editing and production services. ${ }^{76}$

In general, publishers are more liberal with submitted works and allow them to be made publicly available if there is no conflict with their policies regarding prior publication and the posting is for non-commercial purposes. As soon as the submitted work is accepted, the document should incorporate a reference to the published work.

For accepted or published works, publishers often apply more restrictive conditions. For example, for (most of the) journals published by the American Chemical Society (ACS), an accepted work may be made available on websites or repositories if this is mandated by the author's funding agency, employer or university administration, and if additionally the authors have received written confirmation (via letter or email) from the journal editor that the posting does not conflict with the journal's prior publication policies, and the published work is not made publicly available until at least twelve months after the work's online publication. ${ }^{77}$

To support authors in fulfilling the requirements of funder or institutional OA mandates, several publishers have already set up workflows for depositing articles on behalf of the authors. This publisher-assisted deposit helps to reduce the burden on authors and secures the timely provision of content. In effect, this transforms individual or institutional obligations based on grant agreements into collective contributions of all the involved stakeholders and beneficiaries.

Currently, authors have the following options: 
- the author-pays option: Many publishers offer an open access option where, in return for a fee, the publisher will make the article freely available on the publishers' website. A number of publishers will deposit the article on behalf of the author into an OA repository.

- self-archiving: Many publishers allow authors to self-archive the author manuscript version of their article and to make these freely available within six to twelve months of publication.

- non-compliance: Some publishers have not yet developed a model that allows funded authors to meet their open access obligations. ${ }^{78}$

For the oA mandates of the Wellcome Trust and several other funders, the majority of publishers will deposit the final version of the published article in PubMed Central and u $\mathrm{K}$ PubMed Central and make this work available at the time of publication. Authors are encouraged to select this option, with the costs associated with this option being met by additional funds provided by the Wellcome Trust. ${ }^{79}$ Wellcome Trust created a list of 200 journals frequently used by Wellcome Trust-funded authors, along with advice - at the journal title level - on how best to comply with the Trust's open access requirements in a way that also meets the journal's publishing policy. ${ }^{80}$

\section{Conclusions}

The main emphasis of the oA policies of the European Commission and the European Research Council is on the depositing of the author's final manuscripts. Therefore, the majority of publisher policies are compatible with the EC and ERC's policies. Nevertheless, special clauses in publishers' or journal policies can become an obstacle to self-archiving (see section $4.7)$.

OpenaIRE collaborates with SHERPA/ROMEO to make publishers' and journals' compliance with the EC/ERC's OA requirements transparent to authors and institutions. It will support authors and institutions in their dealings with publishers with regard to open access, and it will strive for copyright policies and agreements compliant with these requirements. 


\subsubsection{Related projects}

Scholarly publishers, research institutions, organisations and funders are involved in several projects and initiatives exploring the opportunities and challenges of oA publishing and oA self-archiving. They include:

- Publishing and the Ecology of European Research (PEER $)^{81}$

- Open Access Publishing in European Networks (OAPEN)

- Study on Open Access Publishing (sOAP)

These and other projects are highly relevant to policymakers and those involved in implementing oA policies.

\section{PEER}

The PEER project, supported by the European Commission's eContentplus programme (2008-2012), investigated the potential effects of large-scale, systematic depositing of authors' final peer-reviewed manuscripts on reader access, author visibility and journal viability, as well as on the broader ecology of European research. The project has developed an 'observatory' to monitor the effects of systematic archiving over time and is creating a substantial body of evidence. Participating publishers collectively contribute to the project, which is also co-funded by the European Union.

Related research studies currently being conducted address issues such as:

- how large-scale archiving will affect journal viability;

- whether large-scale archiving increases access;

- how large-scale archiving will affect the broader ecology of European research; and

- which factors influence the readiness of authors to deposit their research into institutional and disciplinary repositories and what the associated costs might be.

The research results will inform the work being undertaken to develop models that will illustrate how traditional publishing systems can coexist with self-archiving.

To provide the observatory with content, participating publishers have 
collectively provided the project with 241 journals with EU-authored manuscripts. The publishers either directly submitted accepted manuscripts (\& metadata) or invited authors to self-deposit their accepted manuscript, with the publishers providing matching metadata. By the end of year two, publishers had submitted almost 25,000 manuscripts, of which approximately 10,000 have corresponding authors based in the $\mathrm{EU} .{ }^{82}$

The PEER Depot, which has been developed and is hosted by INRIA, serves multiple functions within PEER. It receives all publisher and authorsubmitted content which it then processes (including the transformation of metadata) and filters for EU research content. This content is then held for a specified embargo period prior to distributing to participating repositories. Additionally, the depot acts as a dark archive for PEER.

With the exception of one social sciences disciplinary repository, each of the participating PEER repositories hosts all valid PEER content, providing multiple mirror sites for the project. Seven repositories across the EU are participating in PEER, with four fully integrated into the infrastructure by August 2010.

As of August 2010, the PEER Depot had processed:

- nearly 25,000 manuscripts (with metadata) submitted by publishers for the publisher submission pathway;

- more than 5,000 metadata files submitted by publishers for matching with author submissions;

- 85 manuscripts self-deposited by authors (resulting from more than 5,500 invitations to do so which were sent out by publishers).

The final category represents a $1.5 \%$ rate of response by authors who were invited by their publishers to self-deposit their manuscripts.

The PEer Depot has developed tools to support the PEER observatory infrastructure, including:

- a unique format of metadata exchange (from publishers to repositories) by means of a T EI customisation plus the mapping of different metadata schemas;

- a deposit interface specifically designed for authors;

- an embargo management facility to manage different embargo periods assigned to each journal; 
- the SWORD protocol to allow application-level deposit of material into repositories;

- additional filtering of social sciences content;

- the ability to extract metadata from manuscript PDFS;

- a bug that tracks and reports workflow.

Procedures for the provision of usage data (logfiles) and manuscript deposit for repository managers and publishers were addressed in great detail during the first year of PEER. These discussions resulted in two reports which are available via the PEER website. ${ }^{83}$

The main achievements and results of the second year include a baseline report for the behavioural research, based on a series of focus groups, followed by a representative survey with more than 3,000 respondents. With regard to the research on usage, a (confidential) interim report has been delivered, followed by a comprehensive proof of concept that demonstrates the possibility of extensive logfile analysis, by which data at the article level may be aggregated and compared across repositories and publishers. For research in the field of economics, a (confidential) interim report has been delivered based on the collection of data about the cost of making 'stage 2' manuscripts available in open access, leading to the identification of major models, their value proposition and cost drivers.

The project's results and stakeholders views on these have been discussed at the final conference, held on 29 May 2012 in Brussels.

\section{Conclusions}

Institutions and projects with oA mandates based on central repositories have been quite successful in asking publishers to submit a copy of the final published article or the final author manuscript into the selected repository. Another alternative, which has been set up by the PEER project, is to use a central repository (the PEER Depot) as an intermediary for publisher-assisted deposits in a range of repositories. The central repository collects metadata and content from publishers, converts these into agreed standard formats, selects and then submits metadata and content to the participating PEER repositories residing at research institutions and one disciplinary repository based on the swORD protocol. These workflows and standards could be used for publisher-assisted deposits into institu- 
tional and disciplinary repositories in the context of funder and institutional oA mandates, for central as well as for distributed approaches.

Within the framework of the PEER project, it was observed that even if authors were invited to submit manuscripts to a repository of their choice, only about $1.5 \%$ responded to this invitation. In this process, the metadata was provided by the publisher and the author was asked to provide his/her final manuscript.

In a press release, OpenAIRE welcomed the results of the PEER project, presented at the final conference. Publishers, research libraries and research organisations effectively collaborated in building a controlled research environment to study the effects of green open access. Usage research in this so-called "PEER Observatory" revealed that large-scale deposit of research articles results in increased access and use, including via the publisher website. Norbert Lossau, Scientific Coordinator of OpenAIRE and member of the PEER Executive, pointed out that "the economic research of the PEER project could not find any evidence for the hypothesis that self-archiving affects journal viability". He called upon publishers, libraries and repositories to re-use the PEER-infrastructure for large-scale publisher-/library-assisted deposit of research articles: "Re-using the PEER infrastructure and stepping up the transition from subscription to gold open access journals will provide comfortable ways for researchers to comply with the important open access mandate of the European Commission which we expect to be expanded in Horizon 2020". ${ }^{4}$ The results remain controversial however, for example some project partners such at S T M interpreted the results as a strong argument in favour of the gold open access route. In short, supporting the hypothesis that readers prefer to access the publication via the publisher's website instead of via the institutional repository. ${ }^{85}$ This remains however open to debate and is no clear argument in favour of either approach.

\section{OAPEN}

Open Access Publishing in European Networks (OAPEN), ${ }^{86}$ a project funded by the eContentplus programme (2008-2011), is a collaborative initiative to develop and implement a sustainable open access publication model for academic books in the humanities and social sciences. The OAPEN Library aggregates peer-reviewed open access publications from across Europe with the aim of improving the visibility and usability of high 
quality academic research. The OAPEN Library, which now houses the open access books of some 20 participating publishers, was launched at the Frankfurt Book Fair in October 2010.

The listing of titles in the OAPEN Library involves a fee, depending on the size of the publisher as well as the number of titles to be integrated into the OAPEN Library.

This initiative has also developed an information network aimed at all kinds of scholarly publishers-with a focus on the humanities and social sciences - that would like to explore open access as a business model for book publishing, institutions with existing publishing programmes or an interest in publishing, as well as research funders with programmes for the humanities and social sciences.

An expansion of the project is envisioned based on national follow-up projects, which currently include OAPEN-NL funded by the Netherlands Organisation for Scientific Research (Nederlandse Organisatie voor Wetenschappelijke Onderzoek, or NWO) and OA PEN-UK funded by JISC (Joint Information Systems Committee). Further national/regional projects are under development.

The project has released various reports exploring the perception of users and the current landscape of oA book publishing, best practices and recommendations. ${ }^{87}$ Among its recommendations, OAPEN acknowledges the important role of libraries in the promotion of oA, "not only by encouraging their clients/scholars to deposit their works online (green Open Access) but also by promoting gold Open Access publishing". Moreover, OAPEN notes that "funders and universities can also play an important advocacy role through mandates and by acknowledging that the Open Access availability of scholarly books should be part of the research costs (thus setting up Open Access funds)". 88

In April 2012 OAPEN launched the Directory of Open Access Books $(\mathrm{DOAB})^{89}$ - a discovery service for peer reviewed books published under open access friendly licenses ('free to share'; the books that are only 'free to read' are not listed in DOA B). DОАв provides a searchable index to the information about these books, with links to the full texts of the publications at the publisher's website or repository. The primary aim of DOA B is to increase discoverability of open access books. At the start of the service there were just over 20 publishers participating with about 750 Open Access books..$^{90}$ As of 20 August 2012, there are 1,147 academic peer-reviewed 
books from 31 publishers. The Directory of Open Access Books is provided by OAPEN Foundation in cooperation with SemperTool. DOA B was developed in close cooperation with Lars Bjørnshauge and Salam Baker Shanawa (director of SemperTool), who were also responsible for the development of the Directory of Open Access Journals (D OAJ).

\section{Conclusions}

OAPEN aims to develop and promote a common approach and common standards for $\mathrm{OA}$ book publishing. This includes instruments such as $\mathrm{OA}$ repositories to enhance the circulation of books as well as guidelines for peer review, copyright and licences, the publishing process, business models and the marketing of publications.

Further experiments and efforts to promote the publishing model developed by OAPEN and study its impact in a controlled environment are already underway or are under consideration.

\section{SOAP}

The Study on Open Access Publishing (SOAP), ${ }^{91}$ a two-year project funded by the European Commission under the Seventh Framework Programme (2009-2011), surveyed researchers on their experiences with open access publishing and scenarios for the future. The project proceeded in phases: first it described the current supply of open access solutions were described, then it assessed the demand by conducting a large-scale survey of scientists across disciplines and around the world, and in the final phase of the project, supply and demand were compared.

At the SOAP Symposium ${ }^{92}$ in January 2011, the project's main findings regarding the oA publishing landscape, the beliefs and attitudes of researchers towards OA publishing, and the drivers and barriers for the submission of articles to oA journals were presented.

The key findings of the project are as follows:

- The number of oA articles published in "full" or "hybrid" oA journals was around 120,000 in 2009 , some $8-10 \%$ of the estimated yearly global scientific output. ${ }^{93}$ Journals offering a "hybrid" oA option had a take-up of around $2 \%$.

- oA journals in several disciplines (including life sciences, medicine and earth sciences) are of outstanding quality, and have impact factors in the top $1-2 \%$ of their disciplines. 
- Out of some 40,00o published scholars who answered a large-scale online survey, approximately $90 \%$ are convinced that $\mathrm{OA}$ journals are or would be beneficial for their field. The main reasons given are that oA benefits the scientific community as a whole as well as the individual scientist and is good for the public. The vast majority disagrees with the idea that $\mathrm{OA}$ journals are either of low quality or undermine the process of peer review.

- A separate survey of scientists who have published in oA journals reveals that the main drivers for this choice were the free availability of the content to readers and the quality of the journal as well as the speed of publication and, in some cases, the fact that no fee had to be paid directly by the author.

- The main barriers encountered by 5,000 scientists who would like to publish in oA journals but have not managed to do so were lack of funding (39\%) and the lack of journals of sufficient quality in their field $(30 \%)$.

During the event, several funding agencies commented on the SOAP results. Robert Kiley from the Wellcome Trust mentioned that they validated three action items for funding agencies to promote OA: 1) to have clear oA policies, enforce them appropriately and work to communicate the benefits of $\mathrm{OA}$ to researchers; 2) to make it easier for researchers to access funding to cover OA publishing costs; and 3 ) to develop better metrics for assessing research outputs. According to Celina Ramjoué of the European Commission, SOAP Project Officer, the SOAP results illustrate that funding agencies need policies on $\mathrm{OA}$ to mainstream this issue in a way linked with, and strengthened by, national oA policies and strategies. In addition, funding agencies should address the issue of oA publishing and how their evaluation systems work in a broader sense, paying particular attention to the dominant role of impact factors.

\section{Conclusions}

The soAP project has described and analysed the oA publishing landscape and provided facts and evidence. Of particular relevance for European $\mathrm{OA}$ policies is the fact that authors are in principle very positive with regards to open access ${ }^{94}$ but did not manage to identify or acquire sources of funding -in other words, the transparency of available funds does not seem to be optimal. 95 
In all the initiatives mentioned above, OpenAIRE partners have been involved. ${ }^{96}$ OpenaIRE will continue to actively follow the progress of these and other publisher-related projects. Results from the studies carried out in these projects can inform the dissemination and outreach activities as well as the strategies of the OpenaIR E network. Tools, instruments, guidelines and standards will be evaluated as potentially useful to facilitate OpenAIRE's work in having the EC/ERC's policies implemented at the operational level. 


\section{OPEN ACCESS POLICIES}




\section{Implementation}

Ensuring that European policies on open access are implemented involves: 1) identifying the projects that are obliged to follow these oA policies, 2) establishing outreach strategies for the various stakeholders, 3) choosing and adopting practical steps, and 4) evaluating the results and realigning strategies and actions.

\section{Stakeholders}

OpenAIRE's outreach and support activities are primarily directed at researchers. Libraries are usually good candidates to provide the appropriate infrastructures (i.e., an institutional oA repository) to help researchers to comply with the OA policies of the EC and the ERC. Research administrators at the European, national and institutional levels are asked to support these activities, as they have access to information about projects, research programmes and events.

The implementation process integrates a variety of primary stakeholders in direct and indirect ways:

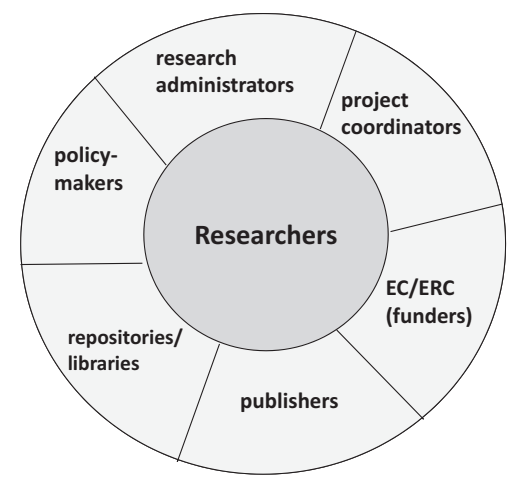

FIGURE 4-1 Stakeholders 
- researchers as investigators and authors, conducting the research, writing papers and publishing them in various ways;

- project coordinators coordinating the research (based on the grant funding) and to some degree the dissemination process;

- funders setting the rules for dissemination, the handling of copyright and reporting procedures;

- research administrators as service providers for the development and administration of research grants and institutional research reporting and evaluation (which might be different service entities);

- policymakers in institutions, research councils, ministries, governments, etc. for developing strategies for the dissemination and exploitation of research results, and for achieving synergies by combining strategies;

- repositories/libraries as service entities providing or developing repositories and related services;

- publishers as service providers for the review and publication process, and as holders of publication rights as assigned by authors.

The following section is not strictly organised along the lines of stakeholders involved but rather considers all of them as targets as well as instruments. The aim is to reach out to researchers to support them in implementing the EC's OA policies. This support will offer benefits and at the same time keep the burden on researchers as low as possible.

\section{Estimated number of projects and grant holders}

As of October 2010, there were 530 projects with grants within the EC Open Access Pilot (i.e. projects in the seven selected research areas of the EU's Seventh Framework Programme and with a grant agreement signed after August 2008 with Special Clause 39 (sC39)). ${ }^{97}$ These projects involve over 120 countries worldwide, of which over 40 were European countries. Overall, in November 2010 representatives of the European Commmission have estimated that by the end of $\mathrm{FP} 7$ there will be about 800 projects with SC39. During the Sixth Framework Programme (FP6), highly productive research areas produced up to 2,00o publications, so one can estimate that for the seven research areas of $\mathrm{FP} 7$, the output might reach 16,000 to 18,000 publications. As of November 2010, there were more than 1,350 individual research grants of the European Research Council, 

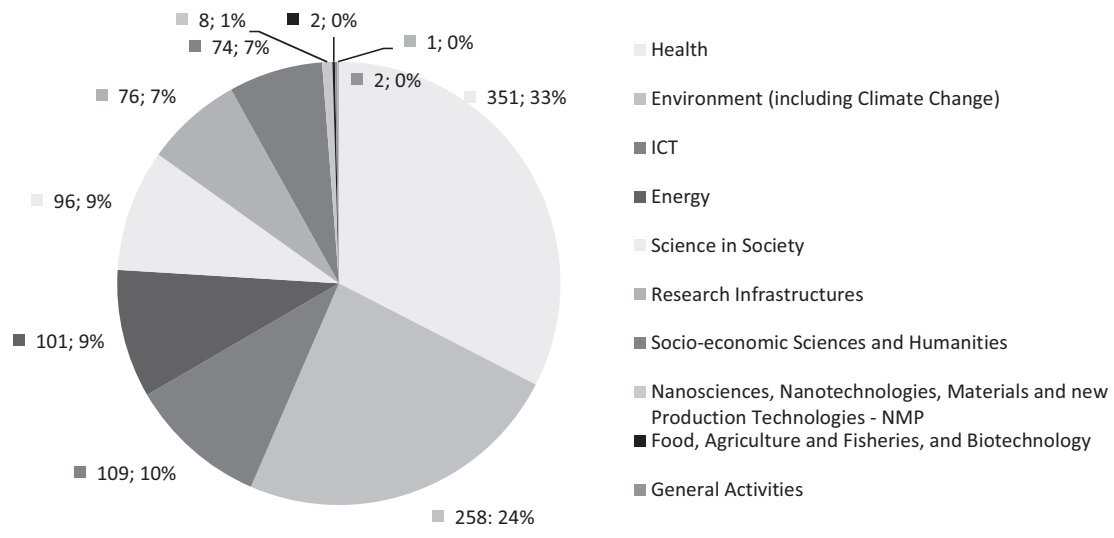

FIGURE 4-2 Ongoing sC39 projects

and it can be expected that these high-profile researchers will also be highly productive in terms of publications.

As of July 2012, according to CORDA, the European Commission's master database listing all EU-funded projects there were 1,078 ongoing FP7 projects with $\mathrm{sc} 39$ :

Further 177 SC 39 projects have already been finalized:

Further SC 39 projects will result from the the final FP7 call which has been release in mid July 2012.

By the end of August 2012, Opena IRE has identified-through various methods including harvesting from repositories and text mining large

FIGURE 4-3 Finalized sc39 projects
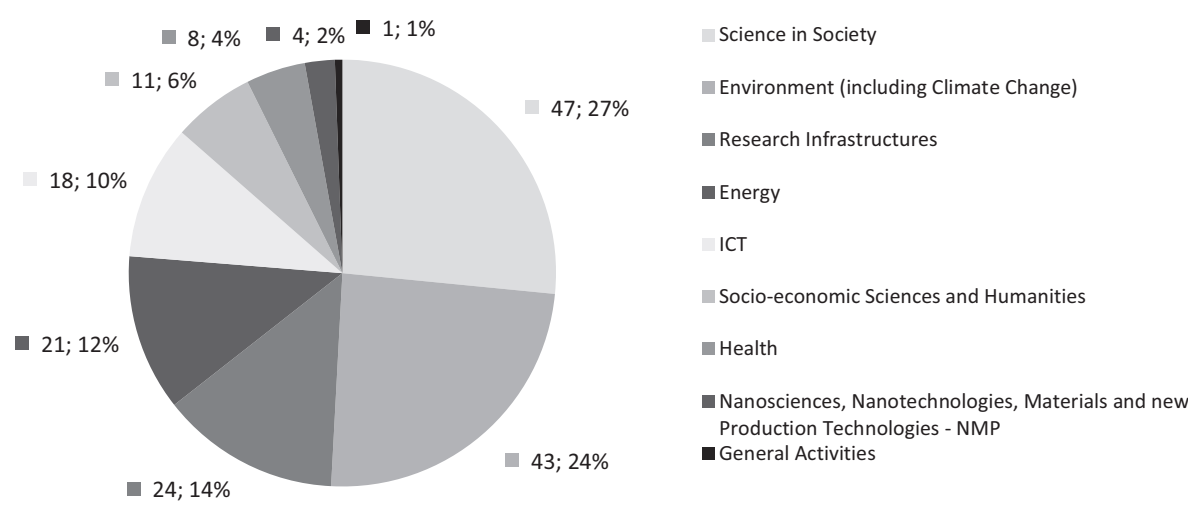
databases-over 27,000 publications (includes some duplicates) resulting from almost 4,000 FP7-funded projects. Of these, at least 9,500 publications $(35 \%)$ are openly accessible through repositories and/or open access journals. 5,731 publications are related to ERC-funding (40\% OA) and about 2,200 publications resulted from SC 39 projects ( $34 \% \mathrm{OA})$.

\section{OpenaIRE's strategy}

OpenAIrE aims to support the implementation of the EC/ERC'S OA policies in all European countries-that is, in at least the $27 \mathrm{EU}$ member states but also in selected candidate states and other European countries. The network of National Open Access Desks (NOADs) in Opena IRE partner countries is OpenAIRE's main instrument to facilitate outreach and cooperation with research institutions, researchers and project coordinators as well as with other stakeholders including publishers. Other European countries will be invited to cooperate on a voluntary basis. The aim is to support institutions in developing their policy with regard to the EC's OA Pilot and the ERC's OA Guidelines and also to achieve synergies by combining institutions' efforts in this regard.

\subsection{EC, ERC and research areas}

Research funders and their representatives play a crucial role in the implementation process of $\mathrm{OA}$ mandates, as they set the rules for disseminating funded results, the handling of copyright, the reimbursement of dissemination costs as well as the reporting procedures.

The European Commission is divided into several departments, known as Directorates-General (D Gs), ${ }^{98}$ which can be classified according to the policy they deal with. For OpenAIRE, two DGs are of particular relevance: the Information Society and Media DG ${ }^{99}$ (DG INFso, Commissioner: Neelie Kroes) and the Research and Innovation $\mathrm{DG}^{100}$ (Commissioner: Máire Geoghegan-Quinn).

The Directorate-General for Research and Innovation's mission is to develop and implement the European research and innovation policy with a view to achieving the goals of Europe 2020 and the Innovation Union. Among other things, this DG: 
- supports research and innovation through European Framework Programmes;

- is responsible for the coordination and support of national and regional research and innovation programmes;

- contributes to the creation of the European Research Area by developing the conditions for researchers and knowledge to circulate freely; and

- supports European organisations and researchers in their cooperation at the international level.

This DG is highly relevant for OpenAIRE, as it comprises the directorate for the Framework Programme as well as the directorates that are responsible for six of the seven areas of research covered by the oA pilot. Cooperating with these directorates is important in order to disseminate and promote the open access idea among researchers working in these areas as well as to stress the relevance of OpenAIRE outside academia.

The seventh field of research in F 7 -information and communication technologies-is covered by DG INFSO. This DG is also crucial for OpenAIRE's mission to make every European citizen digital by promoting the access and use of ICT to the benefit of EU society, by achieving the digital single market and by reinforcing Europe's competitiveness by increasing investment in IC T research and innovation. The success of this mission depends partly on OpenA IRE's ability to deliver on the objectives and actions of the Digital Agenda for Europe as well as related flagship initiatives of the Europe 2020 strategy. The Vice President of the EC and Commissioner for the Digital Agenda, Neelie Kroes, launched the Opena IRE platform in Ghent on 2 December 2010. In her speech, Neelie Kroes stressed that open access to scientific information will be one of the main topics in an upcoming communication by the European Commission. ${ }^{101}$

Some other DGs might also be relevant for OpenAIRE. Open access to scientific research can also have an impact on issues such as copyright and the dissolution of monopolies. Thus, the Directorate-General for Internal Market and Services ${ }^{102}$ and the Directorate-General for Competition ${ }^{103}$ might also be persuaded to take an interest in OpenaIRE: the former because it is responsible for proposing and controlling the implementing of a European legal framework for intellectual and industrial property, and the latter because it is also responsible for the IC T sector and its impact on net- 
work-building, on people's capacity to manage information in a life-long learning process, and on the contribution of users to the pool of knowledge and the creation of content.

In addition to the Commission, the European Research Council is a strong supporter of open access and has been promoting it since 2007 in its guidelines for open access (updated in June 2012, compare 3.1.2). These guidelines stress the fundamental importance of peer review in ensuring the certification and dissemination of high-quality scientific research as well as the importance of unrestricted access and the efficient dissemination of research results. OpenAIRE can provide the ERC with the necessary information to spread the message on its website-through the glossary and FaQ, for example. Through its network of National Open Access Desks (NOADS) OpenAIRE has already offered special training events for personnel of the ERC's National Contact Points (see section 4.2) in order to further promote Europe's OA policies.

\section{Conclusions}

Summarising the above, OpenAIRE aims to:

- establish good working relations with a number of Directorates-General of the European Commission, including the DG Information Society and Media, the D G Research and Innovation, the D G Internal Market and Services, and the $\mathrm{DG}$ Competition;

- support the ERC by providing trainings for its staff as well as targeted information on Europe's OA policies that can be posted on its website.

\subsection{National Contact Points}

As part of FP7, a new network of National Contact Points (NCPS) ${ }^{104}$ was established to provide advice and assistance in all member states and associated states. The type and level of services offered differ from country to country, but all NCPs offer basic services to institutions and their researchers such as guidance in choosing priorities and instruments, advice in administrative procedures and contractual issues, training and assistance in proposal writing, the distribution of documents (forms, guidelines, manuals, etc.), and assistance in partner searches. 
Within the European network of contact points, there are several networks at the national level as well as 18 thematic networks. These correspond to the themes funded in the FP7 and therefore also to the seven areas participating in the oA Pilot. The aim of the thematic networks, which operate on a Europe-wide basis, is to provide services, training and information to regional authorities, research institutions and enterprises. The networks are able to reach many different stakeholders and thus are seen by OpenAIRE as important disseminators of information.

As mentioned in the section above, special workshops and trainings on the EC's Open Access Pilot, the ERC's guidelines and the OpenaIre project can provide the NCP s with information and material (manuals, posters, toolkits, etc.) that are useful for their daily consultation services. Preliminary discussions have already taken place between OpenAIRE and the German NCP for ICT to plan a workshop on open access for representatives of the European NCPS.

OpenAIRE considers the NCPS to be a valuable resource of information about national FP7 projects and ERC researchers. At the same time, they are important disseminators of information about the oA policies of the EC and ERC both to researchers and to institutional research managers and administrators. Several partners representing NOADs have already seen the benefits of collaborating with the NCPS: they received further information about FP7 projects and were able to disseminate information through the NCPS about the requirements in the EC/ERC'S OA policies; hosted meetings for researchers to explain EC OA policies, etc.

\section{Conclusions}

OpenAIRE aims to:

- support the National Contact Points in their dissemination and advocacy efforts towards researchers/research coordinators regarding the OA policies of the EC/ERC and, where necessary and possible, provide tools/recommendations for practical implementation (e.g. specific advice on how to handle copyright issues, instructions on how to follow the deposition guidelines, and the identification of publications resulting from EC/ERC funded projects);

- establish a two-way communication channel between the National Contact Points and the NOADs about (new) relevant projects and 
support the NOADs in coordinating their work with that of the $\mathrm{Na}$ tional Contact Points.

\subsection{Research managers and administrators}

Most universities run service units to facilitate communication between researchers and granting agencies. The services offered are similar to what research funders' representatives such as the NCP s offer, but they are adapted to the local situation and include administrative tasks such as financial accounting and reporting.

Research administration offices have already been contacted by various OpenAIRE partners to ask them for support in promoting the EC/ERC's oA policies to researchers. The role of research administrators/managers as envisioned by OpenAIRE is to support the implementation of OA policies by:

- identifying projects and researchers that are obliged to adhere to the OA policies of the EC/ERC;

- providing basic information about these oA policies to project coordinators; and

- pointing to the library for the deposition of publications and helping out with copyright issues.

Several networking partners have started to cooperate with their EU offices and National Contact Points (NCPs) to reach out to project coordinators and researchers. In particular, at the University of Goettingen, the EU office supports dissemination activities at the regional and national levels (further activities at the European level are currently being planned). The Goettingen EU office has organised a meeting for project coordinators and researchers to explain the requirements of the EC/ERC'S OA policies and to inform researchers about the policies and the support offered by the Goettingen State and University Library. After the meeting, all the relevant material were posted on the EU office's website. ${ }^{105}$ Similar activities have been initiated at various institutions, including the Universities of Vienna, Konstanz and Ghent.

More sessions with groups of research managers and administrators are 
being planned in order to facilitate the promotion of Europe's oA policies and to involve them in support activities. The official OpenAIRE Launch Event on 2 December 2010 has already raised awareness among research administrators and managers about the issue of open access. ${ }^{106}$

\section{Conclusions}

OpenAIRE intends to continue to support the development of working relationships between the NOADs, the networking partners of OpenAIRE ${ }^{107}$ and research administrations. OpenAIRE has been working on a number of tools for project coordinators which generates lists of project publications embedded within the project website ${ }^{108}$. Additionally, to help ease the process of reporting open access publication numbers, tools for project administrators are also being developed, which analyse usage at project and publication level. This cooperation is of great importance, as it enables OpenAIRE to reach out to researchers and project coordinators and to support them in complying with the EC/ERC's OA policies.

\subsection{European countries}

By developing a network of National Open Access Desks (NOA Ds), OpenAIRE aims to spread its infrastructure and support structure to researchers and institutions in all European countries. All NOADs are represented by project partners and contribute their knowledge and contacts to the network. These support structures include training activities, the dissemination of relevant information, and a helpdesk with national contact persons.

Several of the institutions now acting as NOA Ds have already been partners or contact points in the Digital Repository Infrastructure Vision for European Research (DRIVER) ${ }^{109}$ project (which ran from June 2006 to November 2010), and have provided information about open access and repository developments for the DRIVER wiki. ${ }^{110}$ In the OpenAIRE project, several of these national correspondents have become partners of the consortium. New partners have been found to represent other European countries.

OpenAIRE's network of NOADs started in December 2009 with all EU member states covered (with the exception of Luxembourg ${ }^{111}$ ) as well as 
Norway as one of the associate countries. In Opena IREplus however, now well under way, all Eu member states are covered, including Luxembourg and four new associated countries: Iceland, Turkey, Croatia, and Switzerland.

In OpenAIRE, the NOADs are organised in regional groups, which is merely for operational reasons. In general, all European countries face very similar challenges in the implementation of Europe's oA policies. Nevertheless, there may be some regional particularities that facilitate the implementation process or that demand special support actions.

On the OpenAIRE portal, each NOAD has described the national situation with regard to:

- the national research environment, major research funders and their oA policies, and $\mathrm{E} U$ research funding;

- open access and repositories, projects and initiatives, open access journals and initiatives, and organisations and groups involved in oA-related issues.

Based on this information, we asked the NOADs the following follow-up questions:

- How is open access progressing at the national and regional levels? How are oA policies/mandates and repositories developing?

- What strategies are currently being pursued by the various stakeholders to implement open access? Which actions undertaken by the NOA D s had a particularly beneficial impact on national developments in the area of open access?

For a regional perspective, we asked the regional coordinators ${ }^{112}$ of the NOADs the following questions:

- What were the NOADs' main achievements of the past year in terms of networking and information dissemination activities? What kind of advances was booked in terms of moving oA forward in the participating countries?

What are the main issues and needs of the NOADs in the participating countries that need to be addressed by OpenA IRE in the next year? In the 
context of OpenaIReplus, the NOADs scope has widened. As part of the mission of OpenAIRE's next phase is to link to, make visible and encourage reuse of research data. Moreover, in its second phase the project aims to support the building of communities who will use the OpenAIRE infrastructure, reaching researchers at national level, widening the scope, asking them to approach at policy level to have recognition of importance of research data management (RDM), national requirements (and funding schemes) presented side by side with European policies.

\subsubsection{National research environments}

With regard to national research environments, there is a wide variety of universities and other institutions of higher education ( $\mathrm{HE}$ ) in Europe such as the grandes écoles in France, colleges in Ireland and schools of higher education in Belgium. In some countries there are also major research organisations that focus on multi-disciplinary research or research within a specific area. In France, for example, there is the National Center for Scientific Research (Centre National de la Recherche Scientifique, CNRS) which covers many subject areas, the National Institute for Research in Computer Science and Control (Institut National de Recherche en Informatique et en Automatique, IN RIA), and the National Institute of Health and Medical Research (Institut National de la Santé et de la Recherche Médicale, INSE RM). In Germany, the Max Planck Society for the Advancement of Science focuses on basic research in several fields, while the Fraunhofer Society concentrates on applied research in health, security, communication, energy and the environment. In several countries, academies of science play an advisory role and give important impetus to forward-looking research fields (such as the Austrian Academy of Sciences and the Academy of Finland).

The majority of research funding stems from governmental sources distributed through ministries of science, research, education or trade; research councils; agencies; funds and foundations as well as major public and private research organisations. There are also private societies, associations and foundations that support basic and applied research. All countries report that funding supplied by the European Commission plays an important role.

For some countries, national funds are very limited and funding from the $\mathrm{EU}$ is the most significant source of research funding. In these cases, $\mathrm{EU}$ 
funding contributes to an increase in research activities in a substantial way. This holds for some of the 'old' Eu member states such as Italy and Greece as well as for new member states such as Cyprus and Malta.

Eastern European countries have been reforming their traditional research systems in recent decades. For example, in 1990 the Latvian Council of Science was formed and the transition to a new grant system of funding projects on a competitive basis was started. At the end of 1991, the first governmental department responsible for science and research was established. The Latvian Academy of Sciences was reorganised into an association of prominent scientists in 1992. Since 2007, a comprehensive system of research funding has been in place in Latvia. It encompasses funding for state research programmes, institutional funding, funding from the $\mathrm{EU}$ and other foreign countries, and grants and financing from various foundations and funds.

In Poland, the Council for Science was established in 2005 as a new consultative and advisory body for the ministry of science and higher education. The National Centre for Research and Development (NCBiR) was established in July 2007 with the goal of managing and implementing strategic scientific research and development programmes that directly translate into the development of innovative projects and products.

\section{Conclusions}

OpenA IRE will closely follow developments in national research environments and, where possible, relate these to the EC/ERC's OA policies. OpenAIRE will make use of the NOAD network to disseminate and share information on national research environments.

\subsubsection{National awareness of open access, mandates and repositories}

\section{Region West}

Region West consists of Austria, Belgium, France, Germany, Ireland, Luxembourg, the Netherlands, Switzerland and the u K.

In Austria, support for oA policies among scholars and publishers is reported to be poor at present, while awareness of open access remains limited but is expected to grow fast. To support this development, the Austrian Science Fund adopted an OA policy in October 2006, which was strengthened into a mandate in March 2008. The mandate covers journal articles as well as books and data. ${ }^{113}$ In 2009, the government put into law an obliga- 
tion to set up a national institutional repository for the theses and dissertations produced at Austrian universities. ${ }^{114}$ The Austrian Rectors Conference decided at its meeting in January 2010 to publish a recommendation to enhance universities' OA policies in Austria. ${ }^{115}$ At this event, the president of the University of Vienna declared that it was implementing an OA policy.

Currently, repositories in Austria mainly host theses and dissertations. One exception is Phaidra (Permanent Archiving and Indexing of Digital Resources and Assets), ${ }^{116}$ the University of Vienna's repository, which is set up as a comprehensive university digital asset management system with long-term archiving functions.

In Belgium, the DRIVER projects have been instrumental in developing OA awareness across the country. Several technical and legal meetings have been organised to set up DRIVER-compliant repositories. A national conference that brought together major stakeholders was also crucial in furthering the oA cause. During this conference, 14 university rectors, the ministers of science of Flanders and Wallonia, and the president of the Flemish Council of Schools for Higher Education all signed the Berlin Declaration.

The Flanders Research Foundation (FWo) obliges its researchers to selfarchive in $\mathrm{OA}$ repositories all articles coming from research funded by the FWo. ${ }^{117}$ Moreover, there are two institutional mandates requiring immediate deposit with optional access, adopted by the University of Liège in May 2007 and the University of Ghent in December 2009. ${ }^{118}$

There are some 28 institutional and disciplinary repositories in Belgium (according to OpendoAR).

France has played an important role in the development of the European OA movement, in particular in the launch of the Berlin Declaration in 2003. In the early 2000's, the large research organisations CNRS and INSERM played a major role in the launch of the Hyper Articles en Ligne (HAL) open archive ${ }^{119}$ in 2001.

France's main research funder, the Agence Nationale de la Recherche (ANR), ${ }^{120}$ issued an open access policy ${ }^{121}$ in November 2007, strongly encouraging the deposit of funded publications into open archives systems and into HAL in particular. The humanities and social sciences department has adopted a stronger policy mandating the systematic deposit of publications in HAL-SHs (Hyper Article en Ligne - Sciences de l'Homme et de la Société) ${ }^{122}$. Since September 2010, the Institut francais de recherche 
pour l'exploitation de la mer (Ifremer) also has an institutional mandate in place. ${ }^{123}$

France currently has over 60 repositories, two thirds of which are hosted by the HAL platform.

In Germany, the awareness of oA has increased substantially in recent years. This is partially due to the advocacy activities of several institutions and projects, in particular the information platform open-access.net, the projects of the German Initiative for Network Information (DINI), ${ }^{124}$ and the work of the Alliance of Research Organisations. ${ }^{125}$ Over the last few years, the German Research Foundation (DFG) has funded a wide range of open access projects and has encouraged institutions to build up publication funds. ${ }^{126}$ In 2009, Google Books' digitisation initiative triggered a high-profile public discussion ${ }^{127}$ in the national newspapers about intellectual property rights, open access and the freedom of researchers to choose their publication outlets. ${ }^{128}$ This played a major role in raising awareness among authors and publishers. In this context, the Alliance of Research Organisations felt the need to release a statement explaining why its OA policies do not conflict with German regulations on IPR and constitutional rights. ${ }^{129}$

Several research organisations and institutions have established oA policies, but so far there is no oA mandate in place. ${ }^{130}$ The German Research Foundation (DFG) has tied OA into its funding policy and encourages researchers to reserve a non-exclusive right for the purpose of $\mathrm{OA}$ when they publish their funded research results.

Several German universities and research institutions run an institutional or subject-based repository. Currently there are some 150 oA repositories in Germany (according to OpenD OA R, 149; according to DINI, 144; according to ROAR, 150). Of these, 33 have been DINI-certified and integrated into the national network of repositories.

In Ireland, the following research funders have an oA policy or mandate in place:

- the Higher Education Authority (HEA): OA mandate as of 30 June 2009. ${ }^{131}$

- the Health Research Board (HRB): OA recommendations ${ }^{132}$

- the Irish Research Council for Science, Engineering and Technology $(\text { IRCSET })^{133}$ : OA mandate as of 1 May 2008. ${ }^{134}$ 
- Science Foundation Ireland (SFI): OA mandate as of 1 February 2009. ${ }^{135}$

Ireland has six mandates in total, two institutional (Dublin Institute of Technology and Trinity College in Dublin), and four funder mandates. ${ }^{136}$

Awareness of $\mathrm{OA}$ has increased within the research community, particularly since institutional repositories have been built into each Irish university. ${ }^{137}$ Advocacy programmes and funder mandates (IRCSET, SFI, HEA) have had a positive effect. However, there is still some way to go before the majority of Irish researchers automatically deposit their papers into their local oA repository.

In the Netherlands, the major research funders-in particular the Netherlands Organisation for Scientific Research (Nwo) ${ }^{138}$ and the Royal Netherlands Academy of Arts and Sciences (Koninklijke Nederlandse Akademie van Wetenschappen, KNAW $)^{139}$ - are strong supporters of OA but have yet to adopt oA mandates. In September 2010, the Erasmus University of Rotterdam announced it was introducing an institutional oA mandate. ${ }^{140}$

There is widespread awareness of open access in the Netherlands. Since 2005, all Dutch universities, the нво-raad (Netherlands Association of Universities of Applied Sciences), the KNAW, the Nwo, the Royal Library and SURF have signed the Berlin Declaration. In 2009, the rectors of the Dutch universities met to discuss ways of stimulating open access.

The Netherlands is one of the leaders in the development of research repositories. All Dutch universities have one or more repositories. Central access to these repositories is provided by the portal NARCIS, ${ }^{141}$ hosted by the KNAW. NARCIS not only offers access to open access publications, it also provides the main entrance to datasets, restricted access publications, Dutch research descriptions, and experts and organisations. The universities of applied sciences work together in collecting the materials deposited in their repositories and presenting these on one portal, the нво-kennisbank. ${ }^{122}$ This portal now provides open access to over 21,000 research outputs, educational materials and student theses.

Most of Switzerland's academic research institutions have jointly signed the Berlin Declaration in 2006 through their governing bodies: the Rector's Conference of the Swiss Universities (CRUS), the Conference of the Swiss Universities of Applied Sciences ( $\mathrm{KFH})$, the Swiss Conference of 
Schools for Teacher Education (SK PH), and the Council of the Swiss Scientific Academies (CAss). In addition, some Swiss research institutions have also signed the Berlin Declaration as single institution: University of Zurich, 2004; Swiss Federal Institute of Technology (Етн Zurich), 2006; Paul Scherrer Institut, 2006; University of St. Gallen, 2006; University of Basel, 2007; University of Bern, 2007; University of Fribourg, 2008; Swiss Centre of Expertise in the Social Sciences (FORS), 2010.

The Swiss National Science Foundation (sNsf), Switzerland's leading provider of scientific research funding and also co-signatory of the Berlin Declaration in 2006, requires grantees to provide open access to research results obtained with the help of sNSF grants (Article 44 Funding Regulations). While strongly supporting self-archiving in repositories, the SNSF does not yet cover costs for Open Access publications. ${ }^{143}$

Among other public research funders of Switzerland, the Swiss Academy of Humanities and Social Sciences (sAGW) supports the implementation of Open Access. The SAGW calls upon its member societies to obtain the necessary rights for their authors from the publishers. Several sAGWsponsored journals are freely available.

Besides the SNSF, a few Swiss academic research institutions have introduced open access mandates concerning scholarly publications by their researchers. Such institutional policies have been formulated by the ETH Zurich, the University of Geneva, the University of St. Gallen, and the University of Zurich. Currently, there are 10 institutional repositories hosting scientific publications (University of St. Gallen, University of Geneva, zHB Lucerne, University of Basel, ETH Zurich, E PF L Lausanne, Médecins sans Frontières, Reseau Romand, University of Lausanne, University of Zurich).

The University of Zurich commissioned an expert opinion on open access in Swiss law. In particular, to clarify which publications are permitted to be deposited in repositories. It turns out that authors who have not completed a copyright agreement with their publisher upon publishing their work are allowed to deposit journal articles, book chapters or conference papers on repositories three months after these works have been published in full. This also applies in the case of foreign publishers if the author's place of residence and the repository are in Switzerland.

DOAJ lists more than 100 Open Access journals from Switzerland. The majority are published by MDPI AG (Basel) and Frontiers (Lausanne). Fur- 
ther 160 retroactively digitized journals culturally based in Switzerland are freely accessible, usually with a moving wall, at retro.seals.ch.

In the $U K$, most of the seven research councils, which are collectively known as RCUK, ${ }^{144}$ have adopted mandates for open access dissemination of the research outputs that they fund. Another significant funder in the $\mathrm{UK}$ is the Wellcome Trust, ${ }^{145}$ which has a mandate that requires grant recipients to make their information available through open access-in this case through the repository U K P MC. ${ }^{146}$ Other major funders have mandated the deposit of publications in UKPMC, in most cases deposited by the journal on behalf of the author: Arthritis Research UK, Biotechnology and Biological Sciences Research Council (в B SRC), the British Heart Foundation (внғ), Cancer Research uк, the Chief Scientist Office (сso) and the Medical Research Council (MRC). ${ }^{147}$ Additionally, the Department of Health (DH) and the National Institutes of Health Research (NIHR) require all grant recipients to deposit articles arising from grants. ${ }^{148}$ As recently as the summer of 2012, both the Finch report and a recommendation made by the RCUK stirred a lively debate about open access. ${ }^{149}$

According to the UK NOAD, awareness of open access has grown since 2008, "particularly in the subject areas covered by funding agency mandates. The majority of UK-based researchers are now covered by either a funder's mandate (17) and/or institutional mandate (23, some of these departmental mandates), and have access to an institutional or subject repository (over 200). However, this awareness is not yet translating into depositions."

In Luxembourg, there is growing awareness of open access but currently no funder mandate. On the 10 May 2012, the University of Luxembourg launched their open access initiative by signing a collaboration agreement with the University of Liège. This launch announced the establishment of both a digital repository, ORBi ${ }^{1 \mathrm{lu}}$, as well as a campaign designed to inform researchers about open access and their rights as authors. The repository is expected to be available in the first half of 2013 .

\section{Conclusions for Region West}

Region West can boast of active open access communities, although they are mainly restricted to some research areas and the library community. Moreover, the research system is very fragmented and characterised by regionalities and inhomogeneous research databases. 
Raising awareness of OpenAIRE at events and conferences in this region was of high priority over the first years. The distribution of information about the project and about oA guidelines is going according to plan, and a strong regional network has been established.

The main challenges OpenAIRE currently faces in this region are: improving communication strategies, identifying SC 39 projects, and dealing with issues of copyright legislation. In addition, the following issues and needs have been identified:

- The outreach to target groups could be improved: researchers, university research managers and repository managers need specific approaches. It can be difficult to reach each group and to get proper feedback.

- All the NOADs report that getting information on SC39 projects is very difficult, as there is no secure way to ensure that all concerned projects are identified.

- At the level of national policy, there is no uniform copyright legislation, making communication with researchers about copyright difficult. More action at the policy level is needed.

\section{Region North}

Region North consists of Denmark, Finland, Iceland, Norway and Sweden.

In Denmark, four out of the country's eight universities have introduced open access policies (Aarhus University, the Technical University of Denmark, Roskilde University and Copenhagen Business School), the latter two being mandates. Of the main funders, at present only the Danish Research Council has introduced an oA mandate for research in the humanities. This mandate is restricted to financial support for academic journals only: in order to receive grant funding, journals must make their content openly accessible six months after publication.

A working group under the Ministry of Science, Technology and Innovation is currently working on recommendations and an action plan on open access for the minister, covering three levels: public funders, universities and nationally. ${ }^{150}$ This work has been presented in a public hearing in June/July 2010. The recommendations are expected to result in concrete policies in 2011.

Awareness of open access was for a long time restricted to mainly the re- 
search library community. However, it seems that interest in the topic is growing among university administrations and also at the research policy level. Besides the four universities that already have policies, other universities are engaging in ongoing work regarding open access. Plans for a national policy on open access have sparked an important discussion in the media between those for and those against a national open access policy. This debate is mainly being driven by two parties - on the one side are the small Danish publishers within the arts and humanities that fear the consequences of open access, and on the other side you have the Danish Society of Engineers, which ran a series of articles on open access in its weekly newpaper Ingeniøren arguing for the benefits of open access.

All eight universities in Denmark have established research management systems or current research information systems (CRIS) that also function as oA full-text repositories. Since the repositories are first and foremost CRIS and only function as oA repositories in the second place, the focus has been on the bibliographic metadata quality and coverage, and not as much on oA. This means that the repositories cover a very high percentage of the universities' production as bibliographic descriptions but have few oA full texts. On average, oA full texts comprise some $4.3 \%$ of the material in the repositories, but the number varies a great deal from institution to institution. ${ }^{151}$ The percentage tends to be higher for newer publications.

In Finland, 27 institutional oA mandates have been established, including the University of Helsinki $\mathrm{i}^{152}$ and 26 applied universities in Finland as of 1 January 2010. The latter jointly released an oA statement requiring all teachers and researchers "to save a copy of their research essays that are published in scientific publications, or a university publication series, in the open electronic library, Theseus." ${ }^{53}$ The University of Tampere and the University of Jyväskylä have strong OA policies that since January 2011 request researchers to deposit their publications in the institutional repository.

Awareness of open access in Finland varies greatly from one researcher to the other. There are some fields of science (such as physics) where open access is widely adopted. There is also much confusion and misunderstanding surrounding the concept of open access, especially with regards to the institutional mandates that universities have implemented or plan to implement. In general, funder mandates seem to be better known in the 
fields where they apply. Moreover, there is still a strong sense of apprehension that open access will spell the end of smaller scholarly journals published in Finnish and Swedish and thus "be the end of sciences in national languages".

Currently, there are 38 open access journals in Finland.

Most Finnish universities run their own repositories. Those who do not run their own systems, are using the Doria Repository Systems provided by the National Library of Finland. Since none of the universities had mandated open access to peer-reviewed journal articles until early 2010, repositories are still mostly used for depositing materials such as student theses, course and other study material as well as other publications by the university.

In Iceland, open access is acknowledged and endorsed through government statements but there is only one oA mandate. In line with the Icelandic government's Policy on the Information Society 2004-7, the Ministry of Education, Science and Culture and The Science and Technology Policy Council have made statements that include support of open access. The Science and Technology Council of Iceland signed the Berlin Declaration on 27 May 2010. In March 2012, Bifröst University became the first higher education institution in Iceland to adopt an Open Access mandate. The mandate was initiated by the faculty and is a declaration of the faculty member's preference to publish in open access journals and their obligation to store research articles in the university's open repository. The mandate is closely modelled on similar ones passed by for instance Harvard's Faculty of Arts and Sciences and by the Harvard Law School.

The first repository in Iceland, Hirslan, the Landspitali University Hospital repository, was started in 2006. The second one, Skemman, the joint repository of the University of Iceland, University of Akureyri, University of Bifröst and the Iceland Academy of the Art, started in 2008. The lack of mandates in Iceland might have had the effect that only a low percentage of submitted research literature is deposited in the repositories. The two open-access repositories, hirslan.is and skemman.is were established and maintained by the Landspitali Health Sciences Library and the National and University Library respectively. Skemman.is houses theses and other works for five of Iceland's seven university-level institutions.

In Norway, open access is increasingly on the national agenda, but few researchers are participating in the debate. However, libraries and policy- 
makers are becoming increasingly engaged. The Ministry of Education and Research has OA on its agenda, and it will require reports from institutions on their $\mathrm{OA}$ activities in 2010.

Currently, there are three institutional oA mandates issued by the Universities of Bergen and Troms $\varnothing$ and the Norwegian Knowledge Centre for Health Services, and one funder mandate issued by the Norwegian Research Council. ${ }^{154}$

All government-funded universities and nearly all university colleges as well as most private universities and some private university colleges have institutional repositories. Only a few research institutes have repositories.

The Norwegian Open Research Archives (NORA) is an initiative launched by the four 'old' universities of Oslo, Bergen, Trondheim and Tromsø to harmonise the Norwegian approach to the development of open access. Other higher education institutions have since joined in. The development of institutional repositories in Norway has been coordinated by NORA and has followed NORA metadata standards and vocabularies. NORA has also to some extent supported the establishment of oA publishing services and has attempted to co-ordinate activities related to oA journals. CRIstin - Current Research Information System in Norway-a new joint research documentation system, was established in 2010, replacing the former system FRIDA. It will be used in the higher education sector and by research institutes and the regional health authorities. CRIstin has taken over NORAs metadata and national search facility for OA in Norway, still called NORA. NORA operates a metadata harvesting service that provides metadata to DRIVER, OpenAIRE and others, in addition to a national search service for OA resources. All Norwegian OA repositories are harvested, and NORA has started to integrate Norwegian OAI-PMH-compliant scientific OA journals into NORA's services. ${ }^{155}$

The CRIstin organisation will also be responsible for ensuring open access to Norwegian research. ${ }^{156}$

In Sweden, an OA mandate was adopted in the autumn of 2009 by the Swedish Research Council (Vetenskapsrådet, SRC), the country's main research council which is focused on basic research but also active in research information and research infrastructure. This mandate requires funded researchers to "archive their articles in open databases within six months of publication, or publish directly in Web-based journals that use 
Open Access." 157 Around the same time, Formas, the Swedish Research Council for Environment, Agricultural Sciences and Spatial Planning, adopted an OA mandate with the same requirements as the SRC mandate. There are also some public and private foundations funding $\mathrm{R} \& \mathrm{D}$ that actively promote open access. The Knowledge Foundation co-funds the Swedish OpenAccess.se programme.

The Riksbankens Jubileumsfond (RJ), which promotes and supports research in the humanities and social sciences, has switched from an oA policy to an oA mandate in June 2010. This oA mandate is similar to others in demanding that all new research publications be made available and openly accessible within six months of publication, while researchers with ongoing grants are encouraged to do the same. The $\mathrm{RJ}$ also adds a standard allowance of 30,000 SE K per project to support open access publishing, both in journals and in the form of monographs. ${ }^{158}$

In the autumn of 2010, the Knut and Alice Wallenberg Foundation also included an open access mandate in its grant policies. This private foundation is an important funder of research, research networks and equipment in the technical, natural sciences and biomedical fields.

The development of e-publishing within Swedish higher education started on a small scale during the 1990s and gathered momentum in 2000-2003. At present, almost all universities and major university colleges have oA repositories. Available full-text contents include doctoral and licentiate theses, journal articles, conference papers, reports, books and book chapters. Most of this content can be found in the SwePub search service. ${ }^{159}$

The majority of Swedish repositories are members of a consortium based on DIVA, a publishing platform developed at Uppsala University. Others have implemented open source software like DSpace or created their own publishing platforms. Today, most higher education institutions (HEIs) have integrated their open access repositories with their publication databases. These are supposed to include metadata from all the academic publications of the institution and have been created to meet the needs of research evaluation and visibility. Most HEIs have mandates for depositing theses and many also have mandates for researchers to register publication metadata. The Chalmers University of Technology and the Blekinge Institute of Technology have explicit open access mandates that also cover journal articles. 


\section{Conclusions for Region North}

Region North is characterised by relatively small countries with highly developed research infrastructures. Open access initiatives have for a long time been driven by library communities and a few engaged academics. Lately, other stakeholders have started to become engaged in the debate about open access and in national initiatives for open access including funder mandates and national policies.

The repository infrastructure in all countries of Region North is very mature, with a high degree of coverage. Most researchers therefore have local repositories into which they can deposit their research outputs. Many of the repositories are related to larger communities or consortia, allowing them to become OpenaIRE-compliant with an update of these repositories. In many institutions, repositories are integrated into the data provision for web and intranets and are also used for research assessments. One of the issues for the region has therefore been to make all repositories OpenAIRE-compliant.

As soon as all repositories are validated, this can be used as leverage for the NOADS to use the repository managers as a bridge to the universities to advocate OpenAIRE and the OA Pilot in FP7. The registration and validation of repositories is an important step, since this is expected to be what drives researchers to use the local repository infrastructures and their support structures.

OpenAIRE and the EC/ERC's open access policies-as well as open access in general-have been communicated by the NOA Ds through presentations, news items on blogs, web pages and journals. There has also been contact with public and private research funders in the Region North countries.

The communication strategy for this region after the first year is to address three main stakeholders: researchers, repository managers and national contact points. Researchers will in many cases be contacted through their repository managers or local representatives. Here, easy access to information about EC projects is essential, as is contact information on not only project coordinators but also project participants. The focus will be on activating researchers to actually deposit their peer-reviewed research publications resulting from $\mathrm{EC}$ funding. 


\section{Region South}

Region South consists of Cyprus, Greece, Italy, Malta, Portugal, Spain and Turkey.

In Cyprus, the Senate of the University of Cyprus, during its $23^{\text {rd }}$ meeting of 2008 which took place on the 5 th of November of 2008 , has supported and accepted the Library Committee's proposal to sign the Berlin Declaration.

The Senate as the highest academic body of the University of Cyprus and responsible for the academic affairs of the University, decided to share the vision expressed in the Berlin Declaration on Open Access to Knowledge in the Sciences and Humanities.

The name of the University of Cyprus is included in the signatories list of the Berlin Declaration. ${ }^{160}$

Furthermore there are no other officially adopted oA policies or mandates at national level. This is due to the fact that there is no national repository that can collect all publications resulting from projects and research. The main funder of research in Cyprus is the $\mathrm{EU}$, which has supported research in the past few years by providing the majority of the funding.

Currently, there is no strong awareness of open access within the research community in Cyprus. Several seminars and presentations on Open Access took place in the Academic - Research society in the last few years, after the involvement of the University of Cyprus Library in the OpenAIRE consortium. On an individual basis, some researchers are aware of open access, mainly those from disciplines where well-established international subject repositories already exist.

An internal project called INTRA was started by the library of the University of Cyprus (UCY) to aggregate and record all scientific publications by the academic staff of UCY. The outcome of this project aimed to contribute to the setting up of an institutional and national repository. University of Cyprus Library as the regional NOAD of Cyprus now offers Lekythos (academic - institutional repository of University of Cyprus) to all the local researchers that would like to deposit their publications that will derive from projects funded under the Special Clause 39.There are only two institutional repository initiatives in Cyprus: one by the Cyprus University of Technology (still not compatible but in the process to comply), ${ }^{161}$ and LE KY THO of the University of Cyprus Library.

In Greece, oA issues are dealt with by individual institutions, and there 
are no official oA policies or mandates issued by the government or by research funders. Institutional initiatives have been limited to creating institutional or subject repositories, journals and journal archives, and signing the Berlin Declaration on OA. It is significant that there are only four signatories to the Berlin Declaration from Greece thus far. This and a variety of other factors suggest that awareness of OA within the research community in Greece is not very high.

According to the information in ROARMAP, no Greek institution thus far has an explicit oA mandate. There are some policies, but deposit is not made obligatory.

According to ROAR, 24 OA repositories were operational in Greece as of June 2012. Of these, 13 are institutional repositories while the remaining are digital collections of cultural material and/or past editions of journals. Overall, approximately half of the 33 higher academic institutions run their own OAI-compliant repository. A few more institutions run a nonOAI-compliant repository or are in a transitional phase to a new OAI repository. ${ }^{162}$

In Italy, awareness of open access within the research community is still low but is growing steadily. Researchers in some disciplines such as physics, mathemathics and biomedical sciences are more aware and are playing a proactive role.

In 2006, the Conference of Italian University Rectors (CRUI $)^{163}$ established a Working Group on OA as part of the CRUI Library Committee. The activities of the CRUI OA Working Group led to the publication in 2007 of guidelines on depositing doctoral dissertations into open access repositories. The impact of this is evident in the adoption of 21 thesis mandates among Italian universities.

In April 2009, the CRU I OA Working Group published more guidelines, including recommendations on $\mathrm{OA}$ and research evaluation, guidelines for oA journals, and guidelines for institutional repositories. Italian universities have thus far not adopted mandates to deposit research output, with the exception of the privately funded university Luiss. A reasonable approach to ensuring the success of oA in Italy would be to link the current research system with institutional repositories.

In 2004, the two Italian supercomputing consortia CASPUR (Consorzia interuniversitario per le Applicazioni di Supercalcolo Per Università e Ricerca) ${ }^{164}$ and Cilea (Consorzio interuniversitario Lombardo per 
L'Elaborazione Automatica) ${ }^{165}$ implemented an Italian national platform to provide central access to digital content deposited in the Italian Open Archives. The platform PLEIAdi (Portal for Italian Electronic Scholarly Literature in Institutional Archives) ${ }^{166}$ has been in place since then and provides access to the more than 505000 documents deposited in Italian academic and research institutional repositories, and open access journals. So far, PLEIA DI indexes only those institutional repositories that contain a substantive amount of full-text content.

Currently, 70 Italian repositories have been registered in OpenDOA R, of which some two-thirds are university institutional archives. The remaining repositories belong to research centres such as the Istituto Superiore di Sanità, the National Research Council (Consiglio Nazionale delle Ricerche or CNR), the Scuola Internazionale Superiore di Studi Avanzati (sissa) in Trieste, and the Abdus Salam International Centre for Theoretical Physics.

In Malta, awareness of open access within the research community is still limited, although researchers in particular disciplines (e.g. physics) are more aware of it than others.

OpenAIRE is the first major open access project that Malta is embarking on, and this will hopefully provide an impetus for further projects and initiatives related to open access. There are no national open access repositories or mandates at present. The Malta Council for Science and Technology (МСST), a partner of OpenAIRE, is the national research funding agency and has introduced an open access obligation similar to that used in the FP7 pilot. It is currently working with the Ministry of Education and with Malta Enterprise, a government agency, to develop an open access policy introducing a clause in standard grant agreements. In addition, MCS T is collaborating with the University of Malta to develop an oA repository.

Portugal reports that its open access repository activities currently have considerable momentum, a reflection of the growing interest and involvement of the Portuguese academic and scientific community in questions related to open access to scientific literature. Open access activities have mostly been carried out by universities, which have taken different initiatives to expand access to research information. The first Portuguese open access initiatives were initiated by the University of Minho with the creation of RepositóriUM, ${ }^{167}$ its institutional repository, in October 2003 and the subsequent implementation of a pioneering self-archiving policy introduced in January 2005. 
In November 2006, the Conference of Rectors of the Portuguese Universities (CRUP) released a declaration on open access recommending that Portuguese universities establish institutional repositories and define institutional policies that call on members to place their publications in those repositories. The statement also addressed the Portuguese Ministry of Science, Technology and Higher Education (MCтеs), asking it to "enforce policies determining that publications resulting from research projects directly or indirectly funded by the MCTEs be placed at least in one open access repository, therefore making publicly available results from research supported by public funds." 168

Neither the Portuguese government nor public or private funders have announced any official oA policies or mandates, but CRUP has urged Portuguese research funding organisations to implement a policy mandating the deposition of research outputs. Furthermore, CRUP generally supports the EUA Working Group recommendations and sees their approval by the European Research Council as an important step towards a generalised mandate on open access by the European Union. Several Portuguese universities have already adopted oA policies: the University of Minho in 2005; ISCTE - Lisbon University Institute in 2007; and the University of Porto, the University of Aberta, the Polytechnic Institute of Bragança, the University of Lisbon and the University of Coimbra in 2010.

In mid-2008, the Portugal Open Access Science Repository (Repositório Científico de Acesso Aberto de Portugal, RCA AP $)^{169}$ initiative was established. It aims to increase the visibility, accessibility and dissemination of Portuguese research outputs and integrate Portugal into the worldwide domain of research. The main components of the RCA AP project are:

- the RCAAP portal, which collects, aggregates and indexes open access scientific contents from Portuguese institutional repositories and forms a single entry point for searching, discovering and viewing thousands of scientific and scholarly publications;

- the SARI (service provider for institutional repositories), which allows institutions to create and completely 'brand' their repositories as desired in a central infrastructure;

- the Repositories Validator, ${ }^{170}$ a tool that measures the degree to which a repository conforms with RCAAP requirements (based on the DRIVER guidelines);

- communication, promotion and training activities. 
The RCAAP project also produced an open access policy kit ${ }^{171}$ which contains useful information and resources for the formulation and implementation of open access policies for research institutions (especially universities) and funders.

Currently there are 32 open access repositories in the production stage indexed on the RCAAP Portal, which indexes more than 226,000 scientific documents (as of February 2011).

In Spain, there is substantial awareness of open access within the library community but this is less so among researchers, where there is no culture of self-archiving or demand for repositories. There is very little awareness of open access among the commercial publishers.

At the national level, the draft National Law of Science includes an open access mandate for publicly funded research. The Ministry of Education has established a mandate to deposit theses and to make them publicly available in institutional repositories. At the regional level, two autonomous regional governments have established open access mandates: the Autonomous Community of Madrid was the pioneer in 2008, followed by the Principality of Asturias in 2009. At the institutional level, OA mandates have been taken up by several universities, including the Universidad Carlos II I de Madrid (2009), the University of Salamanca (2009), the Polytechnic University of Madrid (2010), the King Juan Carlos University (2009), the Open University of Catalonia (2010) and the Technical University of Catalonia (2009). ${ }^{172}$

Several other universities are engaged in ongoing open access work. Some universities such as the University of Alicante give direct financial support to departments or research groups according to the number of documents they deposit in the institutional repository.

Spain currently has over 60 institutional repositories and a fully operable national repository network. Most Spanish repositories (almost 80\%) are institutional, mainly created by universities, but there are also some research institutions such as the Spanish National Research Council (Consejo Superior de Investigaciones Científicas, or CsIC) and even some private organisations involved in the development of different kinds of open access repositories. Library consortia also play a key role in the creation of repositories, especially in Catalonia ( $\mathrm{CBUC})^{173}$ and Madrid (Consorcio Madroño $)^{174}$ whose respective territories account for most of the existing institutional repositories in Spain. 
The materials held in the repositories vary greatly, but full-text research articles and doctoral theses are the most frequently deposited. The vast majority of repositories contain both metadata and the full-text documents. With regard to the type of availability, most of the materials (over $64 \%$ ) are available in open access from the moment they are deposited, and only $19 \%$ (such as articles with publisher restrictions) are subject to some type of embargo. The material deposited represents only a small portion of the entire scientific production of the institutions.

RecOLecTA ${ }^{175}$ is a national aggregator that harvests most of the existing institutional repositories in Spain as well as OAI-compliant journals. In addition, e-ciencia Consorcio Madroño $o^{176}$ is a harvester for public universities in the autonomous region of Madrid, including the repositories of the National Distance Education University of Spain (Universidad $\mathrm{Na}$ cional de Educación, or UNED) and CSIC.

In Turkey, the Anadolu Üniversite Kütüphaneleri Konsorsiyumu Derneği (Anatolian University Libraries Consortium Association-A NKos) $)^{177}$ supports open access initiatives and studies via the ANKos Open Access and Institutional Repositories Study Group.

As of 2006, the term open access has become familiar in the Turkish academic community and libraries and information centers carried out some activities. With the aim of creating awareness of open access, these initiatives have led to the development of institutional archives, especially in universities. These archives were analyzed by consulting the Directory of Open Access Repositories (OpendoAR) and the Registry of Open Access Repositories (ROAR). To date, there is not a specific mandate policy in Turkey on open access, but institutions have been working on creating their repositories and make the authors and researchers share their studies in these repositories. There are 11 repositories which are registered in OpendoA R and 33 repositories listed in ROAR. The largest Open Access Repository System which is working as an umbrella organization is the MITos Interuniversities Open Access System. These are 17 institutions registered to M I T Os System with almost 32,000 records. Regarding compliance issues, the system will be evaluated.

\section{Conclusions for Region South}

Region South consists of very active oA communities, in particular in Portugal, Spain and Italy, and to some degree in Greece. In smaller countries 
such as Malta and Cyprus, open access is still in a very early stage and only just beginning to develop.

Open access is experiencing important developments especially in the first group of countries, driven mainly by the impulse of some national initiatives as well as EC projects and policies. This is reflected in the growth in $\mathrm{OA}$ repositories and in the increase in $\mathrm{OA}$ policies and mandates by institutions and funders. In this growth, the OpenaIRE project has served as an important stimulus.

A strong regional network has been established since early 2010, and the distribution of information is going according to plan. The regional meetings held monthly have demonstrated the importance of sharing work experiences and exchanging ideas about dissemination and communication strategies.

\section{Region East}

Region East includes Bulgaria, Croatia, the Czech Republic, Estonia, Hungary, Latvia, Lithuania, Poland, Romania, Slovakia and Slovenia.

The Bulgarian research community is well informed about the benefits of open access and uses open access research publications, but the promotion of open access is more of an individual effort than the result of institutional support or policy. There is a certain level of awareness among libraries, though still very few institutions are involved in managing repositories. At a special meeting of the Association of University Libraries (AUL) in 2010, the steps to build open repositories were outlined.

The Bulgarian Academy of Sciences (BAS), which coordinates research in Bulgaria, intends to establish a network of scientific open access centres. The Institute of Mathematics and Informatics at the B AS (IMI-BAS) coordinates this network and provides support for academic institutions and researchers. IMI-BAS has also launched a national project to develop the research infrastructure and digital repositories for researchers, educators, public bodies and companies who need contemporary scientific and education information and resources. This fosters the integration of academia, the public sector and industry; it also strengthens the institutional links between all major research and education organisations (the universities, the institutes of the Bulgarian Academy of Sciences, etc.).

In 2010 and 2011 IMI-BAS organised national information days called Open Access to Scientific Information which were broadcasted on Bulgarian National Radio and other Bulgarian news media. 
There are 107 FP7 funded publications in the Bulgarian OpenAIRE Repositor $\mathrm{y}^{178}$ launched by IMI-BAs. It took two about weeks to make the repository OpenaIRE compliant (and most of the time was dedicated to test sessions). It was a medium difficulty level effort and most of the efforts were focused on re-importing FP7 funded publications, filling in missing metadata fields (e.g. Grant Agreement numbers) and other data (had to manually collect missing information).

IMI-BAS is a partner of the European Digital Mathematics Library (Eu$\mathrm{DML}$ ) project that will design and build a collaborative digital library service to collate the current distributed content. It will also help plan the longterm preservation of digital mathematical literature through a network of academic libraries that will eventually be provided as open access.

As of August 2012, there were six Bulgarian open access repositories registered in Opendoar: those of the New Bulgarian University, IMI-BAS (Bulgarian Digital Mathematics Library and Bulgarian OpenA I RE Repository), Burgas Free University, Sofia University “St. Kl. Ohridski”, and Medical University of Sofia. Apart from them there is a repository at Tsenov Academy of Economics and a pilot repository of the University of Rouse. And there are currently 32 Bulgarian open access journals available in the Directory of Open Access Journals (DOAJ).

In Croatia, there is high awareness of open access among academic librarians and an active publishing community is facilitated by a central portal of Croatian scientific journals (H RČAK). ${ }^{179} \mathrm{HRČAK}$ was introduced in 2006 offering an open access publishing platform for Croatian journals ${ }^{180}$, with today over 300 journals and 79.000 full-text articles. HRČAK portal is supported by the Ministry of Science Education and Sports, developed and maintained by the University Computing Centre according the initial idea and concept given by the Croatian Information and Documentation Society (HID). ${ }^{181}$ HID was established to develop information and documentation sciences in Croatia, to promote professional principles and encourage free flow or materials including open access initiatives. It has organized a number of conferences and seminars that have included a focus on open access. OA was also one of the topics of several conferences organized by Croatian Library Association. ${ }^{182}$

The Ministry of Science, Education and Sports encourages open access through its Science and technology policy of the Republic of Croatia 20072010. The policy states that the results of research "financed by public re- 
sources must be accessible to the public in the form of open publications or databases". ${ }^{183}$ However, there are no national or institutional open access mandates in Croatia. Very recently, a small working group of scholars, librarians and students created the document "Croatian oA strategy" which will be presented to the public in October 2012 and hopefully adopted soon by Croatian Parliament, serving as a base for the national oA mandate.

The "green route to open access" is far less developed in Croatia than the "golden route". While the government encourages open access, there are no rules or guidelines for setting up repositories. ${ }^{184}$ Libraries in Croatia are establishing institutional repositories as a part of their regular activities in selection, organization, storage and provision of access to documents created by surrounding communities. To date, there are seven institutional open access repositories in Croatia, five of them listed in OpenDOAR, and two of them just started to collect documents (Ruđer Bošković Institute and University of Zadar, Department of information sciences). It is worth to mention that Croatian Scientific Bibliography CROSB I ${ }^{185}$ with more than 300,000 bibliographic records is also serving as central national repository with more than 13,000 full-text documents in oA provided by authors.

In the Czech Republic, although the Berlin Declaration has been signed by two important Czech institutions (the Academy of Sciences of the Czech Republic and the Czech Science Foundation) and by Association of Libraries of Czech Universities (ALCU); and a growing number of OA journals published by Czech institutions are available in the Directory of Open Access Journals (DOAJ), it is evident that the Czech Republic is only in the initial phase of adopting the idea of open access.

At present, there are nine open access repositories in the Czech Republic: at Charles University in Prague, Digital Library of the Czech Technical University in Prague, the Digital Library of the University of Pardubice, the repository of the Library of the Academy of Sciences of the Czech Republic, the Czech Digital Mathematics Library DML-CZ, the repository of the Technical University of Ostrava, National Repository of Grey Literature at the National Technical Library, Tomas Bata University in Zlin, and University of West Bohemia Digital Library.

The všB-Technical University of Ostrava Central Library (OpenAIRE NOAD) and some other university libraries have started to build the tech- 
nological infrastructure with an installation of DSpace-based repositories $^{186}$ and lead Czech universities activities ${ }^{187}$ supported by the Association of Libraries of Czech Universities. A national Open Access seminar was co-organized with NCP on October 12, 2011 with presentations from the $\mathrm{EC}^{188}$; and last year Open Access Week celebrations have been highlighted on a $\mathrm{TV}$ programme about $\mathrm{OA}^{189}$.

Estonia has neither a uniform open access policy nor an official position at the national level concerning the publication of scientific research. Interest in the issue has been expressed, but any substantive decisions have so far been left to the discretion of each research institution. ${ }^{190}$

The OpenA IRE NOAD - the University of Tartu Library - takes part in the Estonian Ministry of Education and Research programme for monitoring Estonian research policies and is involved in national open access policy discussions. Furthermore, it has become a centre of learning and knowledge sharing for other institutions seeking advice in the field of open access. According to Opend OAR, there are five digital repositories in Estonia: at Tartu University, the University of Tallinn, the Tallinn University of Technology, the Estonian National Library and a private archive centre (Arhiiviskeskus). D OAJ lists 22 open access journals from Estonia.

In Hungary, certain groups within the research community are aware of open access and its benefits, but they are still reluctant to provide open access to their publications. The main obstacles are a lack of knowledge about relevant copyright issues and a reluctance on the part of researchers to allocate time and effort to the depositing process. Advocacy programmes by higher education libraries could be an effective way of increasing the visibility and impact of Hungary's research results.

According to a government mandate on the open availability of $\mathrm{PhD}$ theses (March 2007), universities are responsible for providing open access to the full text of theses.

The Hungarian Scientific Research Fund (откA), the major funding agency of basic science and scholarship since 1986, signed the Berlin Declaration in 2008. Since 2008, all research publications funded by откA must be made openly accessible "either through providing the right of free access during publication, or through depositing the publication to an open access repository. Depositing is possible in a repository of an institution or that of a scientific field, as well as in the Repository of the Library of the Hungarian Academy of Sciences - REAL." ${ }^{191}$ The Hungarian Research 
Fund uses www.open-access.hu (set up and maintained by HUNOR) as a tool to provide information about open access.

In 2008, the HUNOR (Hungarian Open Repositories) consortium was established by the libraries of Corvinus University of Budapest, the University of Debrecen and the University of Miskolc as well as the Library of the Hungarian Academy of Sciences. The members of HUNOR are dedicated to promoting Hungarian research both nationally and internationally and to achieving the effective dissemination of scientific output through the implementation of a national infrastructure of open access repositories. Other proposed activities include the establishment of a methodology centre, the adoption of international know-how and standards, the establishment of complementary scientific communication channels, and international cooperation. There are seven open access repositories in the country: at the Corvinus University of Budapest, the University and National Library University of Debrecen, the University of Miskolc; the Library of the Hungarian Academy of Sciences (also contains full-text publications of research projects funded by отка), the Institute of Business Economics, the University of Szeged, and at the Central European University. And DOAJ lists 24 open access journals published in the country.

In Latvia, national research funders have no clear policy on open access. However, some scientific institutions and researchers publish in open access journals and repositories in order for their work to gain more visibility and to have a greater impact on international research.

During the Open Access Week in 2009, 2010 and 2011, the University of Latvia held workshops, organised in collaboration with EIFL, which brought together researchers, research managers and policymakers, journal editors and publishers, librarians and IC т specialists to discuss the latest developments in open access and how to raise the visibility of research output from Latvian universities and research organisations. ${ }^{192}$ The 2010 and 2011 workshop highlighted European open access policies, practical experiences in creating institutional repositories at the University of Latvia and Riga Technical University, and the opportunities and challenges of the OpenaIRE project.

Many researchers in Latvia publish their papers in open access journals and deposit their papers in subject repositories (such as PubMed Central, ArXiv and CogPrints ${ }^{193}$ ) because they recognise that it results in access to a larger audience than publishing in conventional journals. 
Some initial steps have been taken to support the development of an oA policy in Latvia. The University of Latvia has made scientific papers published by the University of Latvia Press freely accessible in the university portal. In addition, theses (full texts and their summaries) defended at the University of Latvia since 2006 are being made available in the database Theses of the University of Latvia ${ }^{194}$ and at the E-resource repository of the University of Latvia. ${ }^{195}$ This database is accessible through the Electronic Union Catalogue, an aggregation of material from eight nationally significant Latvian libraries, and through the university portal.

In Lithuania, the most active players in the field of open access are research libraries. Awareness-raising events are organised in close collaboration with the Lithuanian Academic Libraries Network, the Ministry of Education and Science, the academic community and the Lithuanian Academic Publishers Association. A broad open access campaign was organized by the LMBA Consortium while implementing the EIFL open access grant in 2011. As a result of this activity printed and video promotional was created.

Vilnius University started the National Open Access Research Data Archive MIDAs (2012-2014). The purpose of the project is to establish the infrastructure of national research data archive that enables collection and storage of research and empirical data and ensures free, easy and convenient access to the data.

In 2006, the Minister of Education and Science issued a decree to establish a Lithuanian information system for electronic documents. Developed by the Kaunas University of Technology, the Lithuanian Academic Electronic Library (еL Ава) stores some 20,000 documents of 14 participating institutions, mainly electronic theses and dissertations, and science publications. In addition, the Kaunas University of Applied Science, Lithuanian University of Agriculture, the Vilnius Gediminas Technical University and Aleksandras Stulginskis University of Lithuania have established institutional repositories of their own.

The issue of public access to the results of publicly funded research has become part of national legislation: Article 45 of the Law on Higher Education and Research of the Republic of Lithuania (which took effect on 12 May 2009) ${ }^{196}$ requires that the results of scientific activity be made publicly available: 
1. In order to ensure the quality of research conducted with funds of the state budget, the transparency of the use of funds of the state budget, to enhance scientific progress, the results of all research works carried out in state higher education and research institutions must be announced publicly (in the Internet or any other way), to the extent this is in compliance with the legal acts regulating the protection of intellectual property, commercial or state and official secrets.

2. The results of research conducted in non-state higher education and research institutions with funds of the state budget shall be announced publicly (in the Internet or any other way), to the extent this is in compliance with the legal acts regulating the protection of intellectual property, commercial or state secrets.

This new law is considered a big step forward, as it introduced many radical changes into Lithuanian academic life that had to be implemented by 2011. As yet, however, no secondary legislation has been adopted. Two research institutions have established institutional regulations on open access: the Vytautas Magnus University in May 2009 and Vilnius University in October 2009.

In 2010, the Consortium of Lithuanian Academic Libraries for the Development and Support of Information Infrastructure for Science and Studies was founded. One of its objectives is the reorganisation and further development of the eLABa repository. In addition, a working group consisting of representatives of all research and higher education institutions has been established and started its activities in September 2010. ${ }^{197}$

DOAJ lists 32 open access journals in Lithuania. In 2011, the Association of Lithuanian Serials promoted open access through the implementation of Open Journal Systems (oJs) and as a result 22 oJs installations (and counting) have been implemented at seven research institutions (with EIF L) grant to improve journal availability and accessibility. ${ }^{198}$

Poland has already developed a strong tradition of open access content, with the active involvement of organisations like ICM, Interdisciplinary Centre for Computational and Mathematical Modelling at the University of Warsaw (Openaire nOAD), Creative Commons Poland ${ }^{199}$ and the Coalition for Open Educational Resources. Poland also actively participates in projects such as DRIVER, DRIVER II and COMMUNIA. ${ }^{200}$

According to OpendoA R, some 74 repositories already exist in Poland, some of which serve as digital libraries of digitized collections. 
In February 2010, the Institute of Biochemistry and Biophysics of the Polish Academy of Sciences issued an open access institutional mandate stipulating that "all newly published manuscripts must be immediately deposited in the repository in the final reviewed version (not the publisher's proprietary pdf). Deposits will become available immediately or after expiration of embargo, depending on the publisher's policy." ${ }^{201}$ On 20 November 2009, the Rector of the Adam Mickiewicz University in Poznan issued an open access $\mathrm{PhD}$ theses mandate-the first of its kind in Poland. ${ }^{202}$

All Polish digital repositories and digital libraries are aggregated in the PIONIER Network Digital Libraries Federation, ${ }^{203}$ which is maintained by the Poznań Supercomputing and Networking Center, an affiliate of the Institute of Bioorganic Chemistry of the Polish Academy of Sciences.

The government of Poland (the Chancellery of the Prime Minister and the Ministry of Science and Higher Education) is working on a legislation to make the results of publicly funded research open access: deposited in open access repositories and/or published in open access journals. The legislation will help small and medium size enterprises to have access to knowledge and innovations. To support these developments ICM launched a national campaign ${ }^{204}$ and as of 21st August collected 12,770 signatories that support introducing a national open access mandate.

ICM has also set up a national OpenAIRE compliant Repository of Centre for Open Science ${ }^{205}$ to collect F P 7 funded publications.

DOAJ lists 135 open access journals published in the country.

The Nicolaus Copernicus University and Akademia Gorniczo-Hutnicza University of Science and Technology collaborated to raise open access awareness among researchers and students by creating an e-learning course "Open Access - Open Science" 206 launched in October 2011 with EIFL funding.

In Romania, the level of awareness of open access within the research community is low. To raise awareness an OpenAIRE NOAD released the "Open Access Understanding" 207 , which has been gradually acknowledged as an important milestone for future developments. The Kosson community maintains the open access website as a central hub for Romanian activities, advocacy and the jump paddle for the medium term target: a Romanian Open Access Repository. And according to D OAJ there are $233 \mathrm{OA}$ journals published in the country. 
ASPeCK ${ }^{208}$ is an institutional repository of the Transilvania University of Brasov that collects only doctoral, postgraduate and undergraduate theses from the university. In the future, the content will be enriched with technical reports and conference papers, with the ultimate goal of AsРеск т becoming a trusted repository for all research activities carried out at the university. Institutional repositories have also been established by the Central University Library "Carol I" of Bucharest and the Faculty of Public Administration of the National School of Political Studies and Public Administration (NSPSPA).

Slovakia's research community is aware of the benefits of open access, but researchers remain reluctant to provide open access to their publications. The major constraint is the time and effort needed for open access depositing. Only a small fraction of researchers deposit their research papers, and even this is a result of proactive advocacy and training on the part of library staff. The country has no open access repositories or mandates at present, but there are 29 OA journals (according to DOAJ). The OpenaIRE project inspired partnership between the University library Bratislava and CERN to set up the first open access repository in the country based on Invenio (the software, which powers the OpenAI RE Orphan repository).

In Slovenia, awareness of open access is generally low within the research community, with sporadic enthusiastic researchers supporting the green or gold oA routes, either experimenting with oA or complying with the open access requirements of projects. A conference held in October 2010 entitled Open Access to the Achievements of Slovenian Scientists was a major breakthrough in this regard, ${ }^{209}$ bringing together funders, researchers and librarians. All oA stakeholders have been able to learn more about the European Commission's Open Access Pilot and about OpenAIRE from the report on the OpenaIRE launch event published on the Slovenian Research Agency's website. ${ }^{210}$

No funder or institutional mandates exist in Slovenia for depositing publications from publicly financed research into open access repositories and none of Slovenia's higher education or research institutions have signed any of the open access declarations. $36 \mathrm{OA}$ journals are published in the country and there is an ongoing project to launch a national oA journal portal (using ojs).

The Rectors Conference of the Republic of Slovenia has supported the 
establishment of a national repository of research publications and data which could be connected to the existing Slovenian current research information system (SICRIS). Considering the size of Slovenia and its research environment, this would help to avoid the duplication of efforts and could address the issue of the lack of relevant expertise at individual higher education or research institutions. At the same time, a national repository would enable the efficient curation of electronic scientific output for longterm use. Such a repository would not exclude individual institutions from setting up and maintaining their own institutional repositories.

This initiative along with others resulted in the inclusion of a national open access infrastructure into the Research Infrastructure Development Plan 2011-2020 211 . The Plan was confirmed by the Government of the Republic of Slovenia in April 2011. The plan lists and briefly describes the important international and national research infrastructure priority areas. Slovenia plans to participate in the international projects ESS, DARIAH and CESSDA ${ }^{212}$ and to build a national open access infrastructure for the deposit of research data and publications from publicly financed research, which will be linked to SICRIs. The deposit of data and publications will be mandatory after the establishment of the infrastructure. Additionally, the plan envisages the establishment of a social sciences and humanities research infrastructure, supported by adequate information technologies.

There are currently five DRIVER-compliant repositories in Slovenia: 1) the repository of the National and University Library (NUK) within the Digital Library of Slovenia dLib.si portal; ${ }^{213}$ dLib.si harvests records of open access and restricted access materials and serves as the national DRIVER aggregator for Slovenia; 2) the Digital Library of the University of Maribor (DKUM), ${ }^{214}$ which currently archives electronic theses, although plans are in place to include the archiving of research publications; 3 ) ePrints.F R ${ }^{215}$ of the Faculty of Computer and Information Science of the University of Ljubljana; 4) PeFprints ${ }^{216}$ of the Faculty of Education of the University of Ljubljana; and 5) Digital Repository of the Faculty of Civil and Geodetic Engineering of the University of Ljubljana (DRUGG). ${ }^{217}$ ePrints.FRI, PeFprints and DRUGG are the electronic theses and research publications repositories. Morever, ELPUB ${ }^{218}$ independently contributes records to DRIVER (currently about 500 records). Four other electronic theses and dissertations repositories are also in operation but are not compliant with DRIVER. Other solutions include links to theses and disserta- 
tions from institutional websites or from records in the Slovenian Union Catalogue (совів.SI). ${ }^{219}$

The consortium of thirteen major research institutions (representing almost all active researchers in the country) launched a national website on OA, openaccess.si funded by EIFL. The project attracted attention, support, and cooperation of all major national actors in R\&D, including the Ministry of Higher Education, Science and Technology, the Slovenian Research Agency, and the Science and Technology Directorate at the Ministry. A core group of OA advocates has been set up acting as the advisory body on oA in Slovenia.

\section{Conclusions for Region East}

Steady progress is being booked in Eastern Europe with regard to open access: new open access repositories and journals are being launched, and open access policies are being actively discussed.

Libraries have become active promoters of open access in the region and have put open access on the agenda of national policymakers and research communities. The OpenAIRE project has been presented at national conferences and meetings. The NOADs cooperate in various ways with each other to promote open access in the region. To name a few examples: the Slovenian NOAD presented at an open access conference in the Czech Republic, Hungarian experts shared their experience with Bulgarian colleagues during the national information day Open Access to Scientific Information, and a Hungarian NOAD recently launched an open access promotion project for Hungary, the Czech Republic, Poland and Slovakia. The F 77 Open Access Pilot has also sparked discussions about open access policies among national research funders in, for example, Bulgaria, Estonia and Slovenia.

At present, many Eastern European institutions have limited experience with European Commission-funded projects and also lack national open access infrastructures. Therefore, the main issues and challenges for the Eastern European NOADs are: the effective promotion of open access among the research communities, the establishment of contacts with managers of EC-funded projects, the development of open access tools (journals and repositories) and making them OpenaIRE-compliant, and the provision of support in copyright management for researchers and research institutions. 


\subsubsection{Conclusions on funder and institutional oa mandates in Europe}

Open access policies and mandates may differ in terms of:

- the type of obligation: Request or requirement;

- the date of deposit: Several mandates request deposition immediately after publication, while other policies leave the deposit date to the discretion of the author;

- the kind of material to be deposited: Most mandates regulate what kind of literature should be deposited. Typically this includes peer-reviewed articles, conference proceedings and theses. Researchers are often advised to deposit other material such as books, book chapters and data sets;

- the version of the material: Most mandates concentrate on the final author manuscript after peer review but recommend that authors provide the publisher's version if allowed by the publishing agreement or the publisher's policy;

- the embargo period: Most mandates include a recommendation or clause on the open access embargo period, some depending on the scientific field (typically up to six to twelve months for s TM and 12-24 months for Hss). Otherwise, the embargo period is determined by the publisher's copyright policy.

- infrastructural approach: Type of repository used-institutional or disciplinary, central repository or distributed network;

- financing: in general based on a mix of resources from funders, institutions and publishers;

- integration of institutional and national research reporting: for example by linking the current research information system and institutional repositories, as in Denmark, Norway and Ireland;

- monitoring of uptake and impacts: This depends on a systematic record of institutional publishing outputs and the collection and analysis of various usage and impact indicators (statistics, journal impact factor, etc.);

- the creation of incentives and sanctions: This may include financial or other rewards if a certain degree of compliance is achieved (e.g. University of Minho);

- support activities: FAQs, library and/or publisher-assisted deposit, copyright tools and clearance, etc. 
Table 1 in Annex 3 summarises the oA mandates that were in place in $\mathrm{Eu}-$ ropean countries as of early January 2011. The main sources of information for this overview are the databases ROARMAP, MELIBEA ${ }^{220}$ and SHERPA/JULIET as well as the country reports in section 4.4 and OpenAIRE's own inspection of several OA policies. ${ }^{221}$

With a few exceptions, the compliance rate of these oA mandates is unknown. This is partially due to the fact that such mandates are a fairly new phenomenon and not all research institutions have a research information system in place that covers all publication outputs of the institution. In some cases such as Region North, Ireland and the United Kingdom, research reporting and assessment is already quite advanced and may in future also serve as a tool to assess the impact of oA mandates.

As already mentioned, the Wellcome Trust boasts a compliance rate of over $50 \%$ just five years after it issued its oA mandate. In the case of Ifremer, $80 \%$ of all publications between 2005 and 2008 were already being deposited in its repository, before it introduced its mandate in September 2009. The mandate was therefore aimed not so much at improving the overall compliance rate but at enforcing the principle within the institutional research community. ${ }^{222}$

\section{Conclusions}

By closely cooperating with research institutions and funders, OpenaIRE can learn from existing policies in implementing the EC/ERC'S OA policies. What is common to all oA mandates is the need to develop and review strategies to activate researchers and to support them in complying. With respect to the European character of the EC/ERC's OA policies, the network of NOADS will be used to exchange experiences among the European countries, to assist institutions in implementing and maintaining the EC/ERC's OA policies and to strive for synergies between institutional, national and regional oA policies.

\subsubsection{Summary of strategies}

Given the level of awareness in individual countries of open access and the development of repository infrastructures and services, the promotion of open access will require a multipronged approach. Below is a summary of the approaches and strategies that have been recommended and practically pursued by various stakeholders: 
- Research institutions and organisations sign the Berlin Declaration, which is an important milestone in the development of an institutional or national oA policy. This is often linked to a public event to demonstrate the willingness to further develop institutional or nationwide oA policies (e.g. Belgium, France).

- Research organisations set up OA policies and related infrastructures to support the adoption of these policies at the institutional level (e.g. CNRS in France, the Max Planck Society in Germany).

- Universities or other research institutions set up and implemented institutional oA policies or mandates. There are several policy variants (see section 4.4.3).

- Rectors conferences recommend that universities and research funders implement oA policies or mandates (e.g. Austria, Portugal).

- The national oA community develops a support network as well as a collaborative platform to keep members informed about oA (e.g. Hungary, Greece, Germany, Denmark, Sweden—see Table 4 in Annex 3).

- A joint national programme or initiative is established to promote, support and coordinate the development of the national digital repository infrastructure (e.g. the RCA AP initiative in Portugal, RECOLECTA in Spain, DINI in Germany).

- A professional body is developed for repository managers to strengthen the profession and to encourage collaboration (e.g. United Kingdom Council of Research Repositories, UKCORR). ${ }^{223}$

- A programme is set up to create or strengthen regional approaches to OA. For example, the Nordbib ${ }^{224}$ funding programme for the Nordic region of Denmark, Finland, Iceland, Norway and Sweden created a joint Nordic approach to open access and research distribution. The programme ran from 2006 to 2009, and upon evaluation, an extension was recommended. In a similar spirit, the Southern European Libraries Link (SELL), ${ }^{225}$ which represents library consortia in six countries (France, Greece, Italy, Portugal, Spain and Turkey), has explored the national situation of open access policies and infrastructures with the aim of developing "common policies towards information acquirement and provision". The results and possible actions were discussed in a joint workshop in May 2010 and led to the Alhambra Declaration. ${ }^{226}$ Building on this, the six Mediterranean countries initiated MedOANet (Mediterranean Open Access Network), ${ }^{227}$ a two-year 
project funded under the Science in Society Programme of the EC 7 th Framework Programme (2012-2014), with the goal to coordinate national and regional open access strategies, policies and structures.

- Agreements are negotiated with publishers on oA publishing and publisher-assisted deposit in repositories-at the level of individual research institutions, consortiums of institutions, as well as at the national or international levels (e.g. consortial agreements with BioMed Central and Springer, national licences with oA clause in Germany); ${ }^{228}$

- An institutional fund for oa publishing is set up, combined with the deposit of these funded publications in the institutional repository (ex: University of Nottingham, University of Lund, University of Bielefeld).

Some of these strategies-such as signing the Berlin Declaration-are of symbolic value and indicate a willingness to take further action. To change the overall attitudes and behaviour of researchers, the timely follow-up of such declarations is essential in order to ensure that policy is put into action.

Several institutions have therefore set up working groups to develop implementation plans covering the various aspects of oA policy, and to monitor the implementation process and the results.

Other actions to facilitate the implemention of ox policies and mandates might include:

- Supporting researchers in complying with other oA requirements and mandates by archiving or registering their publications;

- Taking $\mathrm{OA}$ into account in related institutional strategies regarding intellectual property rights or internationalisation, for example;

- Introducing $\mathrm{OA}$ into the monitoring and evaluation of research outputs by issuing annual reports based on the publications that have been deposited in the institutional repository (e.g. University of Zürich); 229

- Introducing OA availability as a criterion in research evaluation that leads to additional points in the weighting scheme assigned to various forms of publishing. 
The aim of open access is to offer equal opportunities for access to research outputs. Therefore, in addition to the action points mentioned above, one can envision other efforts inspired by gender mainstreaming, ${ }^{230}$ which is typically monitored by an office for equal opportunities.

For some institutions or funders, a review of their policy and its uptake has already been integrated into the policy itself (e.g. Trinity College Dublin).

\section{Conclusions}

Where possible, OpenAIRE will integrate these approaches and actions in its work of implementing European policies on open access. Further strategies might be needed to address the fragmented nature of the implementation and the different stages of awareness of oA.

\subsubsection{Evaluation and update of strategies}

At the Openaire General Assembly on 1 December 2010, all NOADs reported on their countries' activities over the last year supporting the implementation of the EC/ERC's OA policies and about recent OA developments in their countries. ${ }^{231}$

OpenA IRE asked all NOADs the following questions:

1. Implementation of OpenAIRE in your country

Describe your activities for OpenAI RE over the last year:

- Outreach: Which stakeholders have been contacted? (researchers, institutions, repository managers, research funders, journals etc.)

- Dissemination: How have you informed about OpenAIRE? (presentations, interviews, mailing lists, portals, blogs, twitter, translation and dissemination of leaflets etc.)

- OpenaIRE Guidelines: When will your repository be compliant? How many are compliant in your country?

- Best Practices / Nice to Have: What has been particularly beneficial/ efficient? Your wish list for OpenAIRE?

2. Recent OA Developments in your country

Describe developments of relevance for $\mathrm{OA}$ in your country:

- Events \& Workshops: Which themes have been addressed? 
- Policy development \& implementation: Any new developments from research funders, institutions?

- Projects \& Initiatives: Any important new projects, initiatives, results of discussions etc.?

- Challenges \& Needs: What is needed nationally or on the European level?

The answers to these questions have been taken into account in the writing of the country reports (see section 4.4.1 ff).

In a follow-up session, the NOADs were split into three groups-1) dissemination and outreach strategies; 2) networking activities; and 3) compliance-to which participants were assigned at random in order to have a mix of regions and expertise levels. Based on these discussions, each group came up with two to three recommendations for further actions during the second year of OpenAIRE.

\section{Dissemination and outreach strategies}

This working group recommended:

- early outreach to researchers: Get involved in FP7 researchers' networks from the beginning and present the OA policies, OpenAIRE's support structures, success stories for using repositories. Demonstrate the idea of usage data as is under development for the OpenAIRE infrastructure.

- involvement of the European Commission: The NCPs should be actively involved in dissemination activities based on various channels, inclulding personal communication, websites and magazines. Moreover, it might be advisable to require OpenaIRE compliance in research assessments.

\section{Networking activities}

The group recommended:

- internal communication strategies: Existing problems include an abundance of mailings and difficulties finding information when it is needed. Improvements to the portal were suggested (tagging, translations, etc.). When translating or for internal FAQS, a wiki might be useful. 
- sharing of information: It would be useful for information about conferences and related $\mathrm{F}$ 7 7 projects to be shared more regularly. In addition, a FP7 mailing list might be helpful for outreach activities addressing F P7 projects.

\section{Compliance}

In order to help researchers to comply with the EC/ERC's OA policies, the group recommended:

- atwo-stage-process:

o first stage: Identify the NCPs and research communities of importance to your country, then use this to put some pressure on repository managers to comply ("help your researchers to comply").

o second stage: Better results will be achieved with personal contacts instead of mailings, because personal contact counts.

- technical support for compliance: Provide a site where repository managers can go when they have problems with compliance. This site should serve as a more dedicated part of the helpdesk for technical problems as well as software solutions such as DSpace and EPrints.

Updates about the NOAD's activities and experiences have been gathered regularly and discussed at a NOADs' workshop in June 2011 and the $2^{\text {nd }}$ General Assembly in December 2011. Based on expressed needs specific information, trainings and actions have been developed such as a series of webinars addressing repository and journal managers.

\subsection{Repository infrastructures in Europe}

OpenaIRE relies on a distributed approach of a network of open access repositories and a support network. To comply with the EC/ERC's grant conditions, researchers are encouraged to deposit the final peer-reviewed author manuscript in an institutional or disciplinary repository if available, or in the OpenAire Orphan Repository. The latter repository acts as a host for 'homeless publications', as not all institutions have a repository set up and disciplinary repositories are not available for all disciplines.

According to the Directory of Open Access Repositories (OpendoAR) 
and the Registry of Open Access Repositories (ROAR), ${ }^{232}$ there are some 750 to 800 digital repositories in Europe, including thesis, institutional, disciplinary, funder repositories and some collections of journals. Some countries have already achieved a high rate of institutions with repositories, while others are still in an early stage of development.

To support researchers in finding a repository, there are various solutions such as a simple search based on the registered repositories or based on the IP address of the user. The latter is used by the interdisciplinary OpenDepot, for example. ${ }^{233}$

An overview of existing repositories can be found in Table 2 (see Annex 3).

To facilitate the integration of these (and newly built) repositories into the OpenaIre Information Space, the OpenAIre Guidelines have been developed.

\subsubsection{OpenaIRE Guidelines}

The OpenA IRE Guidelines ${ }^{234}$ provide repository managers with the necessary information to define and implement their local data management policies in compliance with the open access demands of the European Commission. They are supplementary to the DRIVER Guidelines ${ }^{235}$ and comply with the technical requirements of the OpenaIRE infrastructure which is being established to support and monitor the implementation of the FP7 OA Pilot and ERC Guidelines for Open Access. By implementing these guidelines, repository managers can help authors comply with the EC's open access requirements.

The current version (1.1) of the OpenAIRE Guidelines is available in English, Spanish and Portuguese.

Moreover, for developers of repository platforms, the guidelines provide guidance on adding supportive functionalities for authors of EC-funded research in future versions. In particular, for DSpace an OAI-extended add-on has been developed which provides the tool to create an oA I set according to the OpenaIre Guidelines.

The developers of the Open Journals System (oJs) have released a plugin to support OpenAIRE compliance in January 2011. ${ }^{236}$ Developers of other software solutions such as EPrints and opUs have been invited to adapt their software accordingly.

To be integrated into the OpenAIRE network, repository managers only need to carry out a few basic steps: 
1. Adapt the repository to become compliant with the OpenAIRE Guidelines.

2. Register the repository with OpenAIRE in order to be integrated into the OpenAIre network (available from March 2011).

3. After receiving a validation report and possible adaptions, OpenAIRE will start harvesting the set of EC-funded publications and display them.

This of course holds for institutional and disciplinary repositories as well as publishers or journal editors that disseminate their publications via an open access repository.

At the launch of OpenAIRE, about 30 repositories were compliant, and as of August 2012 the number has tripled to 90 repositories.

\subsubsection{Disciplinary repositories and networks}

Currently, there are over 200 disciplinary repositories (219 according to OpendoAR) collecting and indexing research outputs of a specific field. The largest and oldest ones include PubMed Central ${ }^{237}$ (over two million records), Research Papers in Economics ${ }^{238}$ (RePEc) (over one million records, with over 875,000 available online) and the $\operatorname{arXiv}^{239}$ for e-prints in physics, mathematics, computer science, quantitative biology, quantitative finance and statistics (more than 655,000 records).

Several new disciplinary repositories have been built up in recent years. The number is growing substantially, particularly those with an excellent reputation in their field. Some of these are national initiatives embedded in multinational networks. The inclusion of these (large) disciplinary repositories in the OpenAIRE information space is important for OpenAIrE's goal of displaying all publications of the OA Pilot on OpenaIre's platform as well as for reaching out to researchers and disciplinary repository networks in Europe.

Below we give a few examples of disciplinary repositories and networks that are already in contact with OpenAIRE.

\section{UKPMC}

uK PubMed Central (UKPMC) is a full-text article repository for the life sciences run by a partnership of the European Bioinformatics Institute (ЕBI), the British Library and the University of Manchester. It is funded by 
eighteen funders of biomedical research, including charities and government organisations in the UK, Austria, and Italy, led by the Wellcome Trust. $^{240}$

UKP MC contains about 2.2 million full-text research articles from the life sciences, of which over 400,000 are open access articles. In January 2010, UKPMC released a platform with enhanced functionalities for information retrieval and knowledge discovery. The European Bioinformatics Institute, supported by the National Centre for Text Mining ( $\mathrm{NaCTeM}$ ), is using text-mining technologies to extract biomedical concepts and facts from the UK PMC literature.

UKPMC is working with research funders and external bodies to identify sources of additional content (for example $\mathrm{PhD}$ theses in health and biomedical fields). As announced in July 2012, U K PubMed Central will be renamed to Europe PMC from 1 November 2012 on, and with the European Research Council as a new member will now be supporting 19 national and European funders' mandates and in collaboration with other European OA policy initiatives. ${ }^{241}$ In contrast to Us and UK mandates, European research funders' mandates do not typically require the use of a specific repository for deposit such as PMC or UKPMC. This collaborative effort would help share content bidirectionally between UKPMC and institutional repositories.

For Openaire, it would be beneficial if well-established disciplinary repositories such as UKPMC join the network by collecting and exposing metadata (for harvesting) according to the OpenAIre Guidelines. The following collaboration between OpenA IRE and U K PMC can be envisaged:

- The development of a 'reference scenario' for subject-based repositories: registration workflow for EC/ERC-funded publications based on remote deposit in UK PMC and/or institutional repositories.

- The adjustment of specifications to disciplinary requirements (classifications, etc.) in particular to identify relevant content for U K PMC.

- Experiments with interfaces connecting institutional and subjectbased repositories. 
SSOAR

The Social Sciences Open Access Repository ${ }^{242}$ (SSOAR), an open-access document server for the social sciences, indexes and archives scholarly literature (full texts) from the social sciences in Germany and abroad. ssoA R collaborates with the PEER project (see 3.4.1).

\section{OceanDocs}

OceanDocs ${ }^{243}$ is an online repository for marine sciences developed by the Hasselt University Library in Belgium and supported by the Intergovernmental Oceanographic Commission (IOC) of UNEsCO. Its aim is to collect, preserve and facilitate access to all research output from members of the Ocean Data and Information Networks (odins).

\section{EconStor}

EconStor $^{244}$ is the open access server of the German National Library of Economics (zBW) of the Leibniz Information Centre for Economics. It provides a basis for the free publication of academic literature in economics. EconStor currently provides access to working papers from approximately 100 institutions. Among these are the six top-rated German economic research institutes (including the Kiel Institute for the World Economy and DIw Berlin) and the Deutsche Bundesbank. zBW cooperates with Economists Online (see below).

\section{NEEO/Economists Online}

The NEEO ${ }^{245}$ project resulted in an online research portal for economists called Economists Online ${ }^{246}$. The service, launched in January 2010, increases the visibility of economists' research by collecting it in a single, cross-searchable portal. Economists Online showcases institutions, scholars and their academic publications and datasets. The multilingual repository contains over 900,000 bibliographic references, many with links to open access full text. It combines content with RePEc archives ${ }^{247}$ to provide a new information service to economists.

The key objectives of NEEO are:

1. To improve the usability, global visibility and management of economics research.

2. To provide various users easy and open access to high-quality multi- 
lingual academic output of leading economics institutes and their researchers.

3. To offer a reliable and sustainable portal with aggregated and enhanced metadata enabling an infrastructure for new services.

\section{Conclusions}

OpenA IRE will further explore opportunities to collaborate with more disciplinary repositories and federations. By complying with the OpenAIRE Guidelines, these repositories can offer researchers convenient ways to comply with the EC/ERC's requirements within their research communities.

\subsubsection{OpenaIRE Orphan Repository}

All researchers without access to an institutional repository or a subject repository can deposit their EC or ERC-funded articles in the OpenAIRE Orphan Repository. ${ }^{248}$ This supplements the infrastructure of institutional and disciplinary repositories with a 'last resort' for articles without a natural host. That is, Opena IRE encourages researchers to primarily use their institution's repository or a subject repository if they prefer to do so.

The Opena IRE Orphan Repository is hosted by CERN and has been developed on the basis of CERN'S INVENIO software. It is compliant with the Openaire Guidelines, as its content is harvested by Openaire and displayed online in the collection of FP7-funded research outputs.

Researchers can deposit articles in the OpenaIRE Orphan Repository via the OpenaIRe deposit interface or directly on the repository's website. The collection of the repository is open to all EC or ERC-funded peer-reviewed research publications, including all research areas of F P7 (and not just the seven research areas covered in the FP 7 Open Access Pilot).

A further enhancement to the deposition workflow would be to support a supplemental deposit in authors' institutional repositories (based on the SWORD protocol), immediately if already implemented or at a later date if one comes into existence. This would avoid turning away those researchers who choose to use OpenAIRE as the single port of call. It would also allow for the preliminary storage of information destined for thirdparty repositories when they are temporarily unavailable during the deposit process, once again to help researchers and to aid adoption of deposit 
procedures. For this, a specific deposit licence should be provided that asks authors for rights to store their publications in the OpenAIR E Orphan Repository as well as to further transfer these into adequate institutional or disciplinary repositories.

\subsubsection{Networks of repositories}

Several countries have built up a national network of repositories based on harvesting metadata. These networks can help to promote compliance with OpenAIRE and will in some cases be able to expose the oA I set based on a joint collection as provided by their harvester.

OpenAIRE has approached national networks supporting the development of repository infrastructures and networks in order to gain their support in promoting and implementing the OpenaIre Guidelines, including networks of repository managers and developers in Portugal, Germany, uk, Finland and the Netherlands.

Some of these national networks are based on the $\mathrm{D}-\mathrm{NET}^{249}$ software developed by the DRIVER projects and adopted by OpenAIRE to integrate existing services and to build the infrastructure of $\mathrm{OA}$ articles funded by the EC/ERC. Based on D-NET, national repository infrastructures and portals have been built up for the Belgian, Slovenian, Spanish and Bulgarian national consortia, with Greece currently under development.

An overview of existing repository networks and harvesters is given in Table 3 (see Annex 3 ).

\subsection{Advocacy and support networks}

\subsubsection{National networks}

Several countries have already developed advocacy and support networks to address various stakeholders, including authors, institutions, repository managers, librarians, publishers and journal editors.

Several of these national networks have evolved in connection with the development of information platforms or the development of national repository networks. Among these are the Portuguese network RCAAP, the Spanish network ReCOLECTA, the German information platform open-access.net as well as the German repository network oA-Netzwerk, and the Danish Open Access Network. The Repositories Support Project 
(RSP) has offered UK repository managers its support in implementing the Openarre Guidelines. In addition, RSP is in contact with EPrints and DSpace developers to ask them for comments and encourage them to make changes or additions to their software.

An overview of information portals and support networks in European countries can be found in Table 4 (see Annex 3).

Most of of OpenAIRE's NOADs have already established close relationships with the above-mentioned support networks. This collaboration is expected to be particularly beneficial for establishing Europe-wide support for the implementation of the EC/ERC'S OA policies.

\subsubsection{COAR}

The Confederation of Open Access Repositories (COAR) 250 is a not-forprofit association of repository initiatives launched in October 2009. It aims to facilitate greater visibility and application of research outputs through global networks of open access digital repositories. COAR promotes the interoperability of oA repositories on an international scale, based on the ideas and expertise of more than 90 institutions worldwide (Europe, Asia, Latin America, the U.s. and Canada). coAr supports the coordination of global collaborative efforts to make high-quality data easily available and to create interoperable systems. Through its actions, coA R aims to provide support for the open access repository community from institutions, countries, regions and disciplines, through international cooperation and information sharing. Moreover, COAR aims to define and promote interoperability, standards, and infrastructure policies and to stimulate the development and take-up of user added-value services on top of repositories. ${ }^{251}$

COAR has formed three working groups focusing on:

1. repository content: This group aims to populate repositories with content and collect, assemble and disseminate best practices for the inception, operation and growth of $\mathrm{oA}$ repositories.

2. repository interoperability: This group facilitates the discussion on interoperability among $\mathrm{OA}$ repositories and as part of a wider e-Infrastructure.

3. repository and repository networks support \& training: This group supports regional and national repository initiatives and promotes the repository manager profession. 
COAR's objectives are strongly correlated with OpenAIRE's aims and activities. OpenAIRE's cooperation with COAR aims to combine efforts and seek synergies on a worldwide scale. This includes strategies for the acquisition of content, the evaluation and discussion of interoperability guidelines as well as support and training activities.

\subsubsection{EIFL}

Electronic Information for Libraries, or EIFL, ${ }^{252}$ is a not-for-profit organisation that works in collaboration with libraries in more than 60 developing and transition countries in Europe, Africa, Asia and Latin America. EIFL enables access to knowledge for education, learning, research and sustainable community development. Its core initiatives include open access, intellectual property rights, free and open source software for libraries, library consortia management, and negotiating affordable subscriptions to commercially produced scholarly resources. The EIfL Open Access Programme promotes the adoption of oA policies and the sustainability of open repositories. Support actions include the provision of materials and advice related to open access policies and practices as well as the organisation of trainings and events.

EIFL is a networking partner within OpenAIRE and is the regional coordinator for Region East. Several countries represented by National Open Access Desks in OpenaIRE also cooperate with EIFL as EIFL-OA country coordinator, for example Lithuania. ${ }^{253}$

Through EIFL-OA, library consortia in Eastern Europe (Estonia, Latvia, Lithuania, Poland, Serbia, Slovenia and Ukraine) were awarded small grants in 2011 to implement national and institutional oA advocacy campaigns to reach out to research communities. ${ }^{254}$ As a result of the grants, over a thousand national policy makers, research administrators, researchers, students, journal editors and publishers, and librarians attended workshops or other outreach events; educational materials in seven languages have been developed, including six short videos; new oA repositories were set up and there was an increase in research output deposited in existing $\mathrm{OA}$ repositories; and universities launched new oA publishing initiatives.

OpenAIRE's cooperation with EIFL is particularly instrumental in combining the implementation of the EC/ERC's OA policies with advocacy activities for the development and implementation of national oA policies and mandates in Eastern European countries. 


\subsubsection{SPARC Europe}

SPARC (Scholarly Publishing \& Academic Resources Coalition) Europe ${ }^{256}$ is an alliance of European research libraries, library organisations and research institutions providing a voice for the community and the support and tools in order to bring about positive change to the system of scholarly communications. Like the international SPARC organisation based in the U.S., ${ }^{257}$ SPA RC Europe aims to promote an open scholarly communication system in Europe through advocacy and education, the promotion of new models, and partnerships with all interested stakeholders. It strives to take leadership in the debate about open access, and coordinate lobbying actions within Europe for the benefit of researchers and the society at large, both in Europe and beyond.

Together with the Public Knowledge Project (PKP), sParC Europe recently initiated the PKP Europe Network, ${ }^{258}$ a network of users of the Open Journal Systems (oJs) software. This aims at enhancing information exchange about technical developments and needs, and at supporting cooperation in advocacy and training activities.

OpenAIRE is cooperating with SPARC Europe in dissemination and advocacy activities, in the development and implementation of oA policies, and in workshops and events. SPARC Europe has also expressed interest in integrating information from OpenAIRE's NOADs about OA activities in European countries into their website.

\subsubsection{Knowledge Exchange's open access working group}

Knowledge Exchange (KE) is a cooperative effort that supports the use and development of ICT infrastructure for higher education and research. ${ }^{259}$ The partners of Knowledge Exchange are Denmark's Electronic Research Library (DEFF), the German Research Foundation (DFG), Joint Information Systems Committee (JISC) in the United Kingdom and suRF foundation in the Netherlands.

In November 2008, the Knowledge Exchange Strategy Forum agreed on supporting KE activities on open access and established an open access working group. ${ }^{260}$ The group consists of expert colleagues from all four partners and outside who are willing to discuss the current state of affairs, future challenges and opportunities for future collaboration. Activities of the working group focus on the economic side of open access, licensing, ${ }^{261}$ information exchange and promoting best practices. Recent results of the 
working group include a briefing paper on "The Impact of Open Access Outside European Universities" 262 and a report entitled "Submission Fees: A Tool in the Transition to Open Access?". 263

OpenAIRE has a strong relationship with Knowledge Exchange through a number of its partners (sURF, Technical University of Denmark, University of Konstanz). The KE working groups can be used to disseminate OpenaIre's message and also to assist with technological issues (e.g. the Knowledge Exchange Usage Statistics Guidelines ${ }^{264}$ ).

\subsection{Publishers and journals}

Over the last decade, many new open access journals have been developed. Some journals have been converted from subscription to open access journals, and several major commercial and society publishers have introduced fee-based open-access options in addition to their subscription model. The EC/ERC's open access policies support both publishing in OA journals as well as using the oA options of hybrid journals, in the sense that these costs are fully eligible for funding. Similarly, other kinds of publications such as anthologies and monographs can benefit if published in open access, with costs reimbursed within the project budget. Currently, these resources can only be used within the project period. This is particularly unfortunate for outcomes that are only ready for publication at the project's completion, and for more time-intensive publications such as books.

However, the main emphasis of the EC and ERC's OA mandates is the requirement to deposit the published article or the peer-reviewed author manuscript in an OA repository (an institutional or disciplinary repository if available, otherwise the Openaire Orphan Record Repository). This section explores how publishers can (and already do) support compliance with such "green OA mandates". From a practical point of view, there are the following options:

- author self-archiving: The publisher has an OA policy that allows author self-archiving of final peer-reviewed manuscripts ('green publisher', see section 3.4) and leaves it to the discretion of the author to deposit the article.

- publisher-assisted deposit: The publisher agrees with the author to de- 
posit the article on behalf of the author in a repository of the author's choice. The conditions for such an agreement vary significantly in terms of fees, embargo periods, versions of the article, etc.

- OpenAIRE-compliant journal: The publishing platform is adapted to comply with the Opena IR E Guidelines and is registered with OpenAIRE.

It has been observed in the implementation process of funders' open access mandates that publisher-assisted deposition seems to be an effective strategy to achieve a high degree of compliance (see the Wellcome Trust in section 3.1.3).

\subsubsection{Publisher-assisted deposit}

Publisher-assisted deposit supporting authors in complying with oA mandates takes place for various kinds of journals: $\mathrm{OA}$ journals, hybrid journals as well as subscription journals. Below, we give a few examples to highlight the diversity of the landscape.

BioMed Central, a publisher of over 240 open access journals in S TM, offers Creative Commons licensing ${ }^{265}$ of published works to allow them to be distributed, used or re-used. Moreover, an automated article deposit system based on the SwORD protocol can be configured between the publisher's and the institution's repository. As soon as the official final version of an article is published in a BioMed Central journal, it will automatically be transferred to the author's institutional repository (transfers occur on a nightly basis). ${ }^{266}$ Automated Article-Deposit feeds are offered as standard, at no additional charge, to institutions with institutional memberships and to repositories hosted by BioMed Central (within the Open Repository Enhanced Customers service). BioMed Central maps articles to institutions using the same combination of affiliation information, email address stems, and institutional membership payment/discount data that is used to generate BioMed Central's institutional member pages. ${ }^{267}$

Several publishers today combine their subscription model with feebased open access options ("hybrid oA"). Elsevier was the first publisher to offer fee-based deposition on behalf of the author.

Authors of Elsevier journals retain a number of rights for author uses, including: 
the right to post a revised personal version of the text of the final journal article (to reflect changes made in the peer review process) on your personal or institutional web site or server for scholarly purposes, incorporating the complete citation and with a link to the Digital Object Identifier (DOI) of the article (but not in subject-oriented or centralized repositories or institutional repositories with mandates for systematic postings unless there is a specific agreement with the publisher). ${ }^{268}$

Some specific restricitions hold for commercial purposes and systematic distribution:

Authors of Elsevier-published articles may use them only for scholarly purposes ... and may not use or post them for commercial purposes or under policies or other mechanisms designed to aggregate and openly disseminate manuscripts or articles or to substitute for journal-provided services. This includes the use or posting of articles for commercial gain or to substitute for the services provided directly by the journal including the posting by companies of their employee-authored works for use by customers of such companies (e.g. pharmaceutical companies and physician-prescribers); commercial exploitation such as directly associating advertising with such postings; the charging of fees for document delivery or access; the systematic distribution to others via e-mail lists or list servers (to parties other than known colleagues), whether for a fee or for free; the posting of links to sponsored articles by commercial third parties including pharmaceutical companies; institutional, funding body or government manuscript posting policies or mandates that aim to aggregate and openly distribute the accepted, peer reviewed manuscripts or published journal articles authored by its researchers or funded researchers; and subject repositories that aim to aggregate and openly distribute accepted peer reviewed manuscripts or published journal articles authored by researchers in specific subject areas. (ibid.)

This clause prohibiting deposition unless there is a specific agreement seems to date back to 2008. Since June 2007, Elsevier has established a number of agreements with funding bodies such as the National Insti- 
tutes of Health and eight UK-based funders. ${ }^{269}$ The first agreement with the NIH to deposit author manuscripts on behalf of the authors reporting $\mathrm{NIH}$-funded research was introduced in 2005 based on the NIH's voluntary Public Access Policy. ${ }^{270}$ As of August 2012, the number of agreements had increased to 14 funding bodies.

The terms of the agreements differ depending on the date of public access:

- Elsevier deposits on behalf of NIH authors at no fee (to the author) and authorises public access 12 months after final publication.

- Agreement with Howard Hughes Medical Institute (нн мI), in effect since September 2007: HH MI pays a fee for publisher deposit of $\$ 1,500$ for each Elsevier article and $\$ 1,000$ for each Cell Press article. This payment allows public access via PMC six months after the publication date. ${ }^{271}$

- For deposition on behalf of the author with subsequent immediate open access, Elsevier's fee has initially been set at $\$ 3,000$ per article for all Elsevier journals except those published by Cell Press, which have a $\$ 5,000$ per article fee, and The Lancet, which will have a fee of $£ 400$ per page. This kind of agreement was established with the Cancer Research UK, the Medical Research Council (UK) and others.

Several society journals also offer deposition services. The American Society of Hematology (ASH) has implemented a policy for its hybrid journal Blood with regards to the public access policies of several research funders (including NiH, HHMI, Wellcome Trust). ${ }^{272}$ Charges for the deposition of articles on behalf of the author depend on the embargo period: there is no fee for a 12-month embargo and a public access fee of $\$ 2,000$ in addition to the regular publication fee charged to authors.

The approach of the Nature Publishing Group (NPG) will serve as a final example. NPG recently delivered a position statement ${ }^{273}$ on open access emphasising its own liberal self-archiving policy encouraging the archiving of authors' accepted version, with a release date six months after publication. This is compatible with all major funder oA policies including the EC and ERC's OA mandates. NPG also has specified liberal terms and conditions of reuse of such archived material, for example allowing data and text-mining for academic purposes and ensuring that it sits in the open access subset of UKPMC. ${ }^{274}$ 
In July 2008, NPG launched the first phase of its manuscript deposition service. This free service ${ }^{275}$ helps authors of original research articles to fulfil funder and institutional mandates. The service is currently available for:

- articles in Nature and the Nature research titles and many of the society and academic journals published by NPG;

- deposit in PubMed Central (PMC) or UKPMC - that is, for funders who have agreements with these archives.

Authors can opt in to the service during the submission process, and NPG uploads the authors' final version of the accepted manuscript on acceptance. The manuscripts are made publicly accessible six months after publication.

Moreover, NPG announces that it hopes to extend the service to other archives and repositories in the future, including institutional repositories, to help more authors to comply with institutional and funder mandates. NPG also indicates that it is proud to be the first commercial subscription publisher to announce a commitment to deposit in institutional repositories, and is in the early stages of this phase of the project.

\section{Conclusions}

Manuscript deposition combined with grant reporting (i.e. linking articles to research funders and projects) is an evolving but not widely established service. Such services are very desirable, since they help authors to comply with funder and institutional mandates while submitting articles (and other kind of publications) to the publication outlet of their choice. This is particularly valuable if the publisher offers liberal rights of use and reuse, including data and text-mining for academic research and the further dissemination of these oA author manuscripts. Imposing restrictive terms and conditions for use and re-use or charging high fees for deposition services while only providing author manuscripts does not aid researchers, their institutions nor the cause of open access.

This kind of publisher-assisted deposit services can be provided very cost efficiently if the publisher and the repository comply with interoperability standards and agree on a SWORD-based exchange of metadata and full texts. 
The inclusion of further funder and also institutional mandates into deposition services based on a distributed network of oA repositories would be very welcome. OpenAIRE will talk to various types of publishers to explore possible cooperations.

\subsubsection{OpenaIRE compliance of publishers and journals}

OpenAIRE encourages publishers to support authors in open access publishing and dissemination, alert them about the availability of publication funds, allow immediate deposition in open access repositories and - last but not least - to register their journals at the OpenAIRE website. This suitably places publishers within research infrastructures which in turn allowing the seamless integration of European and world-wide research. In principle, any publisher of journals or books, or any independent journal based on a repository with an OAI-interface could be made OpenAIRE compliant and harvested by Openaire. May 2012 was the Openaire Compliance Month for journals, in which OpenaIre gave special attention to the steps required for journals to become compliant with the OpenAIRE infrastructure, and to support and facilitate compliance with the Open Access policies of the EC and the ERC. Copernicus Publications became the first Open Access Publisher visible on Opena Ire. Copernicus and Openaire have worked together to identify publications resulting from EC-funded projects. As a result, well over 400 publications have been imported to the journals' and OpenA IRE's databases and will regularly be updated. Moreover, on submitting articles, authors can easily acknowledge EC-funding and will be alerted about the opportunity to use project funds for article processing charges. ${ }^{276}$

We are working with other publishers who are interested in supporting their authors in compliance with the EC/ERC OA policies are in particular open access publishers as well as platforms of open access journals and books. ${ }^{277}$ Several of these publishers are organized in the Open Access Scholarly Publishers Association (OASPA). ${ }^{278}$ As of late August 2012, some 20 journals are now OpenA I RE compliant.

\section{Open Journal Systems (oJs)}

Open Journal Systems (oJs) ${ }^{279}$ is an online journal management and publishing system that has been developed by the Public Knowledge Project (PKP) through its federally funded efforts to expand and improve access to 
research. It was launched in 2002 as open source software and is used by over 11,500 titles (as of August 2012), the vast majority of which are open access journals. ${ }^{280}$ Among these, there are nearly 1,000 journals in European countries.

PKP, the Freie Universität Berlin (as a development partner of PKР) and Openaire applaud ojs's compliance with the Opena IRe Guidelines, as it makes it very easy for authors and publishers of ojs journals to provide their articles to Openaire. In this case, Openaire compliance leads to the adoption of European oA policies while at the same time promoting the use of ojs journals as a platform for publishing F P 7 research results.

The Freie Universität of Berlin is currently conducting a development project in cooperation with PKP, funded by the German Research Foundation. ${ }^{281}$ The project develops various new functionalities of the ojs software, including features supporting the publication of review articles; compatibility with service providers such as the German National Library and VG Wort; and the adaption of the software for DRIVER and OpenAIRE compliance.

The ojs plug-in, released in early February $2011,{ }^{282}$ is available at the PKP Plugin Gallery. ${ }^{283}$ Releases of the OJs software from 2.3.4 onwards will include this plug-in. ${ }^{284}$ The plug-in modifies the oA Interface of the OJS software and provides a set of all publications resulting from EC/ERC project funding. OpenAIRE harvests the publications from open access repositories and journals, and presents the aggregated collection on the Openaire portal.

One possible further simplification in journals' registration process with OpenAIRE might be to integrate a specific feature into oJs, similar to what has already been established for the registration of journals in the Directory of Open Access Journals (DOAJ).

\section{Conclusions}

Several of the NOAD reported a substantial and growing number of open access journals in their countries, the majority based on ojs. Therefore, the OpenaIRE network expects to significantly benefit from the use of the ojs plug-in. 


\section{OAPEN}

The OAPEN Library, an OA publishing platform launched in October 2010, hosts a variety of academic monographs in the field of the humanities and social sciences (HSs). The project works towards integration with various library and repository services. Compliance with the DRIVER Guidelines has been taken into account during the development of OAPEN's infrastructure, and adaption to the OpenAIR E Guidelines is already under evaluation.

Expansion of the project is envisioned based on national follow-up projects, which currently include OAPEN-NL funded by the NWO and OAPENU K funded by JISC. Further national/regional projects are under development.

\section{Conclusions}

OpenAIRE compliance of book publishing platforms such as OAPEN would enhance the $\mathrm{OA}$ publishing model for the humanities and social sciences (HSS) and strengthen this academic discipline's representation in European oA policies. Moreover, it seems that the eligibility of publication costs for EU funding is currently not sufficiently transparent to authors and publishers. ${ }^{285}$ Publishers would benefit from an extension of the period for reimbursements of publishing costs, as the writing and publication of books is in general more time-intensive than journal publishing. It has to be taken into account that the majority of Hss research is carried out without any third-party funding, and therefore open access funding could be used as a steering instrument. Publication funding in Hss should therefore be more independent of project funding than in sT M fields.

\section{$4.8 \quad$ Other Stakeholders}

\subsubsection{UNESCO}

UNESCO took an early interest in the open access movement and has supported events and activities in various countries. UnEsco's programme and budget mentions the objective of open access to scientific information. And in the Geneva Plan of Action for the World Summit on the Information Society (WSIS), UNESCO has established action lines regarding access 
to information and e-science.

At UnEsco's 67th General Assembly (27-28 June 2007), the members of the German Commission for UNEsCo adopted a resolution that supports the principle of open access. The German Commission and the European Commission jointly published a handbook on open access in German ("Open Access: Chancen und Herausforderungen - ein Handbuch", 2007) and in English ("Open Access: Opportunities and Challenges - a Handbook", 2008). ${ }^{286}$ The 187 th session of the Executive Board approved UNESCO's strategy for promotion of Open Access to scientific information and research, which was also adopted by the General Conference at its 36 th session. In the framework of the overarching objective of "building inclusive knowledge societies through information and communication" ( $34 \mathrm{C} / 4$ ), the strategy focuses on policy development, capacity building, standard setting, partnerships and collaborations, and on playing the role of a clearing-house on Open Access as a forum for international cooperation, exchange of dialogue and reflection. The Open Access activities of UNESCO have been divided into the following three core areas: provision of upstream policy advice and building partnerships; strengthening capacities to adopt Open Access; and serve as a clearing-house and informing the global ox debate.

UNESCO promotes open access with particular emphasis on scientific information (journal articles, conference papers and datasets of various kinds) emanating from publicly funded research.

Working with partners, UNES CO works to improve awareness about the benefits of open access among policymakers, researchers and knowledge managers. Through its global network of field offices, institutes and centres, UNESCO facilitates the development and adoption of open-access-enabling policies. In addition, Unesco engages in global open-access debates and cooperates with local, regional and global initiatives. UNEsCO's open access programme pays particular attention to African ${ }^{287}$ and other developing countries. The Global Open Access Portal (GOAP) ${ }^{288}$, aiming at presenting a high-level snapshot of the state of open access around the world, was launched at a special side event organized during the UNESCO General Conference, on Tuesday 1 November 2011, at Paris Headquarters. Funded by the Governments of Colombia, Denmark, Norway, and the United States Department of State, GoA P highlights critical success factors and aspects of the enabling environment as well as key players, poten- 
tial barriers and opportunities. It was designed to provide the necessary information for policy-makers to learn about the global oA environment and to view their country's status, and understand where and why open access has been most successful. The portal has country reports from over 148 countries with weblinks to over 2000 initiatives/projects in Member States. ${ }^{289}$ The portal is supported by an existing Community of Practice (CoP) on Open Access on the wsis Knowledge Communities Platform that has over 1400 members. ${ }^{290}$

UNESCO has also released "Policy guidelines for the development and promotion of open access" 291 to demystify the concept of open access and to provide concrete steps on putting relevant policies in place and to promote open access in Member States. Written by Dr. Alma Swan, the draft went through an open consultation and peer review at the Open Access Community in the wsis Knowledge Communities.

In the Director-General's regional consultation on the preparation of the draft programme and budget for 2012-2013, the importance of open access is highlighted: ${ }^{292}$

21. Taking into account current global challenges Mrs Bokova emphasised that despite changing realities the need for UNESCO still remains-to mobilise international solidarity, to secure inclusive quality lifelong learning for all, to promote open access and dialogue within sciences to ensure that sciences serve the development of humanity, to establish culture at the heart of development, and to promote freedom of expression to ensure diversity. Yet more needs to be done to increase the visibility of its work and ideals at the national, regional and global level by including more partners in its actions and enhancing cooperation with our global strategic partners UNDP, EU, and all others.

44. The two highest priorities agreed for communication and information are: Freedom of expression, press freedom, safeguarding and developing pluralistic and independent media; and open and permanent access to and freedom of information. The delegates stressed that the issue of open access is a major global challenge, closely linked to development, human rights and democracy, in which UNEsco must better define its role and apply a clear intersectoral approach. Access to documentary heritage via, for example, the Memory of the 
World Programme, and by ensuring the digitalization and preservation of archives and cultural heritage, is an important UNESCO activity. It also plays a key role in UNESCO's visibility and is an important tool for the other programmes.

Moreover, several national commissions for UNESCo have recently addressed the theme of open access:

- Sweden: Open access to research and knowledge - are all winners?, 21 October 2010, Stockholm.

- Denmark: Conference on Open Access - Global and Danish Challenges, 6 December 2010, held in Copenhagen, to discuss international and development aspects of open access to research results. ${ }^{293}$

- The Netherlands: Expert meeting entitled A Global Perspective on Open Access held in Amsterdam, 20 January 2011. 294

- Belarus: Regional Consultation on "Open Access to Scientific Information and Research - Concept and Policies" in Minsk, Belarus, from 5 to 7 September 2012; to discuss the Open Access Policy of the countries of Eastern and Central Europe and the Baltic States; some Eastern European NOADS will be contributing to this event.

\section{Conclusions}

OpenAIRE will establish further contacts with UNESCo to explore how UNESCO might support the implementation process of oA policies. In addition, OpenaIre will look into which areas UnEsCo's and the EC/ERC's open access policies reinforce each other.

\subsubsection{Disciplinary scholarly societies}

In some fields, scholarly societies and their journals and events are crucial for facilitating communication between researchers, research managers and policymakers. Not all of these scholarly societies embrace open access for their journals, as their business models are often based on membership or subscription fees. However, several scholarly societies have modified their policies based on funders' $O A$ mandates and do deposit articles on behalf of authors.

To inform and actively involve societies in the implementation of the EC and ERC's OA policies, OpenA IRE will identify scholarly societies and 
their associations where Ec funding is important. There are several European societies that are active in fields that are of relevance to European OA policies:

- geosciences: the European Geosciences Union (E GU) 295

- mathematics: the European Mathematical Society (E Ms). ${ }^{296}$

- life sciences: the Federation of European Biochemical Societies (FEBS). ${ }^{297}$

- ICT: ICT societies, the Council of European Professional Informatics Societies. ${ }^{298}$

\section{Conclusions}

In the months ahead, OpenAIRE will seek to establish contacts with these scholarly societies to explore possible forms of collaboration. The societies could for their part support OpenA IRE in identifying researchers with an obligation to the EC/ERC's OA policies and informing them about this obligation.

\subsubsection{Younger researchers}

OpenAIRE aims to establish a mode of cooperation with associations of $\mathrm{PhD}$ students and younger researchers in order to promote the concept of open access and inform these next-generation researchers about European OA policies.

\section{EURODOC}

The European Council of Doctoral Candidates and Junior Researchers (Eurodoc) ${ }^{299}$ is an international federation of 34 national organisations of $\mathrm{PhD}$ candidates. It represents young researchers from 33 countries of the European Union and the Council of Europe.

Eurodoc's objectives are to:

- represent doctoral candidates and junior researchers at the European level in matters of education, research and professional development of their careers;

- advance the quality of doctoral programmes and the standards of research activity in Europe;

- promote the circulation of information on issues regarding young re- 
searchers; organise events, take part in debates and assist in the elaboration of policies on higher education and research in Europe;

- establish and promote cooperation between national associations representing doctoral candidates and junior researchers within Europe.

Eurodoc shares the vision that open access provides the means to improve access to the results of research and thus improves the impact of research. Open access and open science has been on the agenda of workshops and meetings for several years. In 2009, Eurodoc and DRIVER signed a memorandum of understanding about their cooperation. ${ }^{300}$

OpenAIRE is in contact with Eurodoc to establish cooperative ties. OpenAIRE's aims and activities have been presented at the Eurodoc Annual Conference, held in Vilnius, Lithuania at the end of March 2011.

\section{IFMSA}

On 19 January 2011, the International Federation of Medical Students' Associations (IF MSA) ${ }^{301}$ announced its membership in the Right to Research Coalition, ${ }^{302}$ an international alliance of undergraduate and graduate student organisations that promotes a more open scholarly publishing system through advocacy and education. ${ }^{303}$ Based in Amsterdam, IF MSA is one of the world's leading student organisations, representing over 1.2 million medical students all over the world. In 2012, I F MSA consists of national medical student associations in 104 countries on six continents. Starting from January 2011, IFMSA began promoting a more open scholarly publishing system by educating students about open access and advocating for policies that expand access to the results of research.

Initial contacts between OpenAIRE and IF MSA have already been established, and concrete plans are being devised for cooperation between OpenAIRE and national members of IF MSA.

\section{Conclusions}

OpenAIRE has a strong interest in establishing relations with organisations of younger researchers, who can serve as instruments of dissemination for informing researchers about the general benefits of open access and the oA policies in European countries. Methods of research are also changing, including the way scientists interact with research output. Keeping an eye on these developments is an important task of the OpenaIre community. 


\subsubsection{Food and Agriculture Organization}

One of the main activities of the Food and Agriculture Organization of the United Nations (FAO) ${ }^{304}$ is to collect, analyse, interpret and disseminate information related to agriculture. The FAO's website receives millions of visits per months, and the organisation has more than 50 years of experience in the production and diffusion of information. With the aim of facilitating access to information, FAO has been an early implementer of many pioneering systems in the field of document management. It has, for example, created: ${ }^{305}$

- an online catalogue for documents produced by FAO (FAODOC), which contains bibliographic metadata of electronic and printed documents produced by FAO since 1945;

- the Corporate Document Repository (CDR), a corporate output interface for FAO's full-text electronic publications and minimal metadata associated; and

- the Electronic Information Management System (EI MS), a workflow management tool and database that manages the publication of electronic documents and multimedia resources on FAO's website.

Currently, FAO is creating the FAO Open Archive (FAO OA), which merges the CDR-EIMS and the FAODOC.

FAO also collaborates in the creation of various repositories and repository federations, including the OceanDocs Network and the Virtual Open Access Agriculture \& Aquaculture Repository (VOA 3 R). ${ }^{306}$

In July 2010,307 FAO and UNESCO-IOC/IODE ${ }^{308}$ (both United Nations agencies) announced a joint initiative to provide AgriOceans DSpace, a customised version of DSpace using standards and controlled vocabularies in oceanography, marine science, food, agriculture, development, fisheries, forestry, natural resources and related sciences. The communities supported by FAO and UNESCO-IOC/IODE are synergistic, and the standards on metadata and controlled vocabularies are similar for both. The Hasselt University Library and the Institute of Biology of the Southern Seas (Ukraine) provided the customization of Dspace 1.7.1 (JSPUI version) which is now available in source code and as an easy-to-install version. FAO provided high quality metadata - Dublin Core, AGRIS AP and MODS - to be OAI-PMH compliant. This is matched by an AgriOcean 
DSpace community to exchange information and experiences among the involved institution. ${ }^{309}$

The collaboration between FAO and UNESCO-IOC/IODE has the following goals:

- promoting open access to scientific information on the topics of food, agriculture, development, fisheries, forestry, natural resources and related sciences for FAO and oceanography and marine sciences for UNESCO-IOC/IODE;

- ensuring the metadata quality of repositories and the use of thesauri and other forms of authority control;

- contributing to the development of sustainable repositories by the use of tools to make scientific publications (and later data) more accessible and visible; and

- removing access barriers by encouraging the creation of new service providers based on existing and mature metadata and semantics technology.

\section{Conclusions}

Collaboration with international organisations specialised in a subject area can help OpenAIRE to reach out to research communities and to enhance access to EC-funded research.

\subsubsection{General public}

Broad access to publicly-funded research benefits small and medium enterprises (SME), school teachers and learners, individuals and their families (as taxpayers and laymen), as well as emerging and developing economies, as these in general do not have access to licensed journals. ${ }^{310}$ For these groups and purposes, open access licences allowing a wide range of use and re-uses are therefore particularly valuable. Of interest to the general public are, for example, the grand challenges of climate change, the environment, biodiversity and public health.

Research funders and governments have a strong interest in developing efficient scientific information systems that maximise the impact of public investments in research. Improving the linkages between research and society should thus be a key strategic aim. 
At the launch of OpenA IRE in December 2010, European Commission Vice-President Neelie Kroes, responsible for the Digital Agenda, stated: "The launch of OpenAIRE marks a very concrete step towards sharing the results of EU-funded research to our mutual benefit. Scientific information has the power to transform our lives for the better-it is too valuable to be locked away. In addition, every $\mathrm{E} \mathrm{U}$ citizen has the right to access and benefit from knowledge produced using public funds." ${ }^{311}$

Máire Geoghegan-Quinn, Commissioner for Research, Innovation and Science, added her comments: "Scientists need access to research results if they are to maximise the potential of further work in the same areas. Industry, not least SMEs, need to know where to find research results if they are to build on them to create jobs and improve the quality of life." (ibid.)

The importance of access to information is also emphasised in the goals of the European Commission's Digital Agenda ${ }^{312}$ and the key elements of its Innovation Union. ${ }^{313}$

After the launch event of OpenAIRE, wide interest of private companies, in particular related to ICT, health and environment issues has been observed in the media and social networks.

The Ghent Declaration, ${ }^{314}$ an initiative of the reviewers of the OpenAIRE project, was submitted to Vice-President Kroes and Commissioner Geoghegan-Quinn in early January 2011. The Ghent Declaration invites the Commission to take up the current opportunities for increasing the circulation of knowledge beyond the aims of the OpenaIre initiative. It encourages a move beyond open access to research and scholarship towards the creation and use of open data, open source software and open educational resources. The declaration was written in the context of OpenAIRE's launch event and its first-year review held on 2-3 December 2011, in Ghent, Belgium. OpenAIRE and its partners have welcomed this declaration and will undertake all efforts to support the full deposit of articles according to the $\mathrm{OA}$ mandate.

Access to these resources of knowledge has a great potential for enhancing European society and strengthening Europe's global competitiveness. Since then access to research data is playing a more prominent role. On 17 July 2012 when the EC announced the new measures for Horizon 2020, the EU's Research \& Innovation funding programme for 2014-2020, to improve access to scientific information produced in Europe. ${ }^{315}$ Broader and more rapid access to scientific papers and data will make it easier for re- 
searchers and businesses to build on the findings of public-funded research. This is expected to boost Europe's innovation capacity and give citizens quicker access to the benefits of scientific discoveries.

Neelie Kroes, European Commission Vice-President for the Digital Agenda, said: "Taxpayers should not have to pay twice for scientific research and they need seamless access to raw data. We want to bring dissemination and exploitation of scientific research results to the next level. Data is the new oil."

Máire Geoghegan-Quinn, European Commissioner for Research and Innovation, said: "We must give taxpayers more bang for their buck. Open access to scientific papers and data will speed up important breakthroughs by our researchers and businesses, boosting knowledge and competitiveness in Europe."

\section{Conclusions}

Openaire will continue to disseminate its achievements and results through the media and social information networks. Awareness of oA and its benefits by the general public is crucial for the implementation of existing and future ox policies of the European Commission and the European Research Council, and for promoting the idea of open science and free access to all publicly funded scientific information. 



\section{Conclusions and Roadmap}

Since the start of the European Commission's Open Access Pilot in August 2008 the number of open access mandates worldwide increased significantly-by some $400 \%$. Overall with the number of open access mandates nearly doubled among research funders and nine times higher among institutions. Some universities, research organisations and funders have reevaluated their open access policies and demonstrated considerably improved compliance rates for open access mandates that have been in place for some time already.

In European countries, there are robust regional and national networks of open access advocates representing libraries and some research discipline communities. More than half of the EU member countries have already established a national repository infrastructure. In other countries, the FP7 OA Pilot has sparked discussions about funders' open access policies and national research infrastructures (e.g. in Bulgaria, Estonia and Slovenia).

OpenaIRE's network of National Open Access Desks (NOADs) provides support to institutions in implementing the Ec's Open Access Pilot and the ERC's Guidelines on Open Access, in building synergies with institutional open access policies, and in making repositories and open access journals OpenaIre compliant. Among Opena IRE's outreach and dissemination strategies, the OpenAIRE project partners highlighted a number of success factors such as: 1) early outreach to researchers (i.e. when the FP7funded project is launched), 2) active involvement of the FP7 National Contact Points, 3) personal interaction with repository managers, and 4) sharing success stories to encourage new developments. Nevertheless, there are still two areas that need to be tackled in the coming months and years: 1) the effective promotion of open access among all research communities, and 2) support in copyright management for researchers and research institutions.

To achieve these goals, the OpenA IR E project cooperates with other Eu- 
ropean and international oA projects, initiatives and organisations, thereby ensuring that synergies are realised.

\section{Openaire Project Roadmap}

\section{Year 1}

- Kickoff Meeting

- Development of network of NOADs

- Development of Opena IRe portal and helpdesk

- Development of central and national communication strategies

- First contacts with EC programme coordinators, NCPS, research administrators/managers, project coordinators

- Outreach to national oA and library community

- Development of handouts and guides ("toolkits") for NOADs, researchers and institutions; start of integration into the OpenAIRE portal

- First training activities

\section{Year 2}

- First General Assembly with reports about implementation activities and recent oA developments

- Openaire Launch Event

- Update of dissemination strategies targeted towards FP7 project managers, researchers and research institutions receiving $\mathrm{F} P 7$ funding

- Integration and update of handouts and guidelines ('toolkits') for researchers and institutions into the OpenAIRE portal

- Development of sustainability strategy

- Outreach activities addressing all relevant stakeholders

- Further development of support and training activities

- Launch of Openaireplus

\section{Year 3}

- Second General Assembly

- Update of dissemination strategy

- Agreements with stakeholders (publishers, scholarly societies, etc.)

- Further development of support and training activities

- Implementation of sustainability strategy

- Openaire Public Event 


\section{References}

\section{1 $\quad$ Articles and reports}

[1] Anglada, L.; Abadal, E. (2010). Open access in Southern European countries, FecYT, Madrid 2010, http://oaseminar.fecyt.es/ Publico/report/index.aspx [accessed 2012-08-14]

[2] Armbruster, C. (2010). Implementing Open Access: Policy Case Studies, 14 October 2010, http://ssrn.com/abstract $=1927772$ [accessed 2012-08-14]

[3] Björk, B.-C.; Welling, P.; Laakso, M.; Majlender, P.; Hedlund, T.; Gudnasson, G. (2010). Open Access to the Scientific Journal Literature: Situation 2009, PloS One, 23.6.2010, http://dx.doi.org/ 10.1371/journal.pone.0011273 [accessed 2012-08-14]

[4] Crummet, C. et al. (2010): Publishing Practices of NIH-Funded Faculty at MIT, Issues in Science and Technology Librarianship, No. 62, Summer 2010, http://www.istl.org/10-summer/refereed 2.html [accessed 2012-08-14]

[5] Dallmeier-Tiessen, S.; Goerner, B.; Darby, R.; Hyppoelae, J.; IgoKemenes, P.; Kahn, D.; Lambert, S.; Lengenfelder, A.; Leonard, C.; Mele, S.; Polydoratou, P.; Ross, D.; Ruiz-Perez, S.; Schimmer, R.; Swaisland, M.; van der Stelt, W. (2010). First results of the SOAP project. Open access publishing in 2010, 14 September 2010, http://arxiv.org/pdf/1010.0506 [accessed 2012-08-14]

[6] Duke \& Jordan Ltd (2009). Evaluation of Nordbib, Final Report for the Board, Undertaken on behalf of the partner organisations, June 2009, http://www.nordbib.net/Initiatives-Reports/Evaluation.aspx [accessed 2012-08-14]

[7] EC/Unesco (2008). Open Access: Opportunities and challenges - A handbook by the European Commission and the German Commission for UnESCO, 2008, translated from the original German edition published by the German Commission for 
UNESCO, http://EC.europa.Eu/research/science-society/document_library/pdf_o6/open-access-handbook_en.pdf, doi:[accessed 2012-08-14]

[8] Edgar, B. D.; Willinsky, J. (2010). A Survey of Scholarly Journals Using Open Journal Systems, Scholarly and Research Communication, Vol 1, No 2 (2010), http://src-online.ca/index.php/src/ article/view/24/41 [accessed 2012-08-14]

[9] Epner, H. (2009). Open Access and a University Library, ScieCom Info 1 (2009), http://nile.lub.lu.se/ojs/index.php/sciecominfo/article/viewFile/1509/1244 [accessed 2012-08-14]

[10] European Commission (2011): National open access and preservation policies in Europe - Analysis of a questionnaire to the $\mathrm{Eu}-$ ropean Research Area Committee, Luxembourg: Publications Office of the European Union, doi:10.2777/74027, http://EC.europa.Eu/research/science-society/document_library/pdf_o6/ open-access-report-2011_en.pdf [accessed 2012-08-31]

[11] European Commission (2012): Open access in F P7, Luxembourg: Publications Office of the European Union, doi:10.2777/81083, http://EC.europa.E U/research/science-society/document_library/pdf_06/survey-on-open-access-inFP7_en.pdf [accessed 2012-08-31]

[12] European Commission (2012): Online survey on scientific information in the digital age, Luxembourg: Publications Office of the European Union, doi:10.2777/7549, http://EC.europa.EU/research/science-society/document_library/pdf_o6/survey-onscientific-information-digital-age_en.pdf [accessed 2012-0831]

[13] European Research Council (2012). Open Access Status of Journal Articles from ERC Funded Projects, Brussels, http://E RC.europa.Eu/sites/default/files/document/file/open_access_study_s tatus_journal_articles_ERC_funded_projects.pdf [accessed 2012-08-31]

[14] Ferreira, M.; Rodrigues, E.; Baptista, A.A.; Saraiva, R. (2008). Carrots and Sticks: Some Ideas on How to Create a Successful Institutional Repository, D-Lib Magazine 1/2, http://www.dlib. org/dlib/januaryo8/ferreira/o fferreira.html [accessed 2012-0814] 
[15] Finch Group report (2012): Accessibility, sustainability, excellence: how to expand access to research publications, Report of the Working Group on Expanding Access to Published Research Findings, June 2012, http://www.researchinfonet.org/ wp-content/uploads/2012/06/Finch-Group-report-FINALVERSION.pdf [accessed 2012-08-30]

[16] Frantsvåg, J.E. (2010). The University of Tromsø adopts an institutional Open Access policy, ScieCom Info 4 (2010), http://www.sciecom.org/ojs/index.php/sciecominfo/article/vie wFile/4764/4325 [accessed 2012-08-14]

[17] Friend, F. (2010). The Impact of Open Access Outside European Universities, Knowledge Exchange Briefing Paper, October 2010, http://www.knowledge-exchange.info/Default.aspx?ID= 412 [accessed 2012-08-14]

[18] Van der Graaf, M.; Van Eijndhoven, K. (2008). The European Repository Landscape: Inventory study into present type and level of OAI compliant Digital Repository activities in the EU, Amsterdam University Press, Amsterdam 2008, http://dare.uva.nl/aup/en/record/260225 [accessed 2012-0814]

[19] Hebrang Grgić, I. (2011). Open Access to Scientific Information in Croatia Increasing Research Impact of a Scientifically Peripheral Country. Lambert Academic Publishing: Saarbrücken, Germany, author manuscript available at http://darhiv.ffzg.hr/1397/ 1/Hebrang_Grgic_ffzg.pdf [accessed 2012-08-31]

[20] Hedlund, T.; Rabow, I. (2007). Open Access in the Nordic Countries: State of the Art Report \& Workshop Views and Recommendations, Commissioned by The Nordbib Programme, 2007, http://www.nordbib.net/Initiatives-Reports/Reports/oA-inthe-Nordic-countries.aspx [accessed 2012-08-14]

[21] IFLA (2010): IFLA World Report 2010, Editor: Bothma, T.JD. IfLA/faife World Report Series, Vol. vili, August 2010, http://www.ifla-world-report.org/files/uploaded/ifla_wr/IFLAWR-2010-Analysis-and-Conclusions.pdf [accessed 2012-0814]

[22] Kempf, J.; Adema, J.; Rutten, P. (2010). Report on Best Practices and Recommendations, OAPEN 2010, http://project.oapen.org/ 
images/documents/d316_oapen_best_practice_public_report.pdf [accessed 2012-08-14]

[23] Kretaviciene, M. (2008). Open Access in the Baltic countries, ScieCom Info 1 (2008), http://www.sciecom.org/ojs/index.php/ sciecominfo/article/viewFile/241/9o [accessed 2012-08-14]

[24] Kuprienè, J.; Petrauskienė, Ž. (2009). Open access to scientific publications: the situation in Lithuania, ScieCom Info 2 (2009), http://www.sciecom.org/ojs/index.php/sciecominfo/article/vie wFile/1625/1315 [accessed 2012-08-14]

[25] Lossau, N. (2012). An overview of research infrastructures in Europe - and recommendations to LIBER. LIBER Quarterly 21 (3/4), April 2012, http://liber.library.uu.nl/index.php/lq/article/view/8028_[accessed 2012-08-31]

[26] McEntyre, J. et al. (2010). U KPMC: a full text article resource for the life sciences, Nucleic Acids Research Vol. 39, Issue suppl. 1 (2011), First published online: November 2010, http://nar.oxfordjournals.org/content/39/suppl_1/D58 [accessed 2012-0814]

[27] Meier zu Verl, C.; Horstmann, W. (Eds.) (2011). Studies on Subject-Specific Requirements for Open Access Infrastructure.

Bielefeld: Universitätsbibliothek, D oI: http://dx.doi.org/10.239o/РUB-2011-1 [accessed 2012-08-31]

[28] Nicolai, C.; Subirats, I.; Katz, S. (2007). The fao Open Archive: Enhancing Access to FAO Publications Using International Standards and Exchange Protocols, Proceedings ELPU B 2007 Conference on Electronic Publishing, Vienna, Austria, June 2007, http://www.fao.org/fileadmin/templates/oek/Doc/FAO_Open_ Archive.pdf [accessed 2012-08-14]

[29] NISO-RP-8-2008: Journal Article Versions (JAV): Recommendations of the NISO/A LPSP JAV Technical Working Group, National Information Standards Organization, Baltimore, April 2008, http://www.niso.org/publications/rp/R P-8-2008.pdf [accessed 2012-08-14]

[30] Rabow, I. (2009): The Status of IR/CR IS in the Nordic Countries. Report commissioned by the NordBib programme. June 2009, Rev. October 2009, http://www.nordbib.net/Initiatives-Reports/Reports/CRIS-status.aspx [accessed 2012-08-14] 
[31] Rettberg, N.; Schmidt, B. (2012): OpenaIRE - Building a collaborative Open access infrastructure for European researchers, LIBER Quarterly 22(3).

[32] RIN (2010): Research Support Services in U K Universities, A Research Information Network Report, October 2010, http://rinarchive.jisc-collections.ac.uk/our-work/using-and-accessing-information-resources/research-support-services-what-servicesdo-resear [accessed 2012-08-14]

[33] Sale, A. (2006). The acquisition of open access research articles, First Monday 11(10), October 2006, http://firstmonday.org/htbin/cgiwrap/bin/ojs/index.php/fm/article/view/1409/1327 [accessed 2012-08-14]

[34] Sale, A. (2007). The Patchwork Mandate, D-Lib Magazine 13(1/2), January/February 2007, http://www.dlib.org/dlib/january07/sale/o1sale.html [accessed 2012-08-14]

[35] Swan, Alma (2012): Open Access Policy Guidelines for the Development and Promotion of Open Access, UNESCO, Paris, http://unesdoc.unesco.org/images/0021/002158/215863e.pdf [accessed 2012-08-15]

[36] Stojanovski, J. (2012). Supporting Open Access nationwide, The Fifth Belgrade International Open Access Conference Proceedings / Šipka, Pero (ur.). Beograd, http://bib.irb.hr/prikazi$\mathrm{rad}$ ? \&rad=591272 [accessed 2012-09-03]

[37] Thorsteinsdóttir, S. (2010). OA Mandates and the Nordic Countries, ScieCom Info 1 (2010), http://www.sciecom.org/ojs/index.php/sciecominfo/article/viewFile/3548/3127 [accessed 2012-08-14]

[38] Wallace, J.; Armbruster, C. (2010). Peer Annual Report - Year 2, September 1st 2009 (M12) - August 31st 2010 (M23), Deliverable D9.8, 30 September 2010, http://www.peerproject.Eu/fileadmin/media/reports/D9_8_annual_public_report_20100930.pdf [accessed 2012-08-14]

[39] Wallace, J. (2012) PEER Final Report - 1 September 2008- 31 May 2012, Deliverable D9.13, 18 June 2012 http://www.peerproject.Eu/fileadmin/media/reports/20120618_PEER_Final_public_report_D9-13.pdf [accessed 2012-08-16]

[40] Marc Ware Consulting (2010): Submission Fees - A tool in the 
transition to open access? Summary of Report to Knowledge Exchange, March 2010, http://www.knowledge-exchange.info/Default.aspx?ID=413 [accessed 2012-08-14]

[41] Zuccala, A. (2010). Open access and civic scientific information literacy, Vol. 15, No. 1, March 2010, http://informationr.net/ir/ 15-1/paper426.html [accessed 2012-08-14]

\subsection{Databases}

[42] DOAJ - Directory of Open Access Journals, http://www.doaj.org [accessed 2012-08-14]

[43] OpendoAR - Directory of Open Access Repositories, http://www.opendoar.org [accessed 2012-08-14]

[44] MELIBEA - Directorio y estimador de políticas en favor del acceso abierto a la producción científica, http://www.accesoabierto.net/politicas/ [accessed 2012-08-14]

[45] ROAR - Registry of Open Access Repositories, http://roar.eprints.org [accessed 2012-08-14]

[46] ROARMAP - Registry of Open Access Repository Material Archiving Policies, http://www.eprints.org/openaccess/policysignup/ [accessed 2012-08-14]

[47] SHERPA/JULIET - Research funders' open access policies, http://www.sherpa.ac.uk/juliet/ [accessed 2012-08-14]

[48] SHERPA/ROMEO - Publisher copyright policies \& self-archiving, http://www.sherpa.ac.uk/romeo/ [accessed 2012-08-14]

\subsection{Policies and Declarations}

[49] Alhambra Declaration (2010): Open Access to Scientific Information: Policies for the development of oA in South European countries, Alhambra declaration on OA, 14 May 2010, http://oaseminar.fecyt.es/Publico/AlhambraDeclaration/index.aspx [accessed 2012-08-14]

[50] Berlin Declaration (2003): Berlin Declaration on Open Access to Knowledge in the Sciences and Humanities, 22 October 2003, 
http://oA.mpg.de/lang/en-uk/berlin-prozess/berliner-erklarung/ [accessed 2012-08-14]

[51] The Digita L Library of Slovenia development strategy - dLib.si 2007-2010, Ljubljana: National and University Library 2007, prepared by Ambrožič, Melita et al., http://www.dlib.si/v2/documents/pdf/strategy_dks.pdf [accessed 2011-02-28]

[52] Dublin Institute of Technology: Open Access Self-Archiving Policy, 1 January 2010, http://arrow.dit.ie/mandate.html [accessed 2012-08-14]

[53] ERC (2008): European Research Council: ERC Scientific Council Guidelines for Open Access, 17 December 2007, includes as Appendix: ERC Scientific Council Statement on Open Access (December 2006), http://ERC.europa.eu/sites/default/files/document/file/ERC_scc_guidelines_open_access.pdf [accessed 2012-08-14] (see Appendix 1)

[54] EUA (2008): Recommendations from the EUA Working Group on Open Access adopted by the EUA Council on 26th of March 2008, University of Barcelona, Spain, http://www.EUA.be/Libraries/Page_files/Recommendations_Open_Access_adopted_by_the_EUA_Council_on_26th_of_March_2008_final_1.s flb.ashx [accessed 2012-08-14]

[55] Eura B (2006): eura B 06.049, Scientific Publication: Policy on Open access, European Research Advisory Board, Final Report, December 2006, http://Ec.europa.Eu/research/eurab/pdf/eurab_scipub_report_recomm_deco6_en.pdf [accessed 2012-0814]

[56] EUROHORCS (2008): EUROHORCS' Recommendations on Open Access (OA), April 2008, http://www.euroh OrCs.org/SiteCollectionDocuments/EUROHORCs_Recommendations_OpenAccess_200805.pdf [accessed 2012-08-14]

[57] EUROHORCS/ESF (2009): EUROHORCS and ESF Vision on a Globally Competitive ERA, and their Road Map for Actions, July 2009, http://www.EUROHORCs.org/SiteCollectionDocuments/ESF_Road\%20Map_long_0907.pdf [accessed 2012-0814]

[58] FW F: Open Access Policy bei FWF-Projekten, http://www.fwf.ac.at/de/public_relations/oai/index.html; Press 
Release of 6 March 2008, http://www.fwf.ac.at/de/public_relations/press/pa20080306.html [accessed 2012-08-14]

[59] Ghent Declaration (2011): Gregor Hagedorn, Gregor; Friend, Frederick; Guédon, Jean-Claude; Willinsky, John: Seizing the Opportunity for Open Access to European Research: The Ghent Declaration Initiated by the Reviewers of the EC OpenAIRE Project, January 2011, http://www.openaire.e U/en/home/76highlights/223-seizing-the-opportunity-for-open-access-to-european-research-ghent-declaration-published [accessed 2012o8-14]

[60] Ifremer: Obligation de dépôt de la documentation Ifremer dans Archimer, September 2010, http://archimer.ifremer.fr/depot.htm [accessed 2012-08-14]

[61] LERU (2010): The LERU Roadmap towards Open Access, October 2010, Leuven, Belgium, http://www.LERU.org/files/meetings/RA_19_02_LERU_Roadmap.pdf [accessed 2012-08-14]

[62] Roskilde University: Digitaliserings- og arkiveringspolitik for Roskilde Universitetscenter, Roskilde, 25 September 2008, http://rudar.ruc.dk/handle/180o/5149 [accessed 2012-08-14]

[63] Research Councils u k Policy on Access to Research Outputs, 17 July 2012, http://www.rcuk.ac.uk/documents/documents/ RCUK\%20_Policy_on_Access_to_Research_Outputs.pdf [accessed 2012-08-30]

[64] Schweizer Nationalfonds zur Förderung der wissenschaftlichen Forschung (SNF): Reglement über die Information, die Valorisierung und die Rechte an Forschungsresultaten, Bern, 17 June 2008, http://www.snf.ch/SiteCollectionDocuments/allg_ reglement_valorisierung_d.pdf [accessed 2012-08-14]

[65] Trinity College Dublin: Trinity College Dublin Open Access Publications Policy, Dublin, 18 October 2010, http://www.tcd.ie/research_innovation/assets/TCD\%20Open\% 20Access\%2oPolicy.pdf [accessed 2012-08-14]

[66] University of Tromsø: Universitetet i Tromsøs prinsipper for Open Access publisering, Tromsø, 14 October 2010, http://www.ub.uit.no/wiki/openaccess/images/o/05/UiT_prinsipper_for_Open_access.pdf [accessed 2012-08-14]

[67] U K Research Council Policy on Access to Research Outputs, 17 
July 2012, http://www.rcuk.ac.uk/research/Pages/outputs.aspx/ [accessed 2012-08-16]

\subsection{Presentations}

[68] Cochrane, T. (2010). Open access - The advantage for the library in the university of a successfull open access Policy, IFLA Satellite Conference "Open access and the Changing Role of Libraries", 9 August 2010, Gothenburg, http://www.kb.se/Dokument/Aktuellt/utbildning/ifla\%200A\%202010/Cochrane_IFLA \%20Conf\%2oAugust\%202010\%20-\%20T\%20Cochrane.pdf [accessed 2012-08-14]

[69] Frantsvåg, J.E. (2010). EU and Open Access: The Opena IR E project, 5 th Munin Conference on scientific publishing: Open Access - The Competitive Advantage, 25 November 2010, http://www.ub.uit.no/baser/ocs/index.php/Munin/MC5/paper/view/2 [accessed 2012-08-14]

[70] Kiley, R. (2010). Open access at the Wellcome Trust: Five years on, Berlin 8 Open Access Conference, Beijing, China, 25 October 2010, http://www.berlin8.org/userfiles/file/berlin8_kiley_ oct_10.pdf [accessed 2012-08-14]

[71] Miszori, K. (2010). How to build an institutional repository? Practical guide from a special library, If L A Satellite Pre-conference "Open Access to Science Information. Trends, Models and Strategies for Libraries", 6-8 August 2010,Chania, Crete, Greece

[72] Tautkeviciene, G. (2010). Open access in national laws - Lithuania, presentation at the EIf L General Assembly, 6 August 2010, Lund, Sweden, www.eifl.net/system/files/201101/oA_lithuania_ga_v1.ppt [accessed 2012-08-14]

[73] Werla, M. (2010). Open science resources in Poland - selected projects and initiative, European co-operation, V Conference Е В I B - Internet in Libraries, Second International Conference on Open Access in Poland, Torun University Library, 14-15 January 2010, http://www.ebib.info/publikacje/matkonf/mat21/index.php [accessed 2012-08-14] 



\section{$7 \quad$ Annex 1: European Policies on Open Access}

\subsection{ERC Scientific Council Guidelines for Open Access (17 December 2007)}

1. Scientific research is generating vast, ever increasing quantities of information, including primary data, data structured and integrated into databases, and scientific publications. In the age of the Internet, free and efficient access to information, including scientific publications and original data, will be the key for sustained progress.

2. Peer-review is of fundamental importance in ensuring the certification and dissemination of high-quality scientific research. Policies towards access to peer reviewed scientific publications must guarantee the ability of the system to continue to deliver high-quality certification services based on scientific integrity.

3. Access to unprocessed data is needed not only for independent verification of results but, more importantly, for secure preservation and fresh analysis and utilisation of the data.

4. A number of freely accessible repositories and curated databases for publications and data already exist serving researchers in the EU. Over 400 research repositories are run by European research institutions and several fields of scientific research have their own international discipline-specific repositories.

These include for example PubMed Central for peer-reviewed publications in the life sciences and medicine, the arXiv Internet preprint archive for physics and mathematics, the DDBJ/EMBL/GenBank nucleotide sequence database and the RSCB-PDB/MSD-EBI/PDBj protein structure database.

5. With few exceptions, the social sciences \& humanities ( $\mathrm{sSH}$ ) do not yet have the benefit of public central repositories for their recent journal publications. The importance of open access to primary data, old manuscripts, collections and archives is even more acute for ss $\mathrm{H}$. In the social sciences 
many primary or secondary data, such as social survey data and statistical data, exist in the public domain, but usually at national level. In the case of the humanities, open access to primary sources (such as archives, manuscripts and collections) is often hindered by private (or even public or nation-state) ownership which permits access either on a highly selective basis or not at all.

Based on these considerations, and following up on its earlier Statement on Open Access (Appendix 1) the ERC Scientific Council has established the following interim position on open access:

1. The ERC requires that all peer-reviewed publications from ERC-funded research projects be deposited on publication into an appropriate research repository where available, such as PubMed Central, ArXiv or an institutional repository, and subsequently made Open Access within 6 months of publication.

2. The ERC considers essential that primary data - which in the life sciences for example could comprise data such as nucleotide/protein sequences, macromolecular atomic coordinates and anonymized epidemiological data - are deposited to the relevant databases as soon as possible, preferably immediately after publication and in any case not later than 6 months after the date of publication.

The ERC is keenly aware of the desirability to shorten the period between publication and open access beyond the currently accepted standard of 6 months.

\section{Appendix 1: ERC Scientific Council Statement on Open Access (December 2006) ${ }^{316}$}

1. The ERC Scientific Council stresses the fundamental importance of peer-reviewed journals in ensuring the certification and dissemination of high-quality scientific research and in guiding appropriate allocation of research funds. Policies towards access to scientific research must guarantee the ability of the system to continue to deliver high-quality certification services.

2. While the certification quality of the scientific publication system is not in doubt, the high prices of some journals - which do not seem to be 
chiefly driven by cost considerations - raise significant worries concerning the ability of the system to deliver wide access and therefore efficient dissemination of research results, with the resulting risk of stifling further scientific progress.

3. These considerations lead the ERC Scientific Council, like other research funding bodies, to stress the attractiveness of policies mandating the public availability of research results - in open access repositories reasonably soon (ideally, 6 months, and in any case no later than 12 months) after publication.

4. Of course, general open-access policies are not trivial to implement because: (i) the speed of 'obsolescence' of knowledge varies across disciplines; and (ii) so does the availability of open access repositories. Moreover, coordination between research funders (at Eu level, across parts of the Framework Programme for example, but also at the level of Member States and their regions) is highly desirable.

5. This being said, it is the firm intention of the ERC Scientific Council to issue specific guidelines for the mandatory deposit in open access repositories of research results - that is, publications, data and primary materials obtained thanks to ERC grants, as soon as pertinent repositories become operational.

6. The E RC Scientific Council moreover hopes that research funders across Europe will join forces in establishing common open-access rules and in building European open access repositories that will help make these rules operational. To facilitate this process for $\mathrm{EU}$ - funded research, it recommends that the European Commission sets up a task force including representatives from the various F P7 programmes (Cooperation, Ideas, People, ...) to develop an operational FP7 policy on open access by the end of 2007 (which takes in particular into account disciplinary differences and technological constraints).

39. OPEN ACCESS (SPECIFIC TO THE THEMATIC AREAS "HEALTH", “ENERGY”, “ENVIRONMENT (INCLUDING CLIMATE CHANGE)”, “INFORMATION \& COMMUNICATION TECHNOLOGIES” (CHALLENGE 2), AND "SOCIO-ECONOMIC SCIENCES AND THE HUMANITIES" AS 


\section{WELL AS TO THE ACTIVITIES “RESEARCH INFRASTRUCTURES” (E- INFRASTRUCTURES), AND “SCIENCE IN SOCIETY”)}

In addition to Article II.30.4, beneficiaries shall deposit an electronic copy of the published version or the final manuscript accepted for publication of a scientific publication relating to foreground published before or after the final report in an institutional or subject-based repository at the moment of publication. Beneficiaries are required to make their best efforts to ensure that this electronic copy becomes freely and electronically available to anyone through this repository:

- immediately if the scientific publication is published "open access", i.e. if an electronic version is also available free of charge via the publisher, or

- within $[\mathrm{X}]$ months of publication.

The number X will be 6 months in the thematic areas "Health", "Energy", "Environment (including Climate Change)", and "Information \& communication technologies" (Challenge 2) and the activity "Research infrastructures" (e-infrastructures), and 12 months in the thematic area "Socio-economic Sciences and the Humanities" and the activity "Science in Society".

Source: Annex 1 - Special Clauses, adopted through Commission Decision of 20 August $2008^{317}$

\subsection{Open Access Guidelines for researchers funded by the ERC} (June 2012)

\section{ERC scientific council - June 2012}

The mission of the European Research Council (ERC) is to support excellent fundamental research in sciences and the humanities. The main outputs of this research are new knowledge, ideas and understanding, which the ERC expects its researchers to publish in peer-reviewed articles and monographs.

The ERC considers that providing free online access to these materials is the most effective way of ensuring that the fruits of the research it funds 
can be accessed, read and used as the basis for further research.

The ERC therefore supports the principle of open access to the published outputs of research as a fundamental part of its mission.

Accordingly, the European Research Council:

- requires electronic copies of any research papers and monographs that are supported in whole, or in part, by E RC funding to be made publicly available as soon as possible, and no later than six months after the official publication date of the original article.

- strongly encourages ERC funded researchers to make their publications available in open access using discipline-specific repositories. A list of recommended repositories is provided in Appendix 1. If there is no appropriate discipline specific repository, researchers should make their publications available in institutional repositories or on their own webpage.

- considers it essential that primary data, as well as data-related products such as computer codes, is deposited in the relevant databases as soon as possible, preferably immediately after publication and in any case not later than six months after the date of publication.

- encourages Host Institutions to cover open access fees of any research papers and monographs that are supported in whole, or in part, by ERC funding which arise in the period up to 24 months after the end of a grant.

- reminds ERC funded researchers that open access fees are eligible costs that can be charged against ERC grants.

Those guidelines will be reviewed periodically.

Appendix 1: Recommended discipline-specific open access repositories

The recommended repository for Life Sciences, is u K PubMed Central (to be known as Europe PMC from 1 November 2012); and for Physical Sciences and Engineering ArXiv is recommended.

The ERC Scientific Council is reviewing existing practices and open access infrastructures in Social Sciences and Humanities and will make recommendations in the future. Source: European Research Council Scientific Council: Open Access Guidelines for researchers funded by the Ec, June 2012 


\subsection{EC Open Access policy for Horizon 2020}

On 17 July 2012, the European Commission published draft versions of a Communication Towards better access to scientific information: Boosting the benefits of public investments in research and a Recommendation on access to and preservation of scientific information. ${ }^{318}$

The Communication formulates the vision underlying the Commission's strategy on open data and knowledge circulation. Moreover, it informs about key measures that will be taken to achieve these goals.

Some of these afore-mentioned measures are made clear in the key policy measures put forward, for example the Communication provides key measures for access and preservation in Horizon 2020 (p. 12):

\section{Access to and preservation of scientific information: key measures}

\section{Policy measures}

- Recommendation to the Member States on access to and preservation of scientific information, 2012.

- Work with national points of reference designated by Member States to draw up common principles and standards, from 2013.

- Work with national points of reference to structure and monitor progress on access and dissemination, from 2013.

\section{Open access to results of EU-funded research}

- Establish open access to scientific publications as a general principle in the Horizon 2020 programme and set up the conditions for optimal compliance, from 2014.

- Maintain the possibility of reimbursing open access publishing fees as part of the Horizon 2020 programme, from 2014.

- Provide a framework and encourage open access to research data in Horizon 2020, taking into account any restrictions that may be needed in order toprotect intellectual property or legitimate commercial interests, from 2014. 


\section{Funding for infrastructures and projects}

- Continue funding relevant projects in Horizon 2020, from 2014.

- Provide $€ 45$ million for infrastructures supporting open access to research articles and data, and for research on digital preservation, 20122013.

\section{Coordination beyond the EU}

- Promote open access policies and the interoperability of data infrastructures with international partners.

\section{Targets:}

- By 2014, policies for open access to scientificarticles and data will have been established in all Member States at all relevant levels.

- By 2016, the share of publicly-funded scientific articles available under open access EU-wide will have increased from $20 \%$ to $60 \% .100 \%$ of scientific publications resulting from Horizon 2020 will be available under open access.

The Recommendation gives clear advice to member states, including (p. 5):

Define clear policies for the dissemination of and open access to scientific publications resulting from publicly funded research. These policies should provide for:

- concrete objectives and indicators to measure progress;

- implementation plans, including the allocation of responsibilities;

- associated financial planning.

Ensure that, as a result of these policies:

- there should be open access to publications resulting from publicly funded research as soon as possible, preferably immediately and in any case no later than six months after the date of publication, and twelve months for social sciences and humanities; 



\section{Annex 2: National Open Access Desks (NOADS)}

\begin{tabular}{|c|c|c|}
\hline Country & Institution & Persons \\
\hline Austria & University of Vienna & $\begin{array}{l}\text { Susanne Blumesberger, Paolo Budroni, } \\
\text { Oliva Kaiser-Dolidze, Gerda McNeill }\end{array}$ \\
\hline Belgium & University of Ghent & Inge Van Nieuwerburgh, Gwen Franck \\
\hline Bulgaria & $\begin{array}{l}\text { Institute of Mathematics } \\
\text { and Informatics, Bulgarian } \\
\text { Academy of Sciences }\end{array}$ & Peter L. Stanchev, Georgi Simeonov \\
\hline Croatia & Ruđer Bošković Institute & Jadranka Stojanovski \\
\hline Cyprus & University of Cyprus & $\begin{array}{l}\text { Filippos Tsimpoglou, Louis Prokopiou, } \\
\text { Sylvia Koukounidou }\end{array}$ \\
\hline Czech Repbl. & $\begin{array}{l}\text { VŠB-Technical } \\
\text { University of Ostrava }\end{array}$ & Daniela Tkačíková, Pavla Rygelova \\
\hline Denmark & $\begin{array}{l}\text { Technical University } \\
\text { of Denmark }\end{array}$ & Mikael K. Elbæk \\
\hline Estonia & University of Tartu Library & Anneli Sepp, Merit Burenkov \\
\hline Finland & University of Helsinki & Veera Ristikartano, Liisa Siipilehto \\
\hline France & Université Henri Poincaré & $\begin{array}{l}\text { Jean-François Lutz, Alexandra Deniot } \\
\text { (until 07/2012), André Dazy }\end{array}$ \\
\hline Germany & University of Konstanz & $\begin{array}{l}\text { Anja Oberländer, Karl-Heinz Pappen- } \\
\text { berger, André Hoffmann }\end{array}$ \\
\hline Greece & $\begin{array}{l}\text { National Documentation } \\
\text { Center }\end{array}$ & Victoria Tsoukala \\
\hline Hungary & University of Debrecen & Gyongyi Karacsony, Edit Gorogh \\
\hline Iceland & $\begin{array}{l}\text { Landspitali - University } \\
\text { Hospital, Reykjavik }\end{array}$ & Solveig Thorsteinsdottir \\
\hline Ireland & Trinity College Dublin & Niamh Brennan, Garret McMahon \\
\hline Italy & CASPUR & Ugo Contino, Paola Gargiulo, Ilaria Fava \\
\hline Latvia & $\begin{array}{l}\text { The Library of the } \\
\text { University of Latvia }\end{array}$ & $\begin{array}{l}\text { Iveta Gudakovska, Sandra Ranka, Ruta } \\
\text { Garklava, Aija Putnina }\end{array}$ \\
\hline Lithuania & $\begin{array}{l}\text { Kaunas University of } \\
\text { Technology }\end{array}$ & $\begin{array}{l}\text { Vilius Kučiukas (until 11/2012), } \\
\text { Gintare Tautkeviciene (from 11/2010) }\end{array}$ \\
\hline Luxemburg & University of Luxembourg & Beth Anne Furlong-Park \\
\hline Malta & $\begin{array}{l}\text { Malta Council for Science } \\
\text { and Technology }\end{array}$ & $\begin{array}{l}\text { Joseph Grima, Brian Warrington (from } \\
\text { 10/2010 on) }\end{array}$ \\
\hline
\end{tabular}




\begin{tabular}{|c|c|c|}
\hline Netherlands & Utrecht University & $\begin{array}{l}\text { Marnix van Berchum (until 12/2010), } \\
\text { Saskia Franken (from 01/2011 on) }\end{array}$ \\
\hline Norway & University of Tromsø & Jan Erik Frantsvåg, Leif Longva \\
\hline Poland & $\begin{array}{l}\text { Interdisciplinary Centre } \\
\text { for Computational and } \\
\text { Mathematical Modelling } \\
\text { at the University of Warsaw }\end{array}$ & $\begin{array}{l}\text { Alek Tarkowski (until o9/2010), Jakub } \\
\text { Szprot, Roman Bogacewicz (from } \\
\text { 12/2010), Marta Hoffman-Sommer } \\
\text { (from 2012) }\end{array}$ \\
\hline Portugal & University of Minho & $\begin{array}{l}\text { Eloy Rodrigues, Ricardo Saraiva, Pedro } \\
\text { Príncipe }\end{array}$ \\
\hline Romania & Kosson & Constantinescu Nicolaie \\
\hline Slovakia & $\begin{array}{l}\text { University Library } \\
\text { Bratislava }\end{array}$ & Alojz Androvic, Tomáš Fiala \\
\hline Slovenia & University of Ljubljana & Mojca Kotar \\
\hline Spain & UNED / RecOLecTA & $\begin{array}{l}\text { Alicia López Medina, Izaskun Lacunza } \\
\text { Aguirrebengoa }\end{array}$ \\
\hline Sweden & National Library of Sweden & $\begin{array}{l}\text { Jan Hagerlid (until 05/2012), Ulf Svenn- } \\
\text { son, Aina Svensson }\end{array}$ \\
\hline Switzerland & University of Zurich & Christian Gutknecht, Christian Fuhrer \\
\hline Turkey & $\begin{array}{l}\text { Izmir Institute of } \\
\text { Technology }\end{array}$ & Gültekin Gürdal, Ata Türkfidani \\
\hline $\begin{array}{l}\text { United } \\
\text { Kingdom }\end{array}$ & University of Nottingham & $\begin{array}{l}\text { Chloe Furnival (until 12/2010), Clara } \\
\text { Boavida (until 12/2011), Bill Hubbard, } \\
\text { Willow Fuchs (until 03/2012) }\end{array}$ \\
\hline
\end{tabular}




\section{Annex 3: Tables}

\subsection{Table : Funder and institutional open access mandates in Europe Status: 25 August 2012}

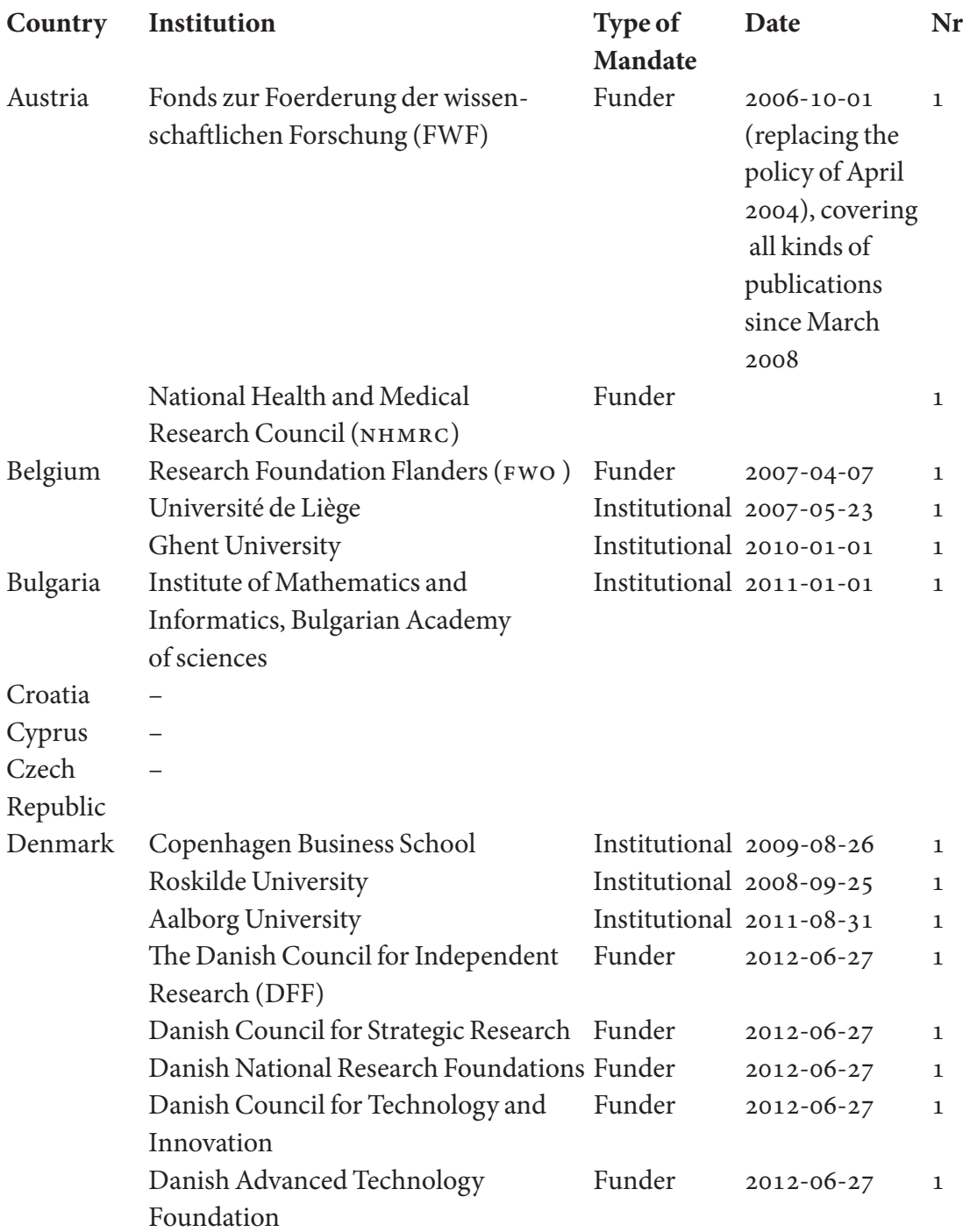




\begin{tabular}{|c|c|c|c|c|}
\hline \multirow{2}{*}{$\begin{array}{l}\text { Estonia } \\
\text { Finland }\end{array}$} & \multicolumn{4}{|l|}{-} \\
\hline & University of Helsinki & Institutional & 2010-01-01 & 1 \\
\hline & University of Jyväskylä* & Institutional & 2011-01-0 & 1 \\
\hline & University of Tampere ${ }^{\star}$ & Institutional & 2011-01-0 & 1 \\
\hline & The 26 universities of Applied Sciences & Institutional & 2010-01-0 1 & 26 \\
\hline \multirow[t]{3}{*}{ France } & $\begin{array}{l}\text { Agence Nationale de la recherche } \\
\text { (ANR) (Humanities and Social } \\
\text { Sciences Branch) }\end{array}$ & Funder & $\begin{array}{l}\text { July } 2008 \\
\text { (in strength- } \\
\text { ening the policy } \\
\text { from November } \\
2007 \text { ) }\end{array}$ & 1 \\
\hline & $\begin{array}{l}\text { Institute national de la recherché } \\
\text { agronomique (INRA) }\end{array}$ & Institutional & 2011-01-011 & 1 \\
\hline & $\begin{array}{l}\text { Institut francais de recherche pour } \\
\text { lexploitation de la mer (Ifremer) }\end{array}$ & Institutional & 2010-09-01 & 1 \\
\hline \multirow[t]{3}{*}{ Germany } & Fraunhofer Gesellschaft ${ }^{\star}$ & Institutional & July 2008 & \\
\hline & $\begin{array}{l}\text { Karlsruhe Institute of Technology } \\
(\text { KIT })^{*}\end{array}$ & Institutional & March 2010 & \\
\hline & Justus-Liebig-Universität Gießen & Institutional & 2011-03-17 & \\
\hline Greece & - & & & \\
\hline Hungary & $\begin{array}{l}\text { Hungarian Scientific Research Fund } \\
\text { (оTKA) }\end{array}$ & Funder & $2009-06-30$ & 1 \\
\hline Iceland & Bifröst University & Institutional & $2012-03-24$ & 1 \\
\hline \multirow[t]{6}{*}{ Ireland } & Higher Education Authority (HEA) & Funder & 2009-06-30 & 1 \\
\hline & $\begin{array}{l}\text { Irish Research Council for Science, } \\
\text { Engineering and Technology (IRCSET) }\end{array}$ & Funder & 2008-05-01 & 1 \\
\hline & Science Foundation Ireland (SFI) & Funder & 2009-02-01 & 1 \\
\hline & Health Research Board (нRв) & Funder & 2010-01-01 & 1 \\
\hline & Dublin Institute of Technology & Institutional & 2010-01-01 & 1 \\
\hline & Trinity College Dublin & Institutional & 2010-10-18 & 1 \\
\hline \multirow[t]{2}{*}{ Italy } & Telethon Italy & Funder & 2010-07-22 & 1 \\
\hline & Istituto Superiore di Sanità (Iss) & Institutional & 2008-01-17 & 1 \\
\hline Latvia & - & & & \\
\hline \multirow[t]{2}{*}{ Lithuania } & $\begin{array}{l}\text { Lietuvos Respublikos. Mokslo Ir } \\
\text { Studiju Istatymas [Republic of } \\
\text { Lithuania. Higher Education and } \\
\text { Research Law] }\end{array}$ & Funder & $2009-05-12$ & 1 \\
\hline & Vilnius University & Institutional & 2011-01-01 & 1 \\
\hline \multicolumn{5}{|c|}{ Luxembourg- } \\
\hline Malta & - & & & \\
\hline \multicolumn{2}{|c|}{ Netherlands Erasmus University Rotterdam } & Institutional & $\begin{array}{l}\text { 2011-01-01 } \\
\text { (thesis mandate } \\
\text { since 2006, gene- } \\
\text { ral oA mandate } \\
\text { approved in Sep- } \\
\text { tember 2010) }\end{array}$ & 1 \\
\hline
\end{tabular}

146 ANNEX 3 
KNAW [The Royal Netherlands

Academy of Arts and Sciences]

Norway

Poland

Portugal

Romania

Slovakia

Slovenia

Spain

Services (NOKC)

University of Bergen

University of Troms $\varnothing$

University of Oslo

Institute of Biochemistry and

University of Minho

University of Porto

University of Aberta

University of Lisbon

Universidade do Algarve

$-$

$-$
Norwegian Research Council (NRC)

Norwegian Knowledge Centre Health

Biophysics Polish Academy of Sciences

ISTE-IUL - Lisbon University Institute

Polytechnic Institute of Bragança

Instituto Politécnico de Castelo Branco

Instituto Politécnico de Viseu (IPV)

Government of the Principality of Asturias

Madrid Autonomous Community of Spain ( $\mathrm{CM}$ )

Universidad Carlos in de Madrid

Universidad Rey Juan Carlos

Universitat Politècnica de Catalunya

Universidad Politécnica de Madrid

Universitat Oberta de Catalunya

(Open University of Catalonia, uoc)

Ministerio de Ciencia e Innovación

Universitat Autònoma de Barcelona

Universitat Politècnica de València

Universidad Politécnica de Cartagena

Swedish Research Council

Knut \& Alice Wallenberg Foundation

The Foundation for Baltic and

East European Studies

Riksbankens Jubileumsfond (RJ)

Swedish Council for Working Life and Social Research (FAS)
Institutional 2012-02-01 1

Funder 2009-01-28 1

Institutional 2008-11-25 1

Institutional 2010-01-01 1

Institutional 2010-10-14 1

Institutional 2012-01-01 1

Institutional 2010-01-26 1

Institutional January $2005 \quad 1$

Institutional 1905-06-29 1

Institutional 2008-09-10 1

Institutional 2010-04-01 1

Institutional 2010-08-01 1

Institutional 2010-06-02 1

Institutional 2012-03-13 1

Institutional 2012-04-02 1

Institutional 2012-04-14 1

Funder 2009-02-04 1

Funder 2008-05-20 1

Institutional 2009-07-01 1

Institutional 2009-05-20 1

Institutional 2009-10-07 1

Institutional 2010-11-28 1

Institutional 2009-10-07 1

Funder 2011-06-02 1

Institutional 2012-04-25 1

Institutional 2011-07-21 1

Institutional 2011-06-01 1

Funder 2010-01-01 1

Funder Autumn $2010 \quad 1$

Funder 1905-07-03 1

Funder 2007-11-06 1

Funder 2012-01-01 1 
The Swedish Research Council for the Funder $\quad$ 2010-05-25 1

Environment, Agricultural Sciences

and Spatial Planning (Formas)

Chalmers University of Technology Institutional 2010-02-18 1

Blekinge Institute of Technology Institutional 2010-01-01 1

Malmö University

Karolinska Institutet

Institutional 2010-01-01 1

Kungliga biblioteket

Institutional 2011-05-31 1

[National Library of Sweden]

Umeå University

Institutional 2010-11-11 1

Institutional 2010-01-01 1

Switzerland Swiss National Science Foundation

(SNF)

Funder 2010-07-01 1

(replacing the

policy of Sep-

tember 2007)

ETH Zürich

Institutional 2008-07-01 1

University of Geneva

Institutional 2009-06-01 1

University of St Gallen

Institutional 2009-01-01 1

University of Zürich

Institutional 2005-07-21 1

Turkey -

$\begin{array}{llll}\text { United Arthritis Research UK } & \text { Funder } & \text { 2007-01-01 } & 1\end{array}$

Kingdom

\begin{tabular}{|c|c|c|}
\hline $\begin{array}{l}\text { Arts and Humanities Research Council } \\
\text { (AHRC) }\end{array}$ & & 2009-02-01 \\
\hline $\begin{array}{l}\text { Biotechnology and Biological Sciences } \\
\text { Research Council (BBSRC) }\end{array}$ & Funder & 2006-10-01 \\
\hline British Heart Foundation (внғ) & Funder & 2007-01-08 \\
\hline Cancer Research U K & Funder & 2007-06-01 \\
\hline $\begin{array}{l}\text { Chief Scientist Office, } \\
\text { Scottish Executive (cso) }\end{array}$ & Funder & 2006-04-01 \\
\hline Department of Health (DH) & Funder & 2007-04-01 \\
\hline Dunhill Medical Trust & Funder & 2011-03-01 \\
\hline $\begin{array}{l}\text { Economic and Social Research } \\
\text { Council (ESRC) }\end{array}$ & Funder & 2006-10-01 \\
\hline $\begin{array}{l}\text { Engineering and Physical Sciences } \\
\text { Research Council (EPSRC) }\end{array}$ & Funder & 2011-09-01 \\
\hline $\begin{array}{l}\text { JISC (Joint Information Systems } \\
\text { Committee) }\end{array}$ & Funder & 2007-01-01 \\
\hline Medical Research Council (MRC) & Funder & 2006-10-01 \\
\hline $\begin{array}{l}\text { National Institute for Health Research } \\
(\mathrm{NIHR})\end{array}$ & Funder & 2007-04-01 \\
\hline $\begin{array}{l}\text { Natural Environment Research } \\
\text { Council (Nerc) }\end{array}$ & Funder & 2006-10-01 \\
\hline $\begin{array}{l}\text { Science and Technology Facilities } \\
\text { Council (sTFC) }\end{array}$ & Funder & 2006-12-01 \\
\hline
\end{tabular}

148 ANNEX 3 
Stroke Association

Wellcome Trust

Aston University

Edinburgh Napier University

Loughborough University
Funder

Funder 2009-06-01

$2005-10-01$

Institutional 2009-06-30

Institutional 2008-04-25

Institutional 2011-09-01
1

1

1

1

Queen Margaret University, Edinburgh Institutional 2008-02-01 1

Roehampton University Institutional 2008-01-01 1

Royal Holloway, University of London Institutional 2010-09-01 1

Teesside University

University College London

University of Abertay Dundee

University of Bath

University of Edinburgh

University of Glasgow

University of Leicester

University of Lincoln

University of Nottingham

University of Reading

University of Salford

University of Southampton

University of Stirling

University of Strathclyde

University of Surrey

University of Westminster

Europe European Commission

European Research Council

CERN (European Organization for

Nuclear Research)
Institutional 2010-09-01 1

Institutional 2009-06-03 1

Institutional 2010-01-01 1

Institutional 2011-06-01 1

Institutional 2010-01-01 1

Institutional 2008-09-22 1

Institutional 2009-05-27 1

Institutional 2010-09-01 1

Institutional 2009-11-01 1

Institutional 2010-01-01 1

Institutional 2006-03-14 1

Institutional 2008-09-22 1

Institutional 2007-01-01 1

Institutional 2010-09-01 1

Institutional 2005-01-01 1

Institutional 2007-01-01 1

Funder 2008-08-21 1

Funder 2007-12-17 1

Institutional 2003-11-17 1

Total number of funder mandates in Europe

Note: ${ }^{\star}$ request, but not requirement, not counted in the overall number of mandates.

Source: ROARMAP, MELIBEA, OpenAIRE country pages 
9.2 Table : Repositories in European countries

Status: 1 January 2011, 25 July 2012

\begin{tabular}{|c|c|c|c|c|}
\hline Country & $\begin{array}{l}\text { OpendoAR } \\
\text { (Jan 2011) }\end{array}$ & $\begin{array}{l}\text { OpendoAR } \\
\text { (July 2012) }\end{array}$ & $\begin{array}{l}\text { ROAR } \\
(\text { Jan 2011)( }\end{array}$ & $\begin{array}{l}\text { ROAR } \\
\text { July 2012) }\end{array}$ \\
\hline Austria & 9 & 9 & 7 & 7 \\
\hline Belgium & 28 & 28 & 20 & 31 \\
\hline Bulgaria & 3 & 6 & 2 & 6 \\
\hline Croatia & 3 & 5 & 3 & 4 \\
\hline Cyprus & 1 & 2 & 3 & 4 \\
\hline Czech Republic & 4 & 6 & 5 & 6 \\
\hline Denmark & 10 & 10 & 13 & 16 \\
\hline Estonia & 5 & 5 & 2 & 4 \\
\hline Finland & 15 & 13 & 16 & 18 \\
\hline France & 57 & 65 & 50 & 73 \\
\hline Germany & 142 & 149 & 111 & 150 \\
\hline Greece & 13 & 14 & 18 & 24 \\
\hline Hungary & 10 & 12 & 9 & 13 \\
\hline Iceland & 2 & 2 & 1 & 2 \\
\hline Ireland & 12 & 14 & 14 & 19 \\
\hline Italy & 59 & 69 & 52 & 79 \\
\hline Latvia & 1 & 3 & 1 & 4 \\
\hline Lithuania & 3 & 3 & 3 & 3 \\
\hline Luxembourg & - & 0 & - & - \\
\hline Malta & - & - & - & - \\
\hline Netherlands & 23 & 24 & 27 & 38 \\
\hline Norway & 42 & 47 & 11 & 50 \\
\hline Poland & 20 & 73 & 12 & 76 \\
\hline Portugal & 33 & 41 & 36 & 44 \\
\hline Romania & 1 & 1 & 7 & 8 \\
\hline Slovakia & - & - & - & - \\
\hline Slovenia & 3 & 5 & 2 & 4 \\
\hline Spain & 67 & 92 & 67 & 127 \\
\hline Sweden & 46 & 46 & 31 & 39 \\
\hline Switzerland & 11 & 13 & 10 & 14 \\
\hline Turkey & 11 & 11 & 16 & 33 \\
\hline United Kingdom & 183 & 207 & 170 & 240 \\
\hline Europe & 817 & 975 & 719 & 1136 \\
\hline
\end{tabular}

Source: OpendoAR, ROAR, OpenAIre country pages. As ROAR is based on automatic harvesting, it contains a number of duplicates. 


\subsection{Table : National networks of repositories Status: 25 August 2012}

\begin{tabular}{|c|c|c|c|c|}
\hline Country & Name & URL & $\begin{array}{l}\text { Reposi- } \\
\text { tories }\end{array}$ & Records \\
\hline Austria & - & - & - & - \\
\hline Belgium & DRIVER Belgium & http://search.belgium. & 10 & $162,000+$ \\
\hline Bulgaria & Bulgarian D-NET portal & - & 3 & $1,900+$ \\
\hline Croatia & - & - & - & - \\
\hline Cyprus & - & - & - & - \\
\hline Czech & - & - & - & - \\
\hline \multicolumn{5}{|l|}{ Republic } \\
\hline Denmark & $\begin{array}{l}\text { DDF (Danish National } \\
\text { Research Database) }\end{array}$ & $\begin{array}{l}\text { http://www.forsknings- } \\
\text { database.dk }\end{array}$ & 13 & $\begin{array}{l}\sim 500,000 \\
(21,000 \sim+ \\
\text { full texts })\end{array}$ \\
\hline Estonia & - & - & - & - \\
\hline Finland & - & - & - & - \\
\hline France & $\begin{array}{l}\text { HAL: Hyper articles en } \\
\text { ligne - central } \\
\text { repository [1] }\end{array}$ & $\begin{array}{l}\text { http://hal.archives- } \\
\text { ouvertes.fr }\end{array}$ & $\begin{array}{l}\sim 4006 \\
\text { subcol } \\
\text { lections }\end{array}$ & $\begin{array}{l}(215,000+ \\
13,000+ \\
\text { full texts })\end{array}$ \\
\hline Germany & $\begin{array}{l}\text { OA-Netzwerk of DINI- } \\
\text { certified repositories }\end{array}$ & $\begin{array}{l}\text { http://oansuche.open- } \\
\text { access.net }\end{array}$ & 35 & $80,000+$ \\
\hline Greece & $\begin{array}{l}\text { Greek digital libraries } \\
\text { search engine }\end{array}$ & http://openarchives.gr & 62 & 430 \\
\hline Hungary & Under development & - & - & - \\
\hline Ireland & $\begin{array}{l}\text { RIAN - Pathways to Irish } \\
\text { Research }\end{array}$ & http://rian.ie & 8 & $19,000+$ \\
\hline Italy & $\begin{array}{l}\text { Pleiadi: Portale per la } \\
\text { Letteratura scientific } \\
\text { Electtronica italiana su } \\
\text { Archivi aperti eDepositi } \\
\text { Istituziona }\end{array}$ & $\begin{array}{l}\text { http://www.open- } \\
\text { archives.it/pleiadi }\end{array}$ & 30 & $515,000+$ \\
\hline Latvia & - & - & - & - \\
\hline Lithuania & $\begin{array}{l}\text { eLABa: Lithuanian acade- } \\
\text { mic e-Library - serves as } \\
\text { a national repository }\end{array}$ & http://elaba.library.lt & 15 & $\begin{array}{l}19,000+ \\
\text { (about } \\
3 / 4 \text { are etds) }\end{array}$ \\
\hline Malta & - & - & - & - \\
\hline \multicolumn{2}{|c|}{ Netherlands NARCIS } & http://www.narcis.nl & 31 & $689,000+$ \\
\hline \multicolumn{2}{|c|}{ Netherlands HBO Kennisbank } & $\begin{array}{l}\text { http://www.hbo- } \\
\text { kennisbank.nl/nl/page/ } \\
\text { page.view/hbo_about. } \\
\text { page }\end{array}$ & 18 & $\begin{array}{l}21,000+ \\
16,000+ \\
\text { (open } \\
\text { access) }\end{array}$ \\
\hline
\end{tabular}




\begin{tabular}{|c|c|c|c|c|}
\hline Norway & $\begin{array}{l}\text { NORA: Norwegian Open } \\
\text { Research Archive }\end{array}$ & $\begin{array}{l}\text { http://www.ub.uio.no/ } \\
\text { nora/search.html }\end{array}$ & 16 & $59,000+$ \\
\hline Poland & $\begin{array}{l}\text { Digital Libraries } \\
\text { Federation }\end{array}$ & http://fbc.pionier.net.pl & 92 & $1,000000+$ \\
\hline Portugal & $\begin{array}{l}\text { RCAAP: Repositorio } \\
\text { cientifico de acceso aberto } \\
\text { de Portugal }\end{array}$ & http://www.rcaap.pt & 32 & $450,000+$ \\
\hline Romania & - & - & - & - \\
\hline Slovakia & - & - & - & - \\
\hline Slovenia & $\begin{array}{l}\text { dLib.si: Digital Library } \\
\text { of Slovenia }\end{array}$ & http://www.dlib.si & 53 & $\begin{array}{l}5,000+ \\
\text { (digitized } \\
\text { collections } \\
\text { and reposi- } \\
\text { tory con- } \\
\text { tent) }\end{array}$ \\
\hline Spain & Recolecta & http://www.recolecta.net & 191 & $\begin{array}{l}1,105,000+ \\
\text { incl. } 60+ \\
\text { institutio- } \\
\text { nal reposi- } \\
\text { tories }\end{array}$ \\
\hline Spain & $\begin{array}{l}\text { Madrid regional } \\
\text { harvester }\end{array}$ & $\begin{array}{l}\text { http://www.madrimasd. } \\
\text { org/informacionidi/e- } \\
\text { ciencia/buscar-docu- } \\
\text { mentos/default.asp }\end{array}$ & 10 & $136,000+$ \\
\hline Sweden & SwePub & http://swepub.kb.se & 29 & $264,000+$ \\
\hline Switzerland & - & - & - & - \\
\hline Turkey & MItos & $\begin{array}{l}\text { http://www.mitosweb. } \\
\text { com }\end{array}$ & 17 & 32,000 \\
\hline United & Intute: Institutional & www.intute.ac.uk/irs & 107 & $351,000+$ \\
\hline Kingdom & $\begin{array}{l}\text { RepositorySearch } \\
\text { (Prototype) }\end{array}$ & & & \\
\hline $\begin{array}{l}\text { U K - } \\
\text { Scotland }\end{array}$ & $\begin{array}{l}\text { IRIscotland Project Pilot } \\
\text { Cross-Repository Service }\end{array}$ & $\begin{array}{l}\text { http://cdlr.strath.ac.uk/ } \\
\text { iriscotland }\end{array}$ & 10 & - \\
\hline
\end{tabular}




\subsection{Table : Information portals and support networks Status: 25 August 2012}

\begin{tabular}{|c|c|c|c|}
\hline Country & Address & Scope & Language \\
\hline Austria & $\begin{array}{l}\text { Cooperation with http:// } \\
\text { www.open-access.net }\end{array}$ & & $\begin{array}{l}\text { German, } \\
\text { English }\end{array}$ \\
\hline Belgium & http://www.openaccess.be & $\begin{array}{l}\text { News, information, } \\
\text { community building }\end{array}$ & $\begin{array}{l}\text { English, } \\
\text { Dutch, } \\
\text { French }\end{array}$ \\
\hline Bulgaria & $\begin{array}{l}\text { http://www.bulgarian- } \\
\text { repositories.EU }\end{array}$ & $\begin{array}{l}\text { News, events, information } \\
\text { about open access }\end{array}$ & $\begin{array}{l}\text { English, } \\
\text { Bulgarian }\end{array}$ \\
\hline Croatia & - & & \\
\hline Cyprus & - & & \\
\hline Czech & http://www.openaccess.cz & Website set up for the Open & Czech \\
\hline Republic & & $\begin{array}{l}\text { Access Week, with } 14 \text { partici- } \\
\text { pating institutions }\end{array}$ & \\
\hline Denmark & $\begin{array}{l}\text { http://www.open-access. } \\
\mathrm{dk} / \text {, published by Denmark's } \\
\text { Electronic Research Library } \\
\text { (DEF) and the Danish oA } \\
\text { network }\end{array}$ & $\begin{array}{l}\text { News, events, information } \\
\text { about initiatives, repositories, } \\
\text { impact, oA profiles of } \\
\text { Danish institutions, etc. }\end{array}$ & Danish \\
\hline Estonia & $\begin{array}{l}\text { http://www.utlib.ee/index. } \\
\text { php?e_id=367 }\end{array}$ & $\begin{array}{l}\text { Information for authors, } \\
\text { librarians, publishers, } \\
\text { institutions }\end{array}$ & Estonian \\
\hline Finland & http://www.openaccess.fi & $\begin{array}{l}\text { Links to FinnoA, oJs working } \\
\text { group and other initiatives }\end{array}$ & Finnish \\
\hline \multirow[t]{2}{*}{ France } & http://openaccess.inist.fr & $\begin{array}{l}\text { News, events, information } \\
\text { for institutions }\end{array}$ & French \\
\hline & $\begin{array}{l}\text { http://www.couperin.org/ } \\
\text { archivesouvertes }\end{array}$ & $\begin{array}{l}\text { News, events, formation for } \\
\text { institutions and repository } \\
\text { managers, guides, surveys, } \\
\text { working guides, groups }\end{array}$ & French \\
\hline \multirow[t]{2}{*}{ Germany } & $\begin{array}{l}\text { http://open-access.net, run } \\
\text { by the universities of Biele- } \\
\text { feld, Konstanz, Göttingen, } \\
\text { Freie Universität Berlin and } \\
\text { various partners }\end{array}$ & $\begin{array}{l}\text { News, events, information } \\
\text { for researchers, publishers, } \\
\text { librarians etc.; addressing } \\
\text { all kinds of stakeholders }\end{array}$ & $\begin{array}{l}\text { German, } \\
\text { English }\end{array}$ \\
\hline & http://www.dini.de/english & $\begin{array}{l}\text { Working group "Electronic } \\
\text { Publishing", DIN I Certificate } \\
\text { for repositories, workshops } \\
\text { etc.; primarily addressing } \\
\text { repository managers and } \\
\text { developers }\end{array}$ & $\begin{array}{l}\text { German, } \\
\text { English }\end{array}$ \\
\hline
\end{tabular}




\begin{tabular}{|c|c|c|c|}
\hline Greece & http://openaccess.gr, run by & News, events, information & Greek \\
\hline & $\begin{array}{l}\text { the National Documentation } \\
\text { Center }\end{array}$ & $\begin{array}{l}\text { about policies, repositories, } \\
\text { etc. }\end{array}$ & \\
\hline Hungary & $\begin{array}{l}\text { www.open-access.hu, run } \\
\text { by the University Library } \\
\text { of Debrecen }\end{array}$ & $\begin{array}{l}\text { News, events, information } \\
\text { for researchers, librarians, } \\
\text { journal publishers, etc. }\end{array}$ & Hungarian \\
\hline Iceland & $\begin{array}{l}\text { http://openaccess.is, run by } \\
\text { the National and University } \\
\text { Library of Iceland }\end{array}$ & $\begin{array}{l}\text { News, events, information } \\
\text { about open access }\end{array}$ & $\begin{array}{l}\text { Icelandic } \\
\text { (intro in } \\
\text { English) }\end{array}$ \\
\hline Ireland & - & & \\
\hline Italy & $\begin{array}{l}\text { http://wiki.openarchives.it, } \\
\text { run by PLEIADI }\end{array}$ & $\begin{array}{l}\text { News, events, information } \\
\text { for authors, librarians, } \\
\text { publishers, institutions, etc. }\end{array}$ & Italian \\
\hline Latvia & $\begin{array}{l}\text { http://www.lu.lv/biblioteka/ } \\
\text { resursi/open-access/ }\end{array}$ & $\begin{array}{l}\text { Informationsfor authors, } \\
\text { librarians, institutions etc. }\end{array}$ & Latvian \\
\hline Lithuania & $\begin{array}{l}\text { www.lmba.lt/oA/liet/oA. } \\
\text { htm, run by the Lithuanian } \\
\text { Research Library Consor- } \\
\text { tium (LMBA) }\end{array}$ & Events, publications, links & Lithuanian \\
\hline \multicolumn{4}{|c|}{ Luxembourg - } \\
\hline Malta & - & & \\
\hline Netherlanc & $\begin{array}{l}\text { s www.openaccess.nl, run by } \\
\text { Utrecht University Library }\end{array}$ & $\begin{array}{l}\text { News, events, information } \\
\text { for researchers, managers, etc. }\end{array}$ & English \\
\hline Norway & $\begin{array}{l}\text { http://openaccess.no, run } \\
\text { by the University of Tromsø }\end{array}$ & $\begin{array}{l}\text { News, events, initiatives, } \\
\text { information for researchers, } \\
\text { institutions, journals, etc. }\end{array}$ & Norwegian \\
\hline \multirow[t]{2}{*}{ Poland } & $\begin{array}{l}\text { http://otwartanauka.cel. } \\
\text { agh.edu.pl/course/view. } \\
\text { php?id=2 }\end{array}$ & $\begin{array}{l}\text { e-learning course about open } \\
\text { access and open science }\end{array}$ & Polish \\
\hline & http://otwartanauka.pl & $\begin{array}{l}\text { information about open } \\
\text { access and open science, news, } \\
\text { events, etc. }\end{array}$ & Polish \\
\hline Portugal & $\begin{array}{l}\text { http://projecto.rcaap.pt/ } \\
\text { index.php?lang=en, } \\
\text { http://blog.rcaap.pt }\end{array}$ & $\begin{array}{l}\text { News, events, information } \\
\text { for institutional leaders, } \\
\text { researchers and teachers, } \\
\text { repository administrators }\end{array}$ & $\begin{array}{l}\text { Portu- } \\
\text { guese, } \\
\text { English }\end{array}$ \\
\hline Romania & http://startad.kosson.ro/ & $\begin{array}{l}\text { Start up collection of docu- } \\
\text { ments for support of oA } \\
\text { activities, open access } \\
\text { declaration Romanian and } \\
\text { six other languages }\end{array}$ & $\begin{array}{l}\text { English, } \\
\text { Ruma- } \\
\text { nian }\end{array}$ \\
\hline & & & \\
\hline
\end{tabular}




\begin{tabular}{|c|c|c|c|}
\hline Slovenia & http://www.openaccess.si & $\begin{array}{l}\text { information about oA, news, } \\
\text { events, etc }\end{array}$ & $\begin{array}{l}\text { Slovenian } \\
\text { English }\end{array}$ \\
\hline Spain & http://www.accesoabierto.net & $\begin{array}{l}\text { News, information about OA, } \\
\text { repositories, journals, copy- } \\
\text { right, etc. }\end{array}$ & Spanish \\
\hline \multirow[t]{2}{*}{ Sweden } & $\begin{array}{l}\text { http://openaccess.se, run by } \\
\text { the National Library of } \\
\text { Sweden }\end{array}$ & $\begin{array}{l}\text { News, information about oA } \\
\text { and the programme open- } \\
\text { access.se }\end{array}$ & Swedish \\
\hline & $\begin{array}{l}\text { http://www.searchguide. } \\
\text { se/oa }\end{array}$ & $\begin{array}{l}\text { Support for repository } \\
\text { managers; information about } \\
\text { oA, journals, copyright, etc.; } \\
\text { tutorials and other materials }\end{array}$ & Swedish \\
\hline \multicolumn{2}{|c|}{ Switzerland http://open-access.net } & $\begin{array}{l}\text { See above, legal information } \\
\text { for Switzerland }\end{array}$ & $\begin{array}{l}\text { German, } \\
\text { English }\end{array}$ \\
\hline Turkey & $\begin{array}{l}\text { http://acikerisim.ankos. } \\
\text { gen.tr, hosted by the oA and } \\
\text { repositories working group } \\
\text { of Anatolian University } \\
\text { Libraries Consortium } \\
\text { (ANKOS) }\end{array}$ & $\begin{array}{l}\text { News, events, information } \\
\text { about repositories, } \\
\text { copyright, glossary, etc. }\end{array}$ & Turkish \\
\hline $\begin{array}{l}\text { United } \\
\text { Kingdom }\end{array}$ & $\begin{array}{l}\text { http://www.rsp.ac.uk } \\
\text { Repository Support Project } \\
\text { hosted by the University of } \\
\text { Nottingham }\end{array}$ & $\begin{array}{l}\text { News, events, support for } \\
\text { repository managers and } \\
\text { developers }\end{array}$ & English \\
\hline UK - Wales & $\begin{array}{l}\text { http://www.wrn.aber.ac.uk/ } \\
\text { en, WRN - Welsh } \\
\text { Repository Network }\end{array}$ & $\begin{array}{l}\text { News, support for repository } \\
\text { managers and developers }\end{array}$ & $\begin{array}{l}\text { English, } \\
\text { Welsh }\end{array}$ \\
\hline Europe & http://www.openaire.eu & $\begin{array}{l}\text { Information about the EC/ } \\
\text { ERC policies, country } \\
\text { information, IPR, etc. }\end{array}$ & $\begin{array}{l}\text { English, } \\
\text { various }\end{array}$ \\
\hline
\end{tabular}

Source: OpenA IRE country pages, literature and web resources. 



\section{Glossary}

\section{Compliancy}

OpenAIRE compliancy means that a repository is harvestable by OpenAIRE. To obtain this, the repository infrastructure needs to be adapted. The 'Opena IRE Guidelines for repository managers' ${ }^{320}$ give an overview of the requirements in order to make the repository compliant.

\section{Depositing}

The act of making an article online available in a digital repository. Synonyms are: uploading, self-archiving, self-publishing.

\section{DRIVER ${ }^{321}$}

The DRIVER and DRIVER-II projects' vision and primary objective was "to create a cohesive, robust and flexible, pan-European infrastructure for digital repositories, offering sophisticated services and functionalities for researchers, administrators and the general public". The DRIVER network forms the basis for the current Opena IRE and Opena IR E plus projects.

\section{Enhanced publications/linked data ${ }^{322}$}

A new type of scholarly publication whereby researchers link directly through to supplementary or accompanying data from their publication. This associated data can include datasets, videos, teaching materials, grant information. The web has provided the platform to make the presentation of research results immediately accessible, thereby enhancing the process of research.

\section{Harvesting ${ }^{323}$}

A harvester is a computer programme used by a service provider ${ }^{324}$ for the collection (harvesting) of metadata in one or several OAI repositories. OpenAIRE harvests relevant material from OpenAIRE-compliant repositories all around Europe. 


\section{Mandate ${ }^{325}$}

In this context, a mandate defines an institution's policy about self-archiving research output. Some funders and institutions ask the researchers they support to deposit their work in a repository (preferably in Open Access), to make sure that this work remains available for consultation.

\section{National Open Acces Desk ${ }^{326}$}

The National Open Access Desks connect researchers, research institutions, and policy makers at a national level on the one end, and the OpenAIRE project services on the other. The focus of the National Open Access Desks activities is on support for compliance with the Ec Open Access Pilot. The National Open Access Desk can help you find the appropriate repository in your country, and can answer your questions concerning Open Access, the EC Open Access Pilot, copyright issues, any special national rules and regulations concerning Open Access, and so on.

\section{OAI ${ }^{327}$}

The oAI (Open Access Initiative) architecture is the technical infrastructure of an information system that is compliant with the OAI-PMH protocol. The OAI-PMH protocol (Open Archives Initiative Protocol for Metadata Harvesting) is a low-barrier mechanism for repository interoperability based on metadata harvesting.

\section{OpenaIRE Orphan repository ${ }^{328}$}

If your institution doesn't have an institutional repository and there is no relevant subject repository where you can deposit your article, then the Openaire Orphan Repository provides an effective solution. The OpenAIRE Orphan Repository is hosted by CERN.

\section{Postprint ${ }^{329}$}

A postprint is the version of the scientific paper that has received full peer review but has not yet been put in the final published layout (also referred to as 'author's final version'). In terms of content, post-prints are the article as published. However, in terms of appearance this might not be the same as the published article, as publishers often reserve for themselves their own arrangement of type-setting and formatting. A lot of publishers allow the postprint version to be put in Open Access (for publisher policies, see the SHE RPA/Rome O website ${ }^{330}$ ). 


\section{Repository ${ }^{331}$}

A repository is a database or a digital archive established to collect and preserve scientific output. Institutional repositories gather the output from the scientific institution they belong to, whereas subject repositories collect publications and data related to a scientific discipline. Depending on personal preferences or publisher's policies, the author can make his work available in Open Access or (temporarily) restrict the access to it.

Ideally, repositories conform to a common metadata protocol created by the Open Archives Initiative ${ }^{332}$, making and them interoperable, forming a global research facility and allowing other web applications, such as text and data mining. Thus, an article placed in a repository is far easier to find than through an individual's website. Moreover, repositories make best efforts to preserve materials in the long-term. The benefit is that if a researcher moves on, or their personal website changes, their articles are in a repository and the links will remain stable, readable and accessible.

\section{SC39 333}

The European Commission adopted a Special Clause 39 in the grant agreements concerning the Open Access requirements specific to the thematic areas "Health", "Energy", "Environment (including Climate Change)", "Information \& Communication Technologies" (Challenge 2), and "Socioeconomic Sciences and the Humanities", as well as to the activities "Research Infrastructures" (e-infrastructures), and "Science in Society". SC39 states:

"In addition to Article II.30.4, beneficiaries shall deposit an electronic copy of the published version or the final manuscript accepted for publication of a scientific publication relating to foreground published before or after the final report in an institutional or subjectbased repository at the moment of publication."

Beneficiaries are required to make their best efforts to ensure that this electronic copy becomes freely and electronically available to anyone through this repository: 
- immediately if the scientific publication is published "open access", i.e. if an electronic version is also available free of charge via the publisher, or

- within 6 months of publication in the thematic areas "Health", "Energy", "Environment (including Climate Change)", and

"Information \& communication technologies" (Challenge 2) and the activity "Research infrastructures" (e-infrastructures), and within 12 months of publication in the thematic area "Socio-economic Sciences and the Humanities" and the activity "Science in Society". 


\section{Notes}

http://www.openaire.eu

Rettberg/Schmidt (2012).

http://www.openaire.eu/en/component/content/article/9-news-events/390copernicus-publications-first-open-access-publisher-visible-on-openaire http://ec.europa.eu/research/science-society/document_library/pdf_o6/eracommunication-towards-better-access-to-scientific-information_en.pdf http://www.openaire.eu/en/open-access/country-information Berlin Declaration 2003. http://www.eprints.org/openaccess/policysignup During Open Access Week 2010 (18-24 October), organised by SPA RC, participants were encouraged to add to this list any further mandates. This resulted in the addition of eight newly registered mandates (of which four were institutional, two were departmental, and two were thesis). http://www.openoasis.org/index.php?option $=$ com_content $\&$ view $=$ article $\&$ id $=615 \&$ catid $=56$

In chapter 3 , we provide a list of European oA mandates that differs somewhat from these figures, as not all European mandates are registered with ROARMAP. See Table 1 in Annex 3.

Sale (2006).

http://www.sherpa.ac.uk/juliet www.sherpa.ac.uk/romeo.php

MELiBEA - Directorio y estimador de polícas en favour del acceso abierto a la producción científica, http://www.accesoabierto.net/politicas

http://ec.europa.eu/research/sciencesociety/index.cfm? fuseaction=public.topic\&id $=1294 \&$ lang $=1$ $\mathrm{ftp} / / / \mathrm{ftp}$.cordis.europa.eu/pub/fp7/docs/fp7-ga-annex2-v3_en.pdf These costs can be paid out of the given project budget but will not be additionally granted. Therefore, projects are advised to include a budget for publication costs in their overall budget; later changes (within the given budget) must be confirmed by the project coordinator.

6 The University of Nottingham was one of the first to develop a model for such funds, http://www.sherpa.ac.uk/documents/ARMA 080618.ppt See Annex 1. http://ec.europa.eu/research/sciencesociety/index.cfm? fuseaction $=$ public.topic $\&$ id $=1300$ http://ec.europa.eu/research/consultations/scientific_information/consultation_en.htm 
23 http://erc.europa.eu

24 http://erc.europa.eu/sites/default/files/document/file/erc_scc_guidelines_ open_access.pdf

European Commission: Survey on open access in FP7 (2012). http://ec.europa.eu/research/sciencesociety/index.cfm? fuseaction $=$ public.topic $\&$ id $=1301$

Scientific data: open access to research results will boost Europe's innovation capacity, European Commission, Press Release, 17 July 2012, http://europa.eu/rapid/pressReleasesAction.do?reference=IP/12/790; Openaire's response to EC Communication and Recommendation, 18 July 2012, http://www.openaire.eu/en/home/9-news-events/401-openaire-response-toec-communication-and-recommendation

$$
\text { http://erc.europa.eu/sites/default/files/document/file/open_access_policy_re- }
$$
searchers_funded_ERC.pdf

Openaire recommends researchers to use discipline-specific and institutional repositories, and not to rely on personal or project websites only. Most repositories are compliant with technical standards that enable cross-archive searching (Open Archives Initiatives Protocol for Metadata Harvesting). Thus, a publication placed in a repository is far easier to find than through an individual's website. Several search engines such as Google or Google Scholar favours repository material, and display these results more prominently. Moreover, repositories are working to preserve materials in the long-term. The benefit is that if a researcher moves on, or their personal website changes, their publications are in a repository and the links will remain stable, readable and accessible.

7 ERC (2012). For this study articles were classified as available in open access if a web-based search from a network with no subscriptions linked to it yielded a copy of the journal article, an author personal copy or a pre-print.

http://erc.europa.eu/sites/default/files/press_release/files/Europepmc_press_ release_WT_ERC_FINAL.pdf

\section{Ghent Declaration (2011).}

See for example Openaire's response to the Ec consultation and hearing of May 2011, http://www.openaire.eu/en/component/content/article/9-newsevents/301-openaire-contributes-to-ec-consulation-a-hearing

1 http://www.wellcome.ac.uk/About-us/Policy/Policy-and-position-statements/WTDoo2766.htm

http://publicaccess.nih.gov/policy.htm, Crummet et al. (2010).

http://www.hhmi.org/about/research/sc320.pdf

http://www.nrc-cnrc.gc.ca/eng/index.html

An overview of open access mandates in European countries can be found in Table 1 in Annex 3.

Kiley (2010)

7 http://www.wellcome.ac.uk/News/Media-office/Press-releases/2012/w TV Mo55745.htm 

access/Guides/wtdo41835.htm

39 http://www.rcuk.ac.uk/media/news/2012news/Pages/120716.aspx

40 http://www.rcuk.ac.uk/documents/documents/RCuk\%20_Policy_on_Access_to_Research_Outputs.pdf

$41 \quad$ www.swordapp.org

42 http://www.mopp.qut.edu.au/F/F_01_03.jsp

43 Cochrane (2010), presentation.

44 http://repositorium.sdum.uminho.pt/handle/1822/6177

45 Ferreira et al 2008

46 Both can be accessed via the registry ROARMAP, http://www.eprints.org/openaccess/policysignup.

http://wwwen.uni.lu/university/news/latest_news/university_of_luxembourg_participates_in_the_open_access_initiative

48 http://archive.ugent.be/input/home?func=open_access\#mandaat

49 More details can be found in section 4.4.

50 http://www.eua.be/eua-work-and-policy-area/research-and-innovation/OpenAccess.aspx

51 EUA (2008).

52 Kretaviciene (2008)

53 http://www.leru.org

54 LERU (2010).

55 Open Access Publishing in European Networks, http://www.oapen.org

56 http://www.unica-network.eu/, http://www.coimbra-group.be, http://www.gcompostela.org/, www.sgroup.be, http://www.utrechtnetwork.org, www.russellgroup.ac.uk http://www.unica-network.eu/event/5th-unica-scholarly-communicationseminar-\%E2\%80\%9Cfind-it-get-it-use-it-store-it $\% \mathrm{E} 2 \% 80 \% 9 \mathrm{D}$

58 For example the European Reference List for the Humanities (ERIH), http://www.esf.org/research-areas/humanities/erih-european-reference-indexfor-the-humanities.html

59 This phenomenon is even more prevalent in the US, as tenure processes often assign higher weights to research publications with high impact factors.

60 http://www.au.dk/fileadmin/www.au.dk/Internationalt_Center/Partnerweb/ internationalisationstrategy.pdf

61 http://www.eurohorcs.org

62 http://www.eurohorcs.org/E/initiatives/groups/Pages/default.aspx

63 http://www.esf.org

64 http://www.esf.org/about-esf/what-is-the-european-science-foundation/mission-statement.html

65 EUROHORCs (2008).

66 http://ec.europa.eu/research/eurab/index_en.html

67 eurab (2006). 
69 EUROHORCS/ESF (2009).

70 www.scienceeurope.org

71 http://www.scienceeurope.org/uploads/Press\%2oReleases/120717_SE_PR_era _signing_FIN.pdf

72 http://www.sherpa.ac.uk/romeo

73 Currently, over $60 \%$ of the publishers listed in SHERPA/ROMEO allow authors to archive their final peer-reviewed author manuscript. Users should be aware that the information in SHEPA/RoMEO is not legally binding and that journal policies may differ within a publishing house.

74 The German version is hosted by the German Initiative for Network Information (DINI), http://www.dini.de/wiss-publizieren/sherparomeo. The Spanish version is provided by Derechos de copyright y las condiciones de auto-archivo de revistas científicas españolas (DULCINEA),

http://www.accesoabierto.net/dulcinea. The Portuguese version was introduced in October 2010, http://www.sherpa.ac.uk/news/2010-10-22-RoMEOPortugues.html, where the information was gathered by the Blimunda Project, http://sites.google.com/site/blimundaproject. The HUNOR (HUngarian Open Repositories) consortium established by the libraries of Hungarian higher education institutions and the Library of the Hungarian Academy of Sciences to advance national open access practices (http://www.open-access.hu/) - started adding Romeo data directly for Hungarian publishers and journals, existing Romeo data for other publishers is in the process of being translated.

75 Outside of Europe, there are similar activities. In Australasia, OA KList addresses publishing agreements and publishers' open access policies and is interoperable with the SHERPA/RoMEO database. http://www.oaklist.qut.edu.au

76 The Niso/ALPSP JAV Technical Working Group recommends that these versions be called submitted manuscript under review (SMUR), accepted manuscript (AM) and version of record (VoR), see NISO RP-8-2008.

77 ACs Journal Publishing Agreement User's Guide, http://pubs.acs.org/userimages/ContentEditor/1285231362937/jpa_user_guide.pdf

78 Some funders such as the Wellcome Trust and uk Cancer Research provide explicit advice on what to do when publishers have not yet established a model allowing OA deposits. http://www.wellcome.ac.uk/About-us/Policy/Spotlight-issues/Open-access/Guides-and-FAQ/W TD018855.htm\#Q10 http://www.wellcome.ac.uk/About-us/Policy/Spotlight-issues/Openaccess/Guides/w T D018855.htm\#thirteen

80 http://www.wellcome.ac.uk/About-us/Policy/Spotlight-issues/Open-access/ Guides/wtdo41835.htm

81 http://www.peerproject.eu

82 D9.8 PeER Annual Report - Year 2 (1 September 2009 - 31 August 2010), http://www.peerproject.eu/fileadmin/media/reports/D9_8_annual_public_report_20100930.pdf 
83 D2.2 Final report on the provision of usage data and manuscript deposit procedures for publishers and repository managers, D3.1 Guidelines for publishers and repository managers on deposit, assisted deposit and self-archiving, http://www.peerproject.eu/ reports

$84 \mathrm{http} / /$ www.openaire.eu/en/component/content/article/9-news-events/387large-scale-deposit-in-repositories-increases-access-and-use

85 http://www.stmassoc.org/2012_05_29_STM_Press_Release_peer_Partners_Consensus_on_ Gold_Open_Access.pdf

86 http://www.oapen.org

87 http://project.oapen.org/index.php/reports

88 Kempf/Adema/Rutten (2010): 21.

89 http://www.doabooks.org

90 http://project.oapen.org/index.php/news/47-doab-is-launched

91 http://project-soap.eu

92 http://project-soap.eu/report-from-the-soap-symposium

93 Dallmeier-Tiessen et al (2010)

94 Here, some self-selectivity of authors familiar with the concept of open access has to be taken into account.

95 As noted in section 3.1.1, publishing costs-including fees for publishing in OA journals-are fully eligible for reimbursements in FP7. This fact is documented in annex 2 of the project's grant agreement.

96 PEER: University of Goettingen, University of Bielefeld, SURF; OAPEN: University of Goettingen; SOAP: CERN.

97 Compare section 3.1.1

98 http://ec.europa.eu/about/ds_en.htm

99 http://ec.europa.eu/dgs/information_society/index_en.htm

$100 \mathrm{http} / / /$ ec.europa.eu/dgs/research/index_en.html

$101 \mathrm{http} / /$ europa.eu/rapid/pressReleasesAction.do?reference=SPEEcH/10/716.

The EC's Communication Towards better access to scientific information has been released on 17 July 2012, compare 3.1.1 and Appendix 1 .

102 http:/ec.europa.eu/dgs/internal_market/index_en.htm

103 http://ec.europa.eu/competition/index_en.html

$104 \mathrm{http}: / /$ cordis.europa.eu/fp7/ncp_en.html

105 http://www.uni-goettingen.de/de/23960.html

106 This finding is based on observations at a meeting with the group of Lower Saxony EU offices in mid-December 2010 in Germany.

(http://www.openaire.eu/en/component/attachments/download/85)

107 The networking partners of Openaire are the University of Goettingen (as scientific coordinator), EIFL, SURF, the University of Ghent, the University of Minho, and the Technical University of Denmark.

108 http://www.openaire.eu/en/component/content/article/76-highlights/398-project-coordinators-its-for-you 
110 http://www.driver-support.eu/pmwiki

111 At the time the OpenAIRE project was being developed, representatives of Luxembourg's library community did not feel ready to join the project. In the meantime, Luxembourg has joined as an Openaireplus NOAD. Also, the University of Luxembourg has established a repository, in collaboration with the University of Liège.

112 Region West is coordinated by the University of Ghent (UGent), Region North by the Technical University of Denmark (DTU), Region South by the University of Minho, and Region East by EIFL.

113 FWF OA Policy http://www.fwf.ac.at/en/public_relations/oai/index.html, FWF Press Release, March 2008, http://www.fwf.ac.at/de/public_relations/press/pa20080306.html

114 Universitätsgesetz-Novelle 2009, Errichtung einer zentralen Datenbank für wissenschaftliche und künstlerische Arbeiten $\$ 85$ U G 2002, http://www.bmwf.gv.at/ fileadmin/user_upload/forschung/publikationen/ftb_2009_en.pdf

$115 \mathrm{http}: / /$ www.reko.ac.at/universitaetspolitik/erklaerungen/?aID=4373\#A4373

116 https://phaidra.univie.ac.at/

117 http://www.fwo.be/Documentatie.aspx?ID=eb16c49f-467d-4b5a-a26a3b869ddcbaed

118 http://archive.ugent.be/input/home?func=open_access, also see section $\mathbf{3 . 2}$.

$119 \mathrm{http} / / /$ hal.archives-ouvertes.fr/index.php?langue=en

120 http://www.agence-nationale-recherche.fr/Intl

121 http://www.agence-nationale-recherche.fr/actualite/13?lngInfoId=159

$122 \mathrm{http}: / /$ halshs.archives-ouvertes.fr

123 http://archimer.ifremer.fr/depot.htm

124 http://www.dini.de/english

125 The Alliance consists of the German Research Foundation, the Fraunhofer Society, the Hermann von Helmholtz Association of German Research Centres, the German Rectors Conference, the Leibniz Association, the Max Planck Society and the German Council of Science and Humanities, http://www.allianzinitiative.de/en/start

126 These include the information platform open-access.net, the Network of DINIcertified Open Access Repositories, Open-Access-Statistics, etc. See http://www.dfg.de/en/research_funding/programmes/infrastructure/lis/digital_information/open_access/index.html

127 The Heidelberger Appell (Heidelberg appeal) of April 2009, initiated by a professor of German language and literature, was signed by over 2,60o book authors and people from the publishing industry and academia, http://www.textkritik.de/urheberrecht

128 This discussion referred to Article 5 (freedom of expression) of the German constitution (Grundgesetz) guaranteeing the freedom of art, scholarship, re- 
search and teaching. This right is also seen as an obstacle in enforcing oA mandates.

129 Open Access und Urheberrecht: Kein Eingriff in die Publikationsfreiheit, Presseerklärung der Allianz der deutschen Wissenschaftsorganisationen, 25 March 2009, http://www.allianzinitiative.de/de/aktuelles_und_presse/25032009

130 ROARMA lists the OA policy of the Fraunhofer Gesellschaft as an institutional mandate.

131 http://www.hea.ie/files/files/file/Open access pdf_.pdf

132 http://www.hrb.ie/research-strategy-funding/policies-and-guidelines/policies/open-access/

133 http://www.ircset.ie/, http://arrow.dit.ie/why_oa.html

134 http://www.irel-open.ie/mod/resource/view.php?id=214

135 http://www.sfi.ie/funding/grant-policies/open-access-acialability-of-published-research-policy

136 http://www.accesoabierto.net

137 Irish universities have received government funding to build their own open access institutional repositories and to develop a federated harvesting and discovery service via a national portal. This work was conducted in the IREL-Open Project, which ran from April 2007 to March 2010, http://www.irel-open.ie/

138 http://www.nwo.nl/nwohome.nsf/pages/SPPD_5R2QE7_Eng

139 http://www.knaw.nl/english

140 In early September, 2010, the rector of Erasmus University, Prof.Dr. Henk Schmidt, announced that open access publishing (the so-called green road) will be mandatory as of January 2011. http://repub.eur.nl/openaccess, http://www.openaccess.nl/ index.php?option $=$ com_content\&view $=$ article\&id $=185$

141 http://www.narcis.info

142 http://www.hbo-kennisbank.nl/nl/page/page.view/hbo_about.page

143 http://www.snf.ch/E/current/Dossiers/Pages/open-access.aspx

144 http://www.rcuk.ac.uk

145 http://www.wellcome.ac.uk

146 http://ukpmc.ac.uk

147 http://ukpmc.ac.uk/Funders

148 http://www.nihr.ac.uk/research/Pages/Research_Open_Access_Policy_Statement.aspx

149 Finch Group report (2012); RCu K Policy on Access to Research Outputs (2012).

150 http://www.fi.dk/forskning/open-access/recommendations-for-implementation-of-open-access-in-denmark-pdf

151 On 7 January 2011, the Danish National Research Database covered 496,523 bibliographic records with open access to 20,871 full texts: http://forskningsdatabasen.dk

152 The University of Helsinki's oA policy was established in May 2008 and requires the deposit of research articles published in an academic journal, serial publica- 
tion, conference publication or any other kind of compilation, that have been approved for publication from 1 January 2010 onwards. The depositing obligation does not apply to monographs. All other deposits are on a voluntary basis. http://www.helsinki.fi/openaccess/open\%20access/english/decision260508_en g.pdf

153 http://theseus.fi/web/guest/open-access-lausuma

154 As adopted in January 2009, the Research Council requires that peer-reviewed scientific articles based on research funded wholly or partially by the Research Council are self-archived in appropriate repositories whenever these are available. The requirement to self-archive must not, however, conflict with the author's academic or legal rights.

http://www.forskningsradet.no/en/Article/The+Research+Councils+Principles+for+Open+Access+to+Scientific + Publications/1240958527698

155 Frantsvåg (2010). Presentation.

156 http://www.cristin.no/english/open-access-eng/

157 http://www.vr.se/inenglish/aboutus/policies/openaccess.4.44482f6612355bb 5ee $780003075 . h t m l$

158 http://www.rj.se/english/projects/open_access_guidelines

159 http://swepub.kb.se

160 http://oa.mpg.de/lang/en-uk/berlin-prozess/signatoren

161 http://ktisis.cut.ac.cy/jspui

162 Anglada/Abadal (2010): 52, 167 f.

163 www.crui.it/english

164 www.caspur.it

165 www.cilea.it

166 http://www.openarchives.it/pleiadi

167 https://repositorium.sdum.uminho.pt

168 https://mx2.arl.org/Lists/sPARC-OAForum/Message/3492.html

169 http://www.rcaap.pt

$170 \mathrm{http}: / /$ validador.rcaap.pt

171 http://projecto.rcaap.pt/index.php/lang-pt/consultar-recursos-de-apoio/remository? func $=$ fileinfo\&id $=336$

172 Anglada/Abadal (2010): 109f.

173 http://www.cbuc.cat

$174 \mathrm{http}: / /$ www.consorciomadrono.es

175 http://www.recolecta.net/buscador/index2.jsp

176 http://www.madrimasd.org/informacionidi/e-ciencia/buscar-documentos/default.asp

177 http://ankos.gen.tr

178 http://www.bg-openaire.eu/

179 http://hrcak.srce.hr/

180 Stojanovski (2012).

181 http://www.mzos.hr/, http://www.srce.unizg.hr/, http://www.hidd.hr/ 
182 http://www.unesco.org/new/en/communication-and-information/portalsand-platforms/goap/access-by-region/europe-and-north-america/croatia/

183 http://public.mzos.hr/fgs.axd?id=14189

184 Hebrang Grgić (2011): 76.

185 http://bib.irb.hr

186 http://www.dspace.cz

187 http://www.openaccess.cz/en/openaccess

188 http://www.fp7.cz/cz/detail-akce/eventid-6458

189 ČT24 on 7. 11. 2011, Milénium with Pavla Rygelová, všB-TU Ostrava: http:// www.ceskatelevize.cz/porady/10159875412-milenium

190 Epner (2009).

191 http://real.mtak.hu/, http://www.otka.hu/index.php?akt_menu=3658

192 Open Access: Maximising Research Quality and Impact (22 October 2009); Open Access and Openaire: challenge and opportunity for Latvian scientific progress (18 October 2010).

193 http://cogprints.org

194 http://roze.lanet.lv:8991/F/YHRDF8JUTYD5VUMQUI4CA925VCKHIKH7 BNEE9HBKM4R3 K 48 3 35-28127? func=find-b-o\&local_base=luao3

195 https://dspace.lu.lv/dspace

196 http://www3.lrs.lt/pls/inter3/dokpaieska.showdoc_l?p_id=343430\&p_query= \&p_tr2=Safariн TML $\backslash$ Shell $\backslash$ Open $\backslash$ Command

197 Tautkeviciene (2010)

198 www.eifl.net/news/open-access-publishing-lithuania-and-serbia-c

199 http://cc.icm.edu.pl

200 www.communia-project.eu

201 Ordnance of the director of the institute (2 February 2010):

http://www.ibb.waw.pl/sites/default/files/ZARZĄDZENIE\%20Nr\%204\%202010. pdf, ROARMAP entry:

http://www.eprints.org/openaccess/policysignup/fullinfo.php?inst=Institute $\% 200$ ofoBiochemistry\%2oand\%2oBiophysics\%2oPolish\%2oAcademy $\% 2$ oof\% 20 Sciences

202 http://www.eifl.net/news/launch-amur-and-open-access-phd-theses-mandat

203 http://fbc.pionier.net.pl

204 http://otwartymandat.pl/

205 http://depot.ceon.pl

206 http://otwartanauka.cel.agh.edu.pl/course

207 http://startad.kosson.ro

208 http://aspeckt.unitbv.ro/jspui

209 Ljubljana, 27-28 October 2010; http://www.dlib.si/details/URN:NBN:SI:DOCJGYFFYW7

210 http://www.arrs.gov.si/sl/obvestila/10/Openaire-131210.asp

211 Research Infrastructure Development Plan 2011-2020, http://www.mvzt.gov.si/fileadmin/mvzt.gov.si/pageuploads/pdf/znanost/nacrtRI.pdf 
212 www.ess-project.eu, www.dariah.eu, www.cessda.org

213 http://www.dlib.si

214 http://dkum.uni-mb.si

215 http://eprints.fri.uni-lj.si

216 http://pefprints.pef.uni-lj.si

217 http://eprints.fgg.uni-lj.si

218 http://elpub.scix.net

219 http://www.cobiss.si

220 MELIBEA - Directorio y estimador de polícas en favour del acceso abierto a la producción científica, http://www.accesoabierto.net/politicas

221 For the Nordic region, see Thorsteinsdóttir (2010). For the South, see Anglada/Abadal (2010).

222 http://archimer.ifremer.fr/results2008.htm

223 www.ukcorr.org

224 See http://www.nordbib.net, Hedlund/Rabow (2007) and the evaluation report of Duke \& Jordan Ltd (2009).

225 http://www.heal-link.gr/sELL/index.html

226 Anglada/Abadal (2010), Alhambra Declaration (2010)

227 http://www.medoanet.eu

228 See Guidelines for the Purchase of Licences within the Framework of the Alliance Initiative 'Digital Information', which are being used in negotiations for the licence period 2011-2013. http://www.dfg.de/download/programme/wissenschaftliche_literaturversorgung_informationssysteme/antragstellung/12_1 8_e/12_18e.pdf The results of these negotiations will be published soon.

229 http://www.oai.uzh.ch/index.php?mos_lng=en

230 Gender mainstreaming is defined by the United Nations Economic and Social Council in 1997 as “a strategy for making women's as well as men's concerns and experiences an integral dimension of...the policies and programmes in all political, economic and societal spheres so that women and men benefit equally and inequality is not perpetuated."

http://www.undp.org/women/mainstream/whatis.shtml

231 The NOAD presentations will be published on the Openaire website, http:// www.openaire.eu.

232 http://www.opendoar.org/, http://roar.eprints.org

233 http://opendepot.org

$234 \mathrm{http} / / / \mathrm{www} .0$ penaire.eu/en/home/207

235 http://www.driver-support.eu/managers.html\#guidelines

$236 \mathrm{http}: / / \mathrm{www} . o p e n a i r e . e u / e n / c o m p o n e n t / c o n t e n t / a r t i c l e / 9-n e w s-e v e n t s / 221$ open-journal-systems-now-compliant-with-openaire-new-plug-in-released

237 http://www.ncbi.nlm.nih.gov/pmc

238 http://repec.org

239 http://arxiv.org

240 http://ukpmc.ac.uk/Funders 


\begin{tabular}{|c|c|}
\hline 241 & http://ukpmc.ac.uk/europepmc \\
\hline 242 & http://www.ssoar.info/en.html \\
\hline 243 & http://www.oceandocs.org \\
\hline 244 & http://www.econstor.eu \\
\hline 245 & http://www.neeoproject.eu \\
\hline 246 & http://www.economistsonline.org \\
\hline 247 & http://repec.org \\
\hline 248 & http://openaire.cern.ch \\
\hline 249 & http://www.d-net.research-infrastructures.eu/node/22 \\
\hline 250 & http://coar-repositories.org \\
\hline 251 & COAR's new Strategy 2012-2015 will be published in September 2012. \\
\hline 252 & http://www.eifl.net \\
\hline 253 & http://www.eifl.net/eifl-oa-coordinators \\
\hline 254 & http://www.eifl.net/eifl-oa-coordinators \\
\hline 255 & http://www.eifl.net/eifl-oa-case-studies \\
\hline 256 & http://www.sparceurope.org \\
\hline 257 & http://www.arl.org/sparc \\
\hline 258 & http://www.sparceurope.org/about-us/pkp-europe-network \\
\hline 259 & http://www.knowledge-exchange.info \\
\hline 260 & http://www.knowledge-exchange.info/Default.aspx?ID=115 \\
\hline 261 & $\begin{array}{l}\text { In cooperation with the KE Working Group Licensing: http://www.knowledge- } \\
\text { exchange.info/Default.aspx?ID=397 }\end{array}$ \\
\hline 262 & http://www.knowledge-exchange.info/Default.aspx?ID=412 \\
\hline 263 & http://www.knowledge-exchange.info/Default.aspx?ID $=413$ \\
\hline 264 & http://www.knowledge-exchange.info/Default.aspx?ID=395 \\
\hline 265 & http://www.biomedcentral.com/info/about/license \\
\hline 266 & http://www.biomedcentral.com/info/libraries/sword \\
\hline 267 & http://www.biomedcentral.com/info/libraries/swordfaq \\
\hline 268 & $\begin{array}{l}\text { http://www.elsevier.com/wps/find/authorsview.authors/copyright\#whatrights. } \\
\text { Details about agreements with funding bodies can be found at: } \\
\text { www.elsevier.com/fundingbodies }\end{array}$ \\
\hline 269 & $\begin{array}{l}\text { Comparing the guide Ways to Use Journal Articles Published by Elsevier: A } \\
\text { Practical Guide", LibraryConnect, pamphlet 4, fourth edition, 2011, http://li- } \\
\text { braryconnect.elsevier.com/articles/supporting-usersorganizations/2011- } \\
\text { 12/ways-use-journal-articles-published-elsevier; and } \\
\text { http://www.elsevier.com/wps/find/authorsview.authors/ fundingbodyagree- } \\
\text { ments, "Web posting of articles", with the "Ways to Use Journal Articles Pub- } \\
\text { lished by Elsevier: A Practical Guide", Editors' Update, June 2007, } \\
\text { http://www.elsevier.com/framework_editors/pdfs/waystousearticles.pdf, page } \\
\text { 3, section "Web posting of articles". }\end{array}$ \\
\hline 270 & http://www.elsevier.com/wps/find/authorsview.authors/nihauthorrequest \\
\hline 271 & $\begin{array}{l}\text { SPARC Open Access Newsletter, issue \#108, } 2 \text { April 2007, } \\
\text { http://www.earlham.edu/ peters/fos/newsletter/04-02-07.htm }\end{array}$ \\
\hline
\end{tabular}


272 http://bloodjournal.hematologylibrary.org/misc/public.dtl

273 NPG position statement on open access publishing and subscription business models, David Hoole, NPG, 6 January 2011, http://www.nature.com/press_releases/statement.html

274 Nature Publishing Group allows data- and text-mining on self-archived manuscripts, NPG, Press Release, 18 June 2009, http://www.nature.com/press_releases/archiving.html

275 That is, there is no charge to authors, funders or their institutions.

$276 \mathrm{http} / / /$ www.openaire.eu/en/component/content/article/9-news-events/39ocopernicus-publications-first-open-access-publisher-visible-on-openaire

277 Some institutions and countries have established publishing platforms, for example in France http://www.revues.org

278 http://www.oaspa.org

279 http://pkp.sfu.ca/?q=ojs

280 Edgar/Willinsky (2010).

281 http://pkp.sfu.ca/wiki/index.php/Projectdescription_FU_Berlin

282 "Open Journal Systems now compliant with Openaire: New plug-in released", Press Release, 2 February 2011 ,

http://www.openaire.eu/index.php?option=com_content\&view=article\&id=2 21:open-journal-systems-now-compliant-with-openaire-new-plug-in-released \&catid=9:news-events\&Itemid=44\&lang=en

283 http://pkp.sfu.ca/support/forum

284 http://pkp.sfu.ca/ojs_download

285 This holds for journals as well as for books. For journals, the soAP studies provide corresponding evidence (see section 2.4.1.).

286 http://www.unesco.de/openaccess.html? $\mathrm{L}=1$

287 Open access to scientific knowledge on agenda of workshop in South Africa: http://portal.unesco.org/ci/en/ev.php-URL_ID=30979\&URL_DO=DO_TOPIC \&URL_SECTION $=201 . \mathrm{html}$

288 http://www.unesco.org/new/en/communication-and-information/portalsand-platforms/goap

289 http://www.unesco.org/new/en/communication-andinformation/resources/news-and-in-focus-articles/allnews/news/global_open_access_portal_launched

290 http://www.wsis-community.org/pg/groups/58145/open-access

291 http://www.unesco.org/new/en/communication-andinformation/resources/publications-and-communication-materials/publications/full-list/policy-guidelines-for-the-development-and-promotion-ofopen-access

292 Director-General's Regional Consultation on the Preparation of the Draft Programme and Budget for 2012-2013 (36 C/5), National Commissions for UNESCO of Europe and North America, London, 5-8 June 2010, London, uk, Final Report, http://erc.unesco.org/publications/nac/ENA_36C5_011_e.pdf 
http://www.uvm.dk/Aktuelt/ /UvM-

DK/Content/News/Int/2010/Nov/101115-Konference-om-fri-og-lige-adgangtil-forskningsresultater

294 http://www.unesco.nl/nieuws-agenda/agenda/expert-meeting-2018a-globalperspective-on-open-access2019/?searchterm=None

295 www.emis.de

296 www.egu.eu

297 http://www.febs.org

298 http://www.ictsocieties.org/, http://www.cepis.org

299 http://www.eurodoc.net

300 http://www.driver-support.eu/newsevents.php?item=oDRIVERandEur44

301 http://www.ifmsa.org

302 http://www.righttoresearch.org

303 http://www.ifmsa.org/index.php?option=com_content\&view=article\&id= 253:home\&catid=67:news

304 http://www.fao.org

305 http://iaald2010.agropolis.fr/proceedings/posters.html and Nicolaie/Subirats/Katz (2007)

306 http://voa3r.eu/

307 http://aims.fao.org/news/fao-and-unesco-iociode-combine-efforts-their-support-open-access

308 International Oceanographic Data and Information Exchange (IODE), http://www.iode.org/, Intergovernmental Oceanographic Commission of unESCO (IOC), http://ioc-unesco.org/

309 http://aims.fao.org/tools/agriocean-dspace/background

310 Friend (2010), Zuccala (2010).

311 Research: Openaire opens access to EU scientific results, Press Release, Brussels, 2 December 2010, http://europa.eu/rapid/pressReleasesAction.do?reference= $\mathrm{IP} / 10 / 1644$

312 http://ec.europa.eu/information_society/digital-agenda/index_en.htm; Digital Agenda: Commission outlines action plan to boost Europe's prosperity and well-being, Press Release, Brussels, 19 May 2010, http://europa.eu/rapid/pressReleasesAction.do? reference $=\mathrm{IP} / 10 / 581$

313 The "Innovation Union" - turning ideas into jobs, green growth and social progress, Press Release, 6 October 2010, http://europa.eu/rapid/pressReleasesAction. do? reference $=\mathrm{IP} / 10 / 1288$

314 Ghent Declaration (2011)

315 European Commission: Scientific data: open access to research results will boost Europe's innovation capacity, Press Release, Brussels, 17 July 2012, http://europa.eu/rapid/pressReleasesAction.do?reference=IP/12/790

316 http://erc.europa.eu/pdf/ScC_Guidelines_Open_Access_revised_Deco7_FINAL.pdf

317 http://ec.europa.eu/research/press/2008/pdf/annex_1_new_clauses.pdf, http:// ec.europa.eu/research/press/2008/pdf/decision_grant_agreement.pdf 
318 http://ec.europa.eu/research/science-society/document_library/pdf_o6/eracommunication-towards-better-access-to-scientific-information_en.pdf, http://ec.europa.eu/research/science-society/document_library/pdf_o6/recommendation-access-and-preservation-scientific-information_en.pdf

319 http://www.openarchives.org/service/listproviders.html

$320 \mathrm{http} / / / \mathrm{www} . o p e n a i r e . e u / \mathrm{en} /$ support/guides/repository-managers

321 http://www.driver-repository.eu/

322 http://www.surf.nl/en/themas/openonderzoek/verrijktepublicaties/Pages/default.aspx

323 http://www.openarchives.org/OAI/openarchivesprotocol.htm\#harvester

324 http://www.openarchives.org/documents/FAQ.html\#What\%2ois\%20a\%2oservice\%2oprovider

325 http://www.openoasis.org/index.php?option=com_content\&view=article\&id= $144 \&$ Itemid $=338$

$326 \mathrm{http} / / / \mathrm{www} . o p e n a i r e . e u / e n / o p e n-a c c e s s / c o u n t r y-i n f o r m a t i o n$

327 http://www.openarchives.org/pmh/

328 http://openaire.cern.ch/

329 http://www.sherpa.ac.uk/romeoinfo.html

330 http://www.sherpa.ac.uk/romeo/

331 http://www.earlham.edu/ peters/fos/overview.htm

332 http://www.openarchives.org/pmh/

333 http://ec.europa.eu/research/press/2008/pdf/annex_1_new_clauses.pdf 


\section{Index}

advocacy 9, 15, 44, 55, 62-63, 81, 86, 101, 103105, 117

American Chemical Society 38

author-pays option $31,36,39$

Berlin Declaration $17,36,61,63-64,68,72-73$, 80-81, 91-92

BioMed Central 27, 92, 106-107

compliance 19, 24-27, 39, 77, 90, 94-97, 101, $106,110-112,123,140,158$

copyright $12,17,20,30-31,33,36,39,45,50$, 52-53, 55-56, 64, 66, 81, 89-90, 123, 130, $155,158,164$

Confederation of Open Access Repositories (COAR) 9, 12, 102-103

Copernicus Publications 15,110 deposition process $13-15,17-18,20,22,24-29$, $31,37-44,55-56,61,63-65,67-68,70-71$, 73-77, 81-83, 85-87, 89-93, 96, 98-101, 104, 106-110, 116, 121, 136-139, 157-159, 164, 168

DOAJ $45,64,79-82,84-86,111,130$

DRIVER $15,31,57,61,85,87-88,96,101,111$ $112,117,151,157$

DSpace. .9, 70, 80, 95, 97, 102, 119

e-infrastructures $15,20,138,159$

Economists Online 99-100

EconStor 99

EIFL 9, 12, 82-85, 88, 103-104, 165-166

Elsevier 107-108, 171

EPrints 95, 97, 102

European Commission 11, 13, 19-21, 30, 39, $43,51-53,59,86,96,113,120-121,123,137-$ $138,140-141,149,159$

European Council of Doctoral Candidates and Junior Researchers (EURODOC) 116-117

European Heads of Research Councils (EUROHORCs) 35-37

European Research Council (ERC) 13, 21-23, $39,50-54,75,98,121,135-139,149$

European Science Foundation (ESF) 35-36

European countries

Austria 59-61, 91, 98, 143, 145, 150-151, 153

Belgium 28-30, 59-61, 91, 99, 101, 121, 143, $145,150-151,153$

Bulgaria $78-79,88,101,123,143,145,150-151$, 153
Croatia 11, 58, 79-80, 143, 145, 150, 169

Cyprus $60,72,78,143,150$

Czech Republic 78, 80-81, 88, 143, 150, 153

Denmark 66-67,89,91, 102, 104-105, 114-115, $143,145,150-151,153,165,167$

Estonia 11, 78, 81, 88, 103, 123, 143, 150, 153

Finland 59, 66-68, 91, 101, 143, 146, 150, 153

France $37,59-62,91-92,143,146,150-151$, 153,172

Germany 59-60, 62, 91-92, 99, 101-102, 104$105,143,146,150-151,153,167$

Greece 60, 72-73, 77, 91-92, 101, 143, 150-151, 154

Hungary $78,81-82,88,91,143,146,150-151$, 154

Iceland $11,58,68,91,143,146,150,154$

Ireland $59-60,62-63,89-90,143,146,150-151$, 154,167

Italy $60,72-74,77,92,98,143,146,150-151$, 154

Latvia $60,78,82-83,103,143,150,154,169$

Lithuania $32,78,83-84,103,117,143,146$, $150-151,154,169$

Luxembourg 29,57-58,65,143,163, 166

Malta $60,72,74,78,143$

Netherlands, The 44, 60, 63, 101, 105, 115, 144, $146-147,150-151,154$

Norway 11, 37, 58, 66, 68-69, 89, 91, 105, 114, $144,147,150,152,154$

Poland $60,78,84-85,88,103,144,147,150$, 152,154

Portugal 28, 72, 74-77, 91-92, 101-102, 144, $147,150,152,154$

Romania $78,85-86,144,150,154$

Slovakia $78,86,88,144$

Slovenia $11,78,86-88,101,103,123,144,150$, 152,155

Spain $31,72,76-77,91-92,101-102,144,147$, $150,152,155$

Sweden 66, 69-70, 91, 115, 144, 147-148, 150, 152,155

Switzerland $11,58,63-65,144,148,150,155$

Turkey 11, 58, 77, 92, 144, 150, 152, 155

United Kingdom 22-27, 39, 44, 60, 65, 90-91, 98-99, 101-102, 104-105, 108-109, 112,139, $144,148-150,152,155,161,164$ 
European University Association (EUA) $30-32$ Food and Agriculture Organisation (FAO) 12, 118-119

general public, the 120-121

Geoghegan-Quinn, Máire 52, 120-121

German Research Foundation (DFG) 62, 104

Ghent Declaration 120

Horizon 2020 15, 21, 43, 121, 140-141

humanities $13,20,23,33-36,43-44,51,61,64$, $66-67,70,72,87,112,135-139,141,159-$ 160,163

International Federation of Medical Students' Association (IMFSA) 117-118

JISC $44,105,112,148$

journals $11,19,25-26,33-35,37-39,41,43,45$ $46,52,58,64-71,73-74,77-89,96-97,105-$ $112,116,120,123,136$

Knowledge Exchange 104-105

Kroes, Neelie 52, 121

League of European Research Universities (LERU) $32-35$

life sciences $21-22,45,98,116,135-139$

mandate(s) $11,17-19,23,26-31,34,37-39,42-$ $44,52,58,60-92,98,104-110,116,123,145$ $149,158,161,167$

MELIBEA 19, 90, 130

National Contact Points $12,54-56,71,123$

National Open Access Desks (NOADs) 11, 13$14,30,52,57-95,103,123,143-144,158$, 166

Nature Publishing Group (NPG) 25, 109

NEEO 99

non-compliance 39

OceanDocs 99

open access (definition) 17

open access publishing ('gold route') 19-21, 33 , $35,43-47,70,79-80,86,110,140$

open access with embargo 18, 24, 26, 31, 41, 77, $85,89,106,108$

Open Access Publishing in European Networks (OAPEN) 9, 33, 43-45, 112

Open Archives Initiative (OAI) 152, 158-159, 162

Open Archives Initiative Protocol for Metadata Harvesting (OAI-PMH) 31, 69, 101, 119, 158

Open Journal Systems (oJs) 84, 104, 111-112, 153

OpenAIRE compliance 94-97, 110-112

OpenaIre Guidelines 96-102, 106, 111-112

Openaireplus $12,15,58-59,124,157,166$

OpendoAR $61,62,74,77,79-81,85,96-97$, 130,150

Orphan repository $86,96,100-101,158$
PEER 9, 27, 40-43, 99

postprint 158

publisher-assisted deposit 27, 38, 42, 90, 92, 106-109

publishers 11-12, 14-15, 24-27, 29, 33, 36-47, $49-50,52,62,64,67,76,83,89,92,97,101$, $103,105-112,124,153-154,158,164$

publishers' policies $17,37-47,85,89,105-110$ repository $11-14,17-18,20,22,24,27-31,33$, $36,40-44,49,57,61-67-90,91-93,95-100-$ $103,105-106,110,112,118,123,136,138$ $139,150-155,157-159,162,165-166,174$ - disciplinary 11-13, 15, 20, 27, 40-43, 59, 61, 89, 96-101, 105, 116, 137

Research Councils UK (RCUK) 26, 65

research assessment/ evaluation 29, 70-71, 73, 93-94

Registry of Open Access Repositories (ROAR) $62,72,77,96,130,150$

ROARMAP $18,72,90,130,149,161,167$

self-archiving ('green route', see also: deposition process) $11,19,21,25,27-28,31-33,35,39$ $40,43-44,64,74,76,80,86,106,109,157$

Science Europe 37

SHERPA/JULIET 19, 90, 130, 161

SHERPA/ROMEO 19, 37, 39, 130, 158, 161, 164, 174

scholarly societies $17,38,105,108-109,116$ social sciences $13,20,22,33,41-42,43-44,61$, $64,70,87,99,112,135,139,141$

Social Sciences Open Access Repository (ssoAR) 99

SPARC Europe 12, 104

Special Clause 39 (SC 39) 14, 20, 50-52, 66, 72, $137-138,159$

stakeholders $12,14,20,21,28,31,33,38,42$, $49-50,52,55,58,61,71,86,91,93,101,104$, $113,124,153$

strategies $11-12,31,33,46-47,49-50,58,66$, $78,90-95,103,123-124$

Study on Open Access Publishing (sOAP) 40, $45-46,125,165,172$

SWORD 27, 42, 101, 106, 110, 163, 171

UKPMC 22-25, 27, 39, 65, 98-99, 109, 128, 139, 167,171

UNESCO 12, 99, 113-115, 119, 125-126, 169, $172-173$

University of Liége 28-29, 145, 166

University of Minho 28, 74-75, 90, 144, 147, 165-166

Wellcome Trust $23-27,39,46,65,90,98,149$, 164

version (of the work) 17, 38-39, 89, 106-107, $109,158-159,164$ 
The implementation of open access policies in Europe is a socio-technical undertaking whereby a wide range of stakeholders work together to bring out the benefits of open access for European and global research. This work provides a unique overview of national awareness of open access in 32 European countries involving all EU member states and in addition, Norway, Iceland, Croatia, Switzerland and Turkey. It describes funder and institutional open access mandates in Europe and national strategies to introduce and implement them. An overview of the current European repository infrastructures is given, including institutional and disciplinary repositories, national repository networks, information portals and support networks. This work also outlines OpenAIREplus, a continuation project which aims to widen the scope of OpenAIRE by connecting publications to contextual information, such as research data and funding information. Opportunities for collaboration in order to achieve European and global synergies are also highlighted.

The OpenAIRE project, a joint collaboration among 38 partners from 27 European countries, has built up a network of open repositories providing free online access to knowledge produced by researchers receiving grants from the European Commission or the European Research Council. It provides support structures for researchers, operates an electronic infrastructure and a portal to access all user-level services and works with several subject communities. Birgit Schmidt is affiliated with Goettingen State and University Library. Iryna Kuchma is affiliated with EIFL. 